\title{
A Photogrammetry Program for Physical Modeling of Subsurface Subsidence Process
}

Yujia Lian

Follow this and additional works at: https://researchrepository.wvu.edu/etd

\section{Recommended Citation}

Lian, Yujia, "A Photogrammetry Program for Physical Modeling of Subsurface Subsidence Process" (2017). Graduate Theses, Dissertations, and Problem Reports. 6082.

https://researchrepository.wvu.edu/etd/6082

This Thesis is protected by copyright and/or related rights. It has been brought to you by the The Research Repository @ WVU with permission from the rights-holder(s). You are free to use this Thesis in any way that is permitted by the copyright and related rights legislation that applies to your use. For other uses you must obtain permission from the rights-holder(s) directly, unless additional rights are indicated by a Creative Commons license in the record and/ or on the work itself. This Thesis has been accepted for inclusion in WVU Graduate Theses, Dissertations, and Problem Reports collection by an authorized administrator of The Research Repository @ WVU. For more information, please contact researchrepository@mail.wvu.edu. 


\title{
A Photogrammetry Program for Physical Modeling of Subsurface Subsidence Process
}

\author{
Yujia Lian
}

\author{
Thesis submitted \\ To the Benjamin M. Statler College of Engineering and Mineral Resources \\ At West Virginia University
}

In partial fulfillment of the requirements for the degree of

Master of Science in

Mining Engineering

Yi Luo, Ph.D. Chair

Keith A. Heasley, Ph.D.

Mark F. Sindelar,Ph.D.

Department of Mining Engineering

Morgantown, West Virginia

2017

Keywords: Physical modeling, Subsurface Subsidence,close-range photogrammetry technology

Copyright 2017 Yujia Lian 


\section{ABSTRACT \\ A Photogrammetry Program for Physical Modeling of Subsurface Subsidence Process \\ Yujia Lian}

Safe and economic longwall coal extraction requires a good knowledge of overburden strata characteristics and understanding of overburden strata movement in response to the full extraction mining. Subsidence induced overburden movement will affect overlying mining, surface and subsurface water bodies, and methane emission and migration in the overburden strata. Therefore, an understanding of subsurface strata movement is essential for optimal layout of multiple seam mining, protecting water resources, and designing of gob hole patterns for longwall degasification.

Physical simulation experiments play an important role in mining engineering research by allowing visual observations of strata movement in the mining process. In recent years, the advantage physical simulations has supplemented to weakness of computer simulation in some aspects. Some advanced research results in ground control have been obtained through physical simulation, and the findings include key hinged-beam theory, the formation of fractured zones with different permeability in overlying strata.

To improve the method of obtaining and processing measured data during a simulation experiment, a photogrammetry program for capturing and processing the data from physical modeling of mine subsurface subsidence has been developed. The program can capture the observation or measurement points accurately by simply clicking a mouse on an image of the experiment. Four point geometric affine transformation was used in the program to make corrections to images with relation to the camera's change of position over the experiment process. Finally, the program can generate the subsurface subsidence database and export to an spreadsheet file for further data analysis. Subsurface displacement, horizontal strain, and void ratio can then obtained from the data generated by the program. Overall, the program provides an alternative, rapid approach to capturing and processing subsurface subsidence data from a physical simulation 
model, and introduces a new way to help minimize the error brought by both human and measurement devices. 


\section{ACKNOWLEDGEMENTS}

I would like to thank my research adviser, Dr. Yi Luo, for his support of my graduate study, and for giving me the opportunity to participate in this project. I have benefited greatly from his suggestions on my academic endeavor and research, I wish to acknowledge Dr. Keith Heasley and Dr.Mark F. Sindelar for being committee members as well as instructors and mentors during my graduate studies.

I would like to thank all the faculty and staff members in the Mining Engineering Department for their kindness and assistance shown to me during my time in WVU.

I would also like to thank Dr. Mingming Li, who gave me a lot of professional suggestions on how to do research.

I especially thank my parents, my uncle and aunt, who keep giving me strong support all the way, materially and spiritually. Without their help, I would not have had the opportunity to study at WVU and work on my master's thesis. 


\section{LIST OF CONTENTS}

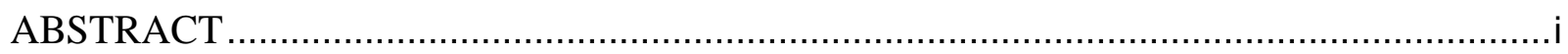

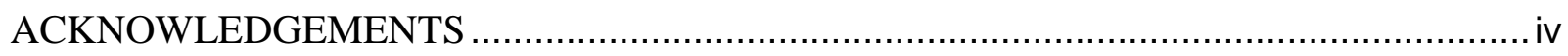

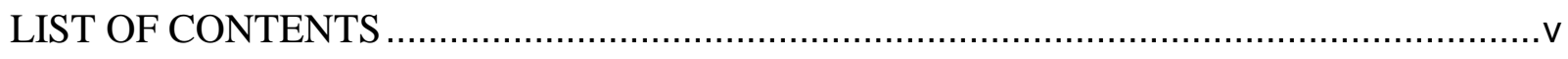

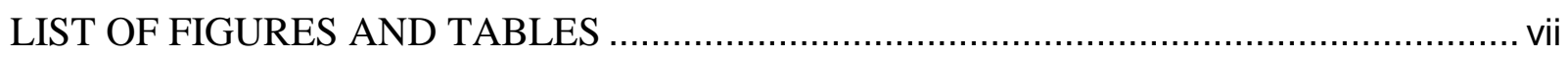

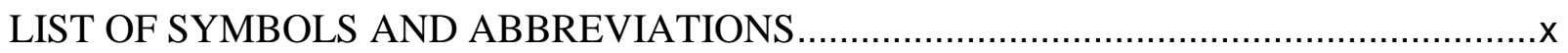

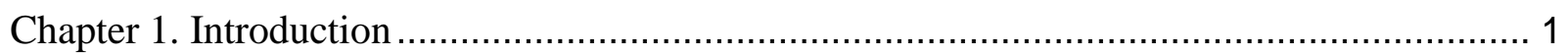

1.1 Background on Study of Ground subsidence ................................................ 1

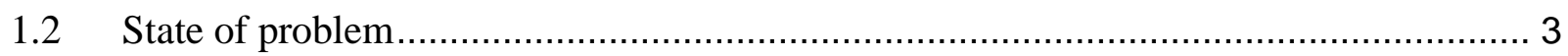

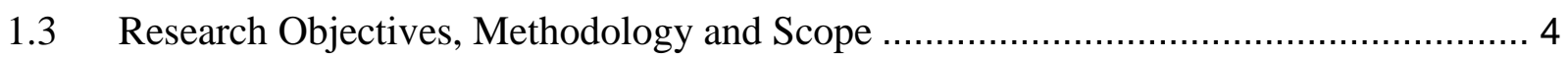

Chapter 2. Literature Review of Subsurface Subsidence and Physical Modeling .................. 7

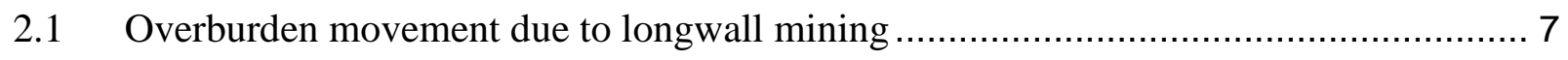

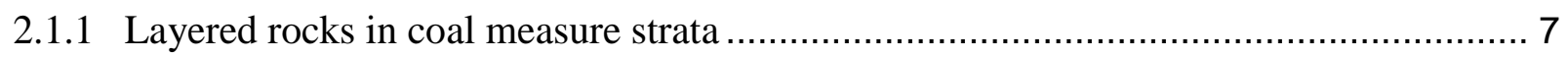

2.1.2 Process of overburden caving and development of deformation ............................ 8

2.1.3 Determination of the height of caved and fractured zones.................................10

2.1.4 Significance of understanding subsurface ground movement ..............................12

2.2 Physical Modeling of Subsurface Subsidence ...............................................13

2.2.1 Dimensional Analysis for Physical Modeling ............................................13

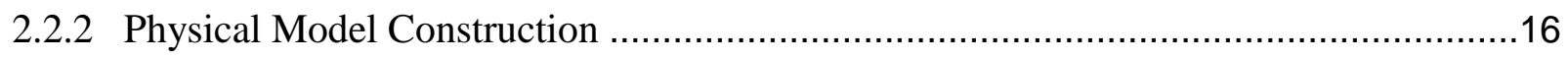

2.3 Physical Modeling of Fracture Development during Longwall Mining ....................18

2.4 Physical Modeling of Caving and Fractured Zones........................................21

2.5 Physical Modeling of Longwall Mining in Inclined Thick Seams ............................22

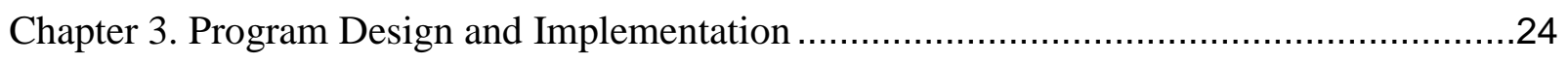

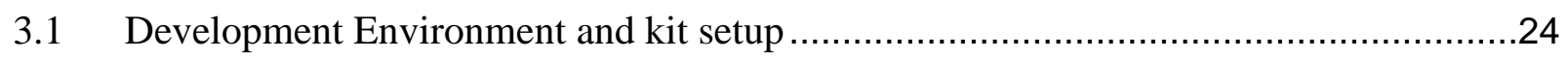

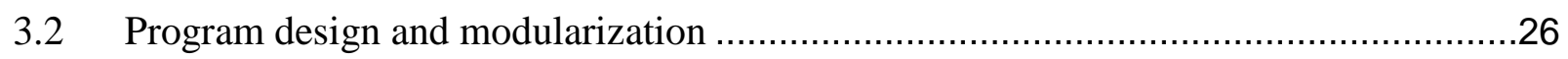


3.3 Computer vision techniques implemented in program .......................................34

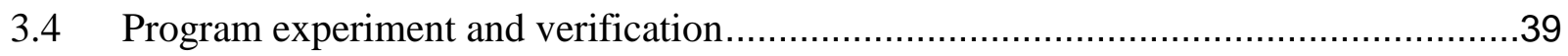

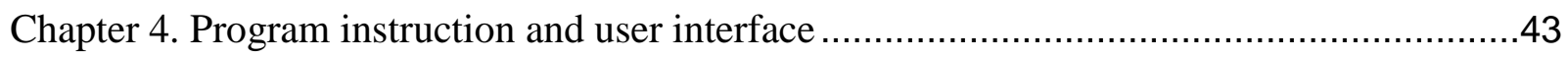

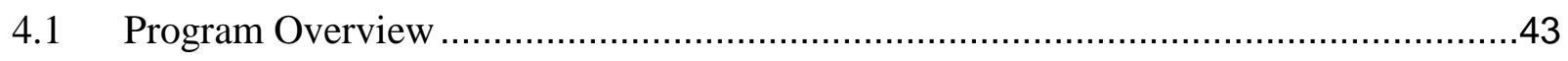

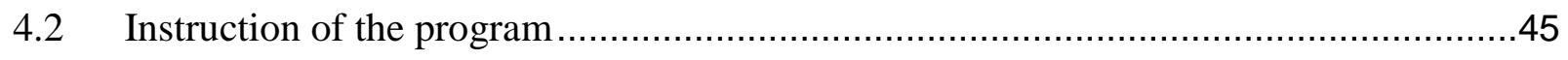

Chapter 5. Analysis of Subsurface Ground Movement from Generated Data ......................59

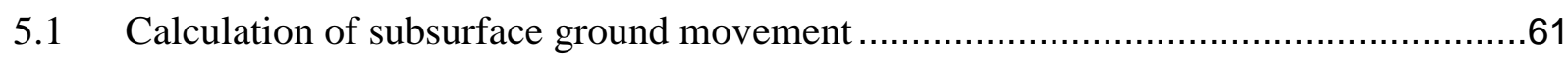

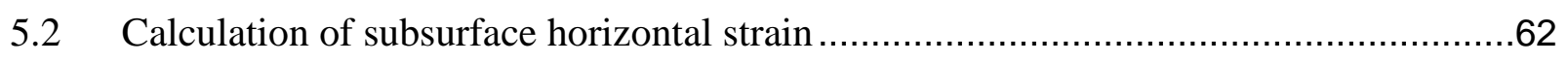

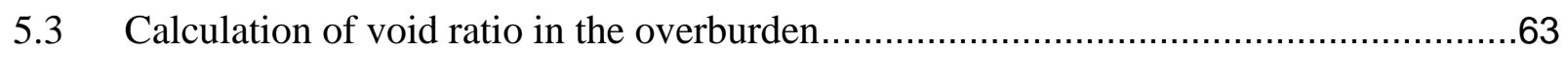

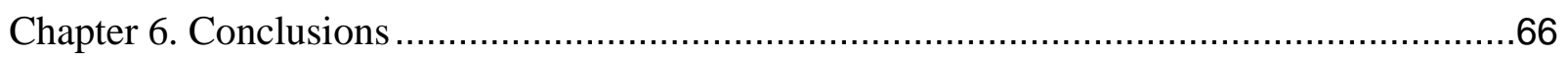

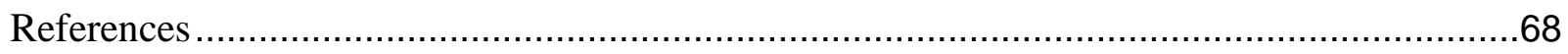




\section{LIST OF FIGURES AND TABLES}

Figure 1-1 Ground subsidence caused by longwall mining ........................................... 1

Figure 1-2 Electronic Total Station for Survey Data Acquisition..................................... 5

Figure 1-3 Flow chart of photogrammetry method .................................................... 5

Figure 2-1 Overburden Movement Resulting from Longwall Mining (Peng, 2006)............... 9

Figure 2-2 A physical modeling experiment being conducted in Xi'an University of Science

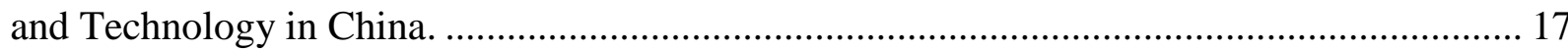

Figure 2-3 Electronic Total Station for Survey Data Acquisition....................................... 17

Figure 2-4 Physical model for caved strata above longwall extraction (Whittaker and Reddish, 1989) 19

Figure 2-5 Fracture distribution between the mining horizon and the surface (Whittaker and

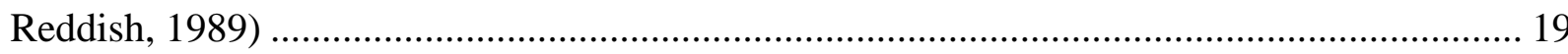

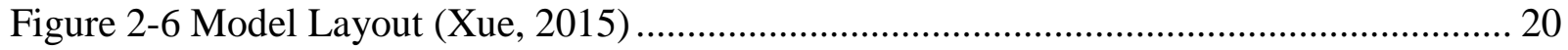

Figure 2-7 Overburden Movement and Fracture Evolution (Xue, 2015) ............................. 21

Figure 2-8 Vertical Displacement at Different Horizon of the Modeled Strata..................... 21

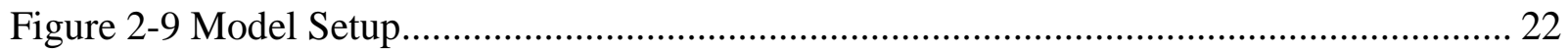

Figure 2-10 Scaled Shields in the Model ..................................................................... 23

Figure 2-11 Strata Movement after Mining ............................................................... 23

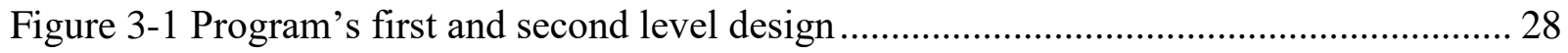

Figure 3-2 Project initiation module design ........................................................... 29

Figure 3-3 Project management module design ....................................................... 30

Figure 3-4 Data collection module design ................................................................ 31

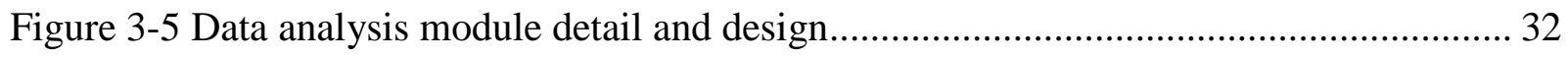

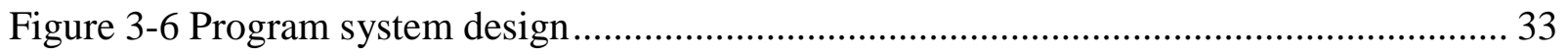

Figure 3-7 The original image on the left. Threshold level 85 selected manually at the center and threshold level 191 on the right. 
Figure 3-8 The threshold level given by Otsu's algorithm, the original image on the left and

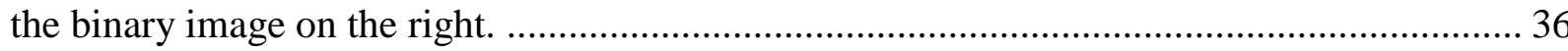

Figure 3-9 Different type of image transformation ...................................................... 37

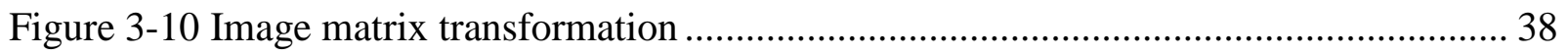

Figure 3-11 Affine transformation example................................................................. 38

Figure 3-12 Image before and after affine transformation ............................................ 39

Figure $3-13$ White board used in the experiment ...................................................... 40

Figure 3-14 Front and side photos taken during the experiment...................................... 41

Figure 3-15 Photo after affine correction .................................................................. 41

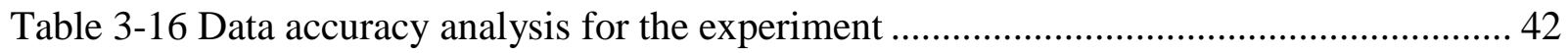

Figure 4-1 Initial opening screen of the program....................................................... 45

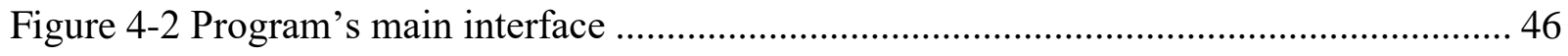

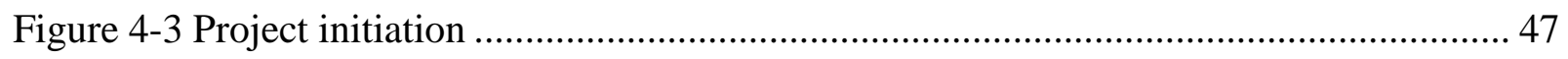

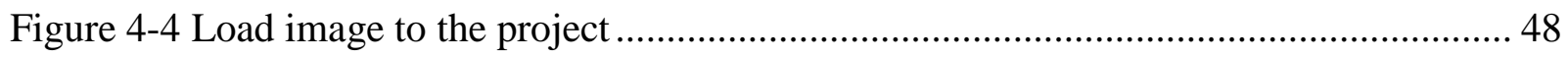

Figure 4-5 Image successfully loaded to the project ................................................... 48

Figure 4-6 Manually set 4 affine correction points ......................................................... 49

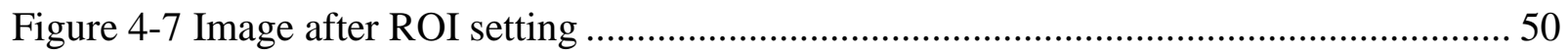

Figure 4-8 The marked points in the image detected ...................................................... 50

Figure 4-9 Manually set up the marking points ...................................................... 51

Figure 4-10 Automatically and manually set up all the needed points .............................. 52

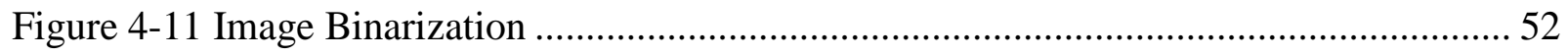

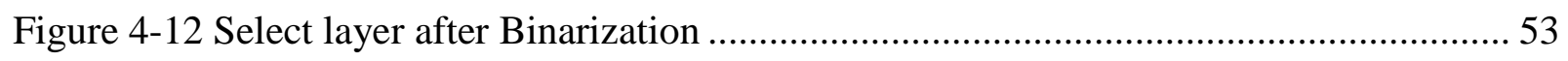

Figure 4-13 Add select layer to the database ............................................................ 54

Figure 4-14 Using multiple rectangles to include all the points ....................................... 54

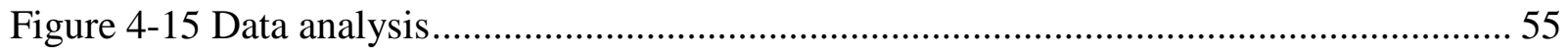




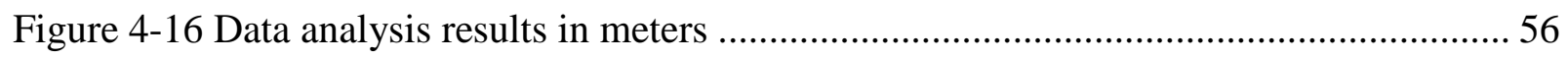

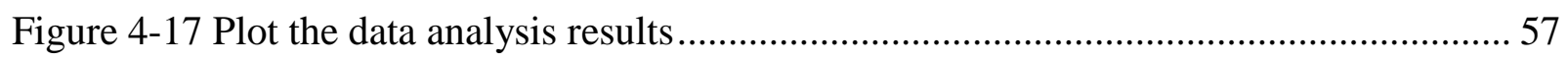

Table 4-18 Export all the data into an Excel file............................................................ 58

Figure 5-1 Physical Model before Excavation ............................................................. 59

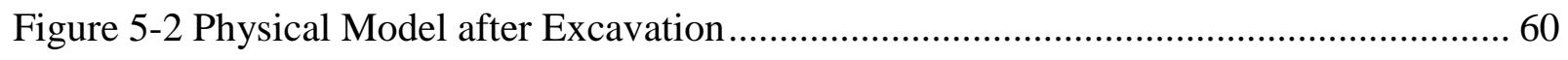

Table 5-3 Coordinates Captured at the Measurement Points .............................................. 60

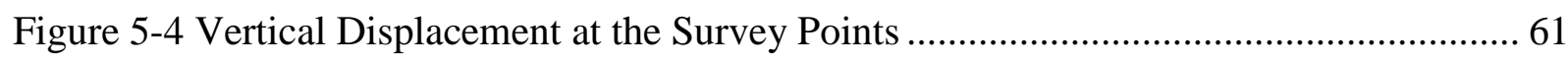

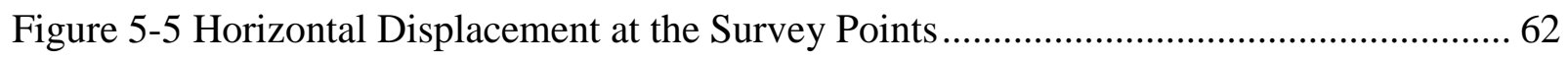

Figure 5-6 the calculated Horizontal Strain Calculated Based on Ground Movement............ 63

Figure 5-7 Area Calculation of Polygon by Coordinates of its Vertices ............................. 64

Figure 5-8 Void Ratio Calculated Based on Ground Movement (values in percentage)......... 65 


\section{LIST OF SYMBOLS AND ABBREVIATIONS}

$\mathrm{G}(\mathrm{ft})$ - The longwall extraction geometry

$\mathrm{T}(\mathrm{psi})$ - The tensile strength of the overburden layers

$\mathrm{C}(\mathrm{psi})$ - The compressive strength of the overburden layers

E(psi) - The Young's Modulus of the overburden layers

$\mathrm{v}$ (dimensionless) - The Poisson's ratio of the overburden layers

$\mathrm{W}\left(\mathrm{lbs} / \mathrm{ft}^{3}\right)$ - The density of the overburden layers, W (lbs/ $\left.\mathrm{ft}^{3}\right)$

$\mathrm{h}$ - Caving height, $\mathrm{ft}$

$\mathrm{H}$ - Mining height, $\mathrm{ft}$

$\mathrm{K}$ - Bulking factor of the immediate roof

PAPMMSP - Photogrammetry Analysis for Physical Modeling of Mine Subsidence Process

RGB - Red Green Blue

ROI - Region of interest

BeforeX - Target point's X coordinate value before subsidence

AfterX - Target point's X coordinate value after subsidence

BeforeY - Target point's y coordinate value before subsidence

AfterY - Target point's y coordinate value after subsidence

SubsidenceX - Target point's deformation in X direction

SubsidenceY - Target point's deformation in Y direction 


\section{Chapter 1. Introduction}

\subsection{Background on Study of Ground subsidence}

The current economic environment and mining regulations place strict operational requirements on modern coal mining. It has to be economic, efficient, safe, and environmentally friendly. A poor understanding of overburden response and movement can lead to ground instability, sudden groundwater ingress, and excessive gas emissions, all of which can negatively affect the safety and economics of a mine.

Longwall mining is a primary method of extracting underground coal seams. The caving of the overburden strata behind the longwall face produces ground subsidence between the mining horizon and the surface (Figure 1-1). The ground subsidence can be divided in to two parts, surface subsidence and subsurface subsidence.

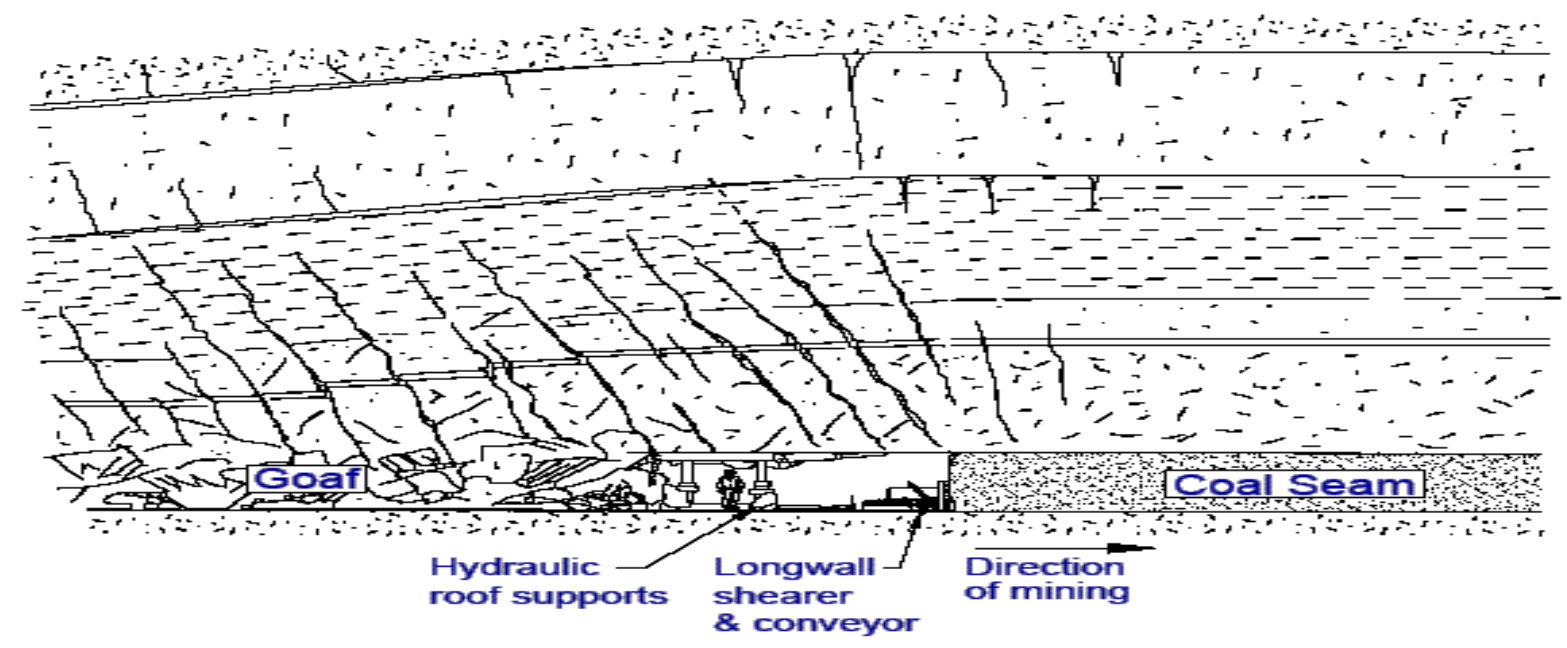

Figure 1-1 Ground subsidence caused by longwall mining 
At present, surface subsidence has been widely studied, and subsidence theory and surface subsidence prediction is fairly mature. Subsidence prediction programs, such as CISPM (Luo, 2008), Lamodel (Keith.A.Heasley, 1996), and SDPS (Agioutantis and Karmis, 2008), has been developed to predict surface subsidence above horizontal seams with satisfactory results.

Compared to the research of surface subsidence, subsurface subsidence and strata movement have not been studied as much as surface movements due to difficulties of measurements and instrumentation.

An analytical subsurface subsidence prediction model has been developed by Luo and Peng $(2000,2010)$ to determine subsurface movements. In this model, the parameter total strain, or void intensity, was introduced to calculate the volumetric expansion of overburden strata under the influence of surface subsidence. The model can be used to predict the distribution of the final void intensity in overburden strata in longwall mining. The strata zones with increased positive void intensity can contain higher permeability for water and methane seepage. The reduced confinement pressure in such zones can also make it easier for methane to desorb from coal or the surrounding rock. The initial subsurface subsidence model was enhanced by Qiu (2013). The improved model employed the influence function method while specifically considering the hard rock layers. The model was applied in analyzing three specific subsidence related ground control problems: the stability of pre-driven longwall recovery room, multiple seam interaction, and ground water flow impacted by longwall mining.

Physical models have also been used to model surface subsidence and overlying ground movement. A physical model is a scaled model to simulate caving process and ground movement in a laboratory. These models typically use a sand/plaster/water mix or combination of similar materials for modeling the overburden. Physical modeling has the following advantages: 
The movement of overburden strata can be observed directly during all stages of mining development.

- Easy to control the geological and mining parameters.

- Geological conditions such as fractures and bedding planes can be simulated easily.

- A large number of observation points can be installed

- Lower cost and less labor-intensive compared to in-situ monitoring.

In using physical models, the dimension of the mining layout and the strength of the overburden strata are suitably scaled to simulate ground movement following excavation. Other forms of physical modeling techniques have been used including gelatine subsiding under its own weight and plaster materials subjected to centrifugal forces.

\subsection{State of problem}

As mentioned above, the subsurface deformation in the model can be measured during the physical modeling process, and the measurement data can be used to analyze subsurface subsidence, strata fracturing, and caving as well as strata movement. The data obtained from the model can include deformation, displacement, stress in the model, and observed strata failure.

There are two traditional measurement methods for physical model experiments: direct measurement and electronic measurement. Direct measurement uses a precision tape to measure the displacement of the model. It is simple, but far from precise, and the data cannot be automatically recorded.

Electronic measurement devices include strain gages and electronic total station. Figure 12 shows an electronic total station used to survey the points on the model to obtain the 
displacements. Both light and electronic devices can obtain the data automatically, but the data acquisition process is inconvenient, the operator has to go through every survey point at each stage of the modeling process, and data collection process is time-consuming. Survey errors could be made by instrument errors and human eyes aligning the crosshairs which are magnified since the device is so close to the model. Besides, in using of total station, only the originally installed points can be measured which result in low density data that would produce less reliable strata deformation indices. As such, a new approach is needed to rapidly acquire measurement data during the experiment process of physical modeling.

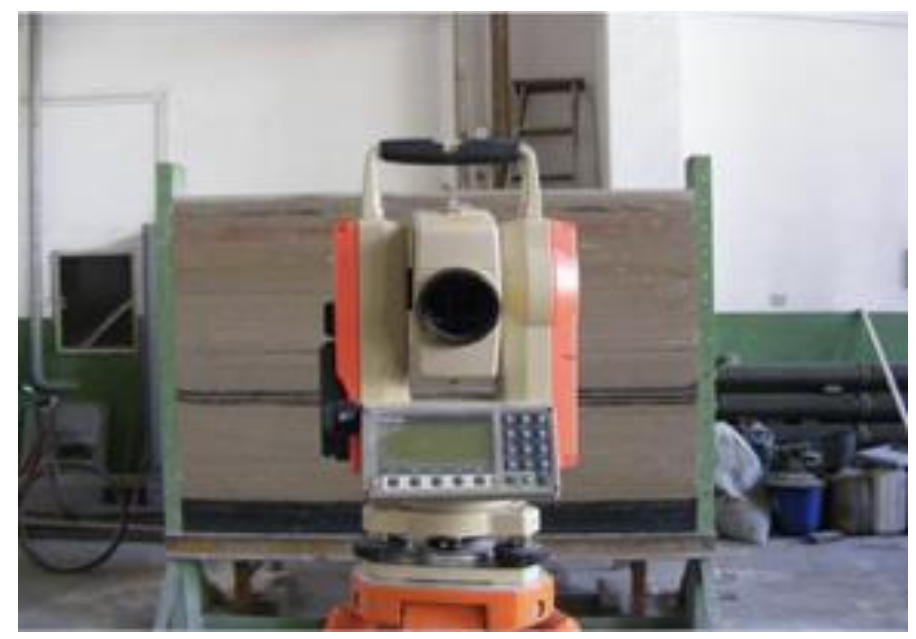

Figure 1-2 Electronic Total Station for Survey Data Acquisition

\subsection{Research Objectives, Methodology and Scope}

The traditional methods of displacement measurement in physical modeling are not only slow but also relatively complicated with respect to data processing. A new method in using photogrammetry is proposed in this thesis to automatically acquire and process the experiment data during physical modeling. The general steps of photogrammetry method are shown in Figure 1-3. The photogrammetry method has the capability of taking photos of the area of study with 
densely placed observation points on the model, then determining the coordinates of the observation points on the photos.

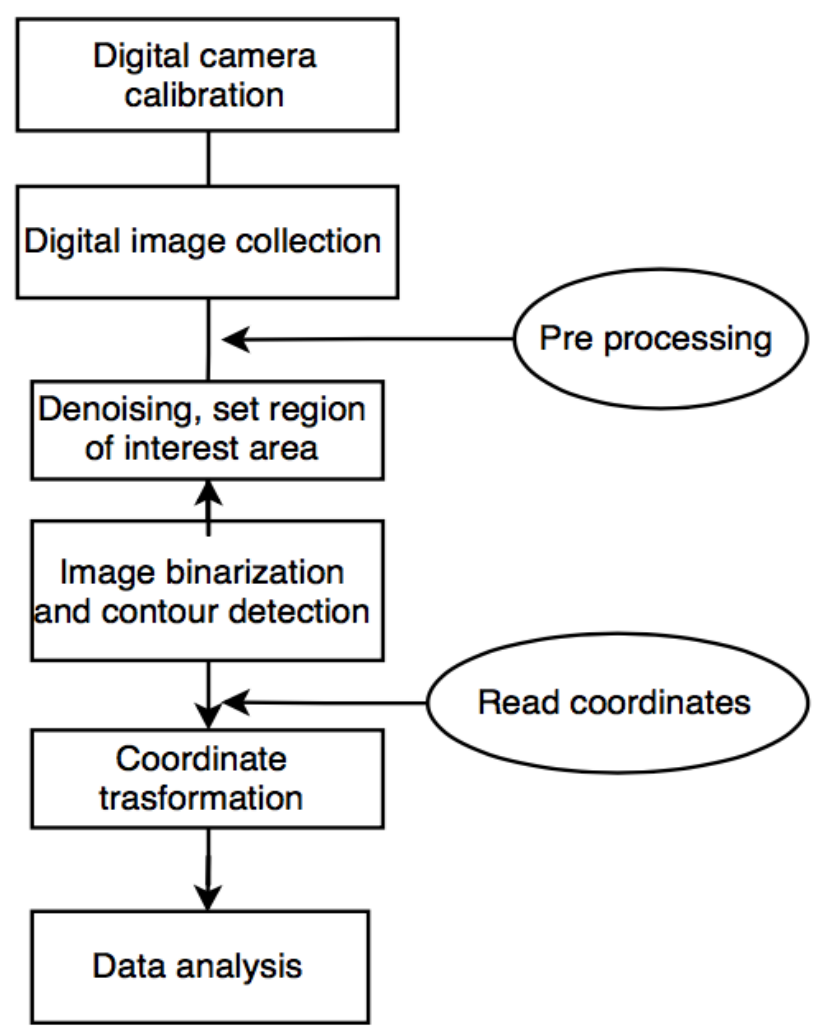

\section{Figure 1-3 Flow chart of photogrammetry method}

To facilitate data collection from physical models, the research objective in this study is to design and develop a program based on photogrammetry method to process the images taken during physical experiment. The purposes of the program are:

- Automatically recognizing the observation points from the photos.

- Determining the coordinates of the points.

- Managing the obtained data at different stages.

- Deriving strata deformation indices. 
The new program, based on the computer vision open source library "OpenCV" and the development platform "QT", provides a new data collection method for physical modeling. The new program has the following features:

- Mouse clicking to read target point - greatly speeds up the surveying process.

- Utilize the four-point perspective transform algorithm to eliminate error caused by changing of the camera position.

- Cooperation of manual and automatic addition of new survey points and making 4point correction, which greatly increases the number of survey points so as to produce reliable strata deformation indices.

- Produce subsurface subsidence database via automatic data analysis, and generate graphs or spreadsheet for further processing. 


\section{Chapter 2. Literature Review of Subsurface Subsidence and Physical Modeling}

Safe and economic coal extraction requires a good knowledge of overburden strata characteristics and understanding of overburden strata movement in response to long-wall mining.

\subsection{Overburden movement due to longwall mining}

\subsubsection{Layered rocks in coal measure strata}

Sedimentary rocks are formed by the deposition and subsequent cementation of materials on the earth's surface and within bodies of water. Common types of sedimentary rocks include shale, claystone, siltstone, sandy shale, limestone and sandstone. Sedimentary rocks represent more than nine-tenths of Earth's surface, and are important sources of fossil fuels, such as coal, oil, and natural gas (Guo, 2017).

Stratification, or a division into layers, is a common characteristics of sedimentary rocks. A single member, or bed, of a stratified rock is called a layer. Each layer represents an uninterrupted deposition of similar material. Bedding planes between layers are formed due to longer or shorter pauses in the deposition process, or to a change in the source material. A stratum is a collection of layers of the same mineral substance that occurs together. The passage from one stratum to another is generally abrupt, and indicates a change in the circumstances of deposition, either in the depth of water, the character of the material brought to a given spot, or both. If the conditions remain the same for a considerable period, significant thickness of similar material may be formed, such as massive sandstone layers (Guo, 2017).

Detailed characteristics of stratified rocks, such as lithology, structural features and mechanical properties, can be obtained from exploration boreholes. Stratified rocks can be highly 
anisotropic in their mechanical strength and deformation characteristics. The shear strength along the bedding plane is generally low and varies depending on surface profile, lithology, and infilling materials. Stratified rock layers have a major influence on the overburden movement due to longwall mining. They directly affect mine stability, surface subsidence, subsurface movement, aquifer interference, mine water inflow, and mine gas emission and flow dynamics.

\subsubsection{Process of overburden caving and development of deformation}

When coal is extracted by longwall mining, the immediate roof deforms and breaks into the mining void. Roof caving and bulking occurs near the coal seam level. This induces shearing, delamination, and separation along the bedding planes, and deformation and bedding of overlying strata. The process of rock deformation begins from the level of the coal seam and propagates upwards. There is a significant delay between the time of coal extraction and the time the ground surface above the extraction point subsides. During this process, the rock layers closer to the mining seam delaminate first from the upper-lying rock layers, bend towards the gob and then fracture and break and tumble. The extent of fracturing and dislocation depends on the layer's position relative to the mining horizon. As the longwall face moves further away, the rock layers lying further above subsequently undergo a similar process of shearing, delamination, bending and fracturing. The process may continue all the way from the coal seam level to surface.

Surface subsidence is caused by caving of the immediate roof when the gob area expands to a sufficient size. The vertical extent of the caving zone is reached when broken rock in the gob is sufficiently high to support the overhanging strata and to stop them from caving. Strata bending and subsidence develop upward until reaching the surface and forming a subsidence basin. The whole overburden strata and the surface subsidence basin will further go through a period of compaction and gradually become stabilized. 
The process of overburden movement has been derived from a few sources: (1) direct observation of the mined section and their surfaces; (2) field monitoring of strata movement in the overburden; (3) numerical modeling; (4) scaled physical modeling in the laboratory (Peng, 1992).

With full extraction, the overburden is subjected to various degrees of movement from bottom to the top. A common approach to understanding the overburden movement has been concentrated on the division of the strata above the longwall face into zones with different deformation characteristics. The size and nature of the zones are based on fracture observations or measurements of pore pressure and permeability changes. According to Peng (1992), the damaged overburden can be divided into four zones (Figure 2-1).

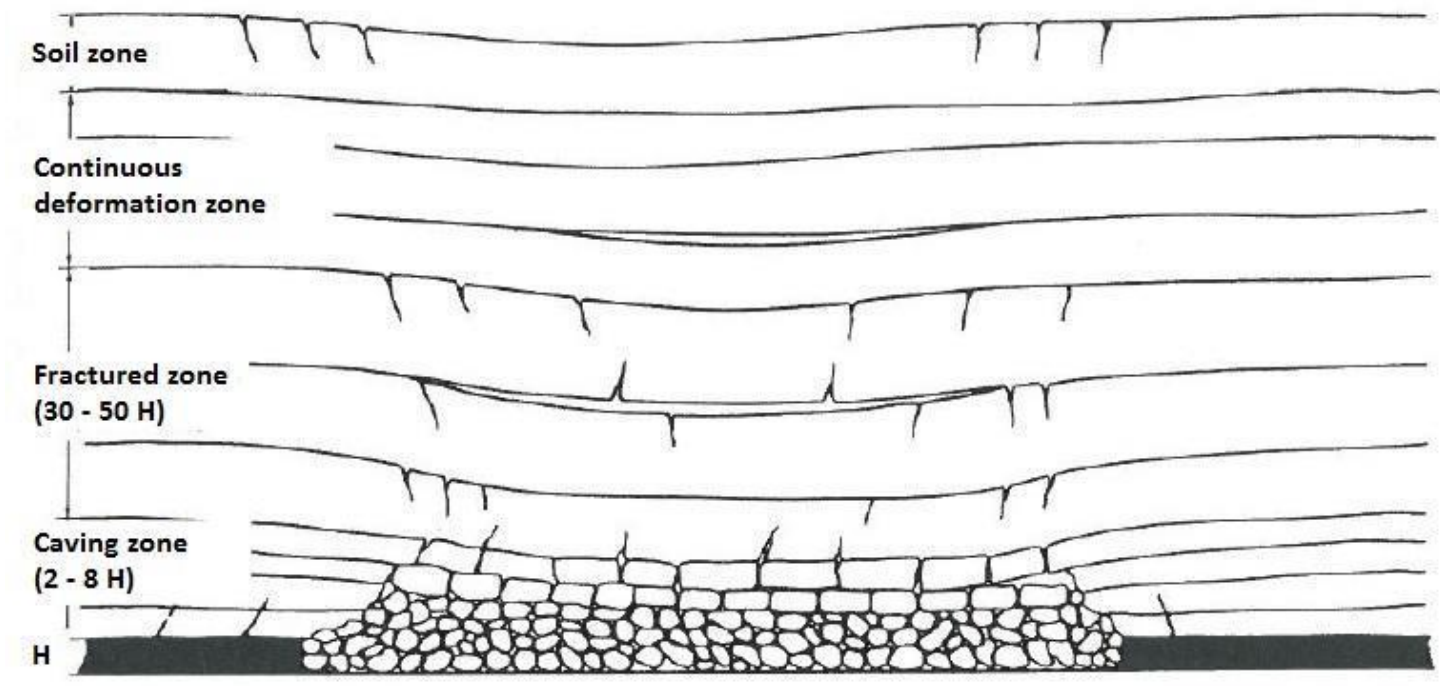

Figure 2-1 Overburden Movement Resulting from Longwall Mining (Peng, 2006)

Caving zone. After the extraction of the coal, the immediate roof fractures and tumbles into the gob and the bulking caused by space in the caved material helps fills up the void caused by coal removal. The strata in this zone not only lose their continuity completely, they also lose their stratified beddings. The caved zone is normally 2-8 times the mining height primarily depending on the properties of the immediate roof and the overburden depth. 
Fractured zone. The fractured zone is located immediately above the caved zone. The strata in this zone are broken and lose their continuity, but essentially remain stratified. The severity of strata breakage reduces from the bottom to the top. The porosity and permeability of the strata will increase greatly, both vertical and horizontally. The combined height of the fractured zone and caved zone is in general 30-50 times of the mining height. The height of the fractured zone for hard and strong strata is larger than that for soft and weak ones. The shape of the fractured zone is related to the height, width and length of opening, overburden depth, overburden properties, and length of the time after mining. A domed shape is generally formed but the boundary of the fractures is often defined by overburden strata and/or discontinuities.

Continuous deformation zone. In this zone, strata between the fractured zone and surface bend downward without breaking. Their continuity and the original layers remain with minimal change of permeability. Some open fissures could occur in the tension zone of the surface subsidence profile.

Soil zone. This is the surface layer the depth of which depends on location. It consists of soil and weathered rock. Depending on the physical properties of the soils, cracks may open in the tensile zone in front of the face and close when the face is far away. Some cracks, especially along the edges of the panel may remain open after mining.

\subsubsection{Determination of the height of caved and fractured zones}

To better understand overburden movement induced by longwall mining, the height of the movement zones in the overburden needs to be determined.

Normally, caving initiates from the lowest strata in the immediate roof and propagates upward into the fractured zone. The process of caving in each stratum is that the stratum sags 
downward as soon as it is undermined. When the downward sagging of the stratum exceeds an elastic bending limit, it breaks, falls and often tumbles. As it falls and tumbles, voids are formed and overall rock volume increases and the gap between the top of the rock piles and the overlying sagged but uncaved stratum continues to decrease as the caving propagates upward. When the overlying strata have received the support of the caved rock piles, the caving stops. For an idealized caving material, the caving height can be determined by the following equation (2.1):

$$
h=\frac{H}{(K-1)}
$$

Where $\mathrm{h}=$ caving height, $\mathrm{ft}$,

$\mathrm{H}=$ mining height, $\mathrm{ft}$,

$\mathrm{K}=$ bulking factor of the immediate roof.

From equation 1.1, It can be seen that the caving height is mainly affected by mining height and the bulking factor of the immediate roof. The caving height is proportional to the mining height, but is inversely proportional to the void ratio of the gob (K-1). The bulking factor is defined as the ratio of the volume of the broken rock strata to the original volume of the same strata before they are broken and caved. The void ratio is defined as the ratio of the volume of the void in the broken strata to the original volume of the same strata. The void ratio is calculated as bulking factor minus 1 . The bulking factor varies with rock type, shape and size of the caved rock fragments, the ways in which the caved rock fragments are piled up, and the pressure imposed on the rock fragments. Caving of the stronger and harder rock will result in larger fragments and orderly arrangement, and therefore, a larger bulking factor. Conversely, the weaker and softer rock will result in smaller fragments, and consequently, a smaller bulking factor. Peng (2006) measured 
the volume of underground roof fall cavities in the entries developed in the Pittsburgh seam and compared them with the volumes of the rock fragments piled up on the floor. He found that the bulking factor for the roof shale ranges from 1.25 to 1.30 with an average of 1.28 . Generally, for medium strong immediate roof, the caving height is about 3-5 times the mining height.

The most effective method to determine the location of the fractured zone in the overburden is direct monitoring. The techniques of monitoring include borehole water pumping, borehole running water quality, borehole photographing, borehole video camera. Based on the analysis of measured data, some basic concepts of factors that control the height of the fractured zone have been established. The major controlling factors are mining height, mining method, rock properties, lithological sequence, and elapsed time after mining (Peng, 1992). The height of the fractured zone is proportional to the mining height. The rock property and strata structure have a great impact on the height of movement in the overburden. Hard and brittle strata are more susceptible to cracks and fractures with minimal bending, while shales and siltstones have a tendency to self-heal with minimal bending. Based on field data analysis, the combined height of the fractured zone and caved zone is generally $20-50$ times the mining height.

\subsubsection{Significance of understanding subsurface ground movement}

The current economic environment and mining regulations place strict operational requirements on modern coal mining. It has to be economic, efficient, safe, and environmentally

friendly. A poor understanding of overburden response and movement can lead to ground instability, sudden groundwater ingress, and excessive gas emissions, all of which can negatively affect the safety and economics of a mine. 
Subsurface subsidence can refer to overburden movement and deformation induced by longwall mining or room and pillar mining with retreat. Subsidence induced overburden movements will affect multiple seam mining, surface and subsurface water bodies, and methane emission and migration in overburden strata. Understanding of subsurface overburden movement is essential for optimal layout of multiple seam mining, protecting surface water resources and gob degasification.

Modern longwall operation demands that the overburden strata deformation be properly quantified and predicted in advance. Current understanding of overburden movement have provided essential background information on generally expected overburden deformation in response to mining. But the use of other advanced technologies, such as field monitoring, long directional drilling, numerical modeling, have helped accurately quantify evaluation of sitespecific overburden movement under complex geological conditions. Scaled physical modeling, as a supplementary modeling technique, can also provide visual and quantitative understanding of overburden movement under specific condition.

\subsection{Physical Modeling of Subsurface Subsidence}

Physical models have been used to study fracture development and caving characteristics above longwall mining excavations. Physical models have the advantages in observing fracture development and caving propagation as the longwall face proceeds from its starting position, and advances during all stages of full subsidence development.

\subsubsection{Dimensional Analysis for Physical Modeling}

The scaled physical subsidence model needs to be based on the laws of dimensional analysis. The independent variables of the model are expressed by their fundamental dimensions, 
usually mass, length, and time. The dependent variables can be expressed by all the independent variables. The subsidence model is dependent on the following parameters:

The longwall extraction geometry, $\mathrm{G}(\mathrm{ft})$

The tensile strength of the overburden layers, $\mathrm{T}(\mathrm{psi})$

The compressive strength of the overburden layers, $\mathrm{C}(\mathrm{psi})$

The Young's Modulus of the overburden layers, E(psi)

The Poisson's ratio of the overburden layers, V(dimensionless)

The density of the overburden layers, $\mathrm{W}\left(\mathrm{lbs} / \mathrm{ft}^{3}\right)$.

There are other parameters that are less significant. Using the above parameters, subsidence can be expressed in terms of the following equation (2.2):

$$
S=f(G, T, C, E, V, W)
$$

The Buckingham $\pi$ theorem is a key theorem in dimensional analysis used in engineering, applied mathematics, and physics (Whitaker, 1989). The theorem states that if there is a physically meaningful equation involving a certain number of physical variables, then the original equation can be rewritten in terms of a set of dimensionless parameters constructed from the original variables. The theorem can be seen as a scheme for dimensionless analysis because it provides a method for computing sets of dimensionless parameters from the given variables, even if the form of the equation is still unknown.

Based on Buckingham's theorem, a complete equation can be reduced to a functional relationship between a complete set of independent dimensionless products. A relationship needs to inter-relate the model with reality and this can be achieved by the various scale factors. 
From Buckingham's theorem, the dimensional relationship can be expressed as (2.3):

$$
\frac{S}{G}=f\left(\frac{T}{C}, \frac{E}{C}, V, \frac{W G}{C}\right)
$$

This needs to be valid for both the model and reality so that (2.4):

$$
\frac{S_{m}}{G_{m}}=\frac{S_{r}}{G_{r}}
$$

Where the subscripts $\mathrm{m}$ refers to the model and $\mathrm{r}$ refers to reality.

It follows that:

$$
\begin{aligned}
& \frac{T_{m}}{C_{m}}=\frac{T_{r}}{C_{r}}, \\
& \frac{E_{m}}{C_{m}}=\frac{E_{r}}{C_{r}}, \\
& \frac{W_{m} * G_{m}}{C_{m}}=\frac{W_{r} * G_{r}}{C_{r}} .
\end{aligned}
$$

Rearrange to obtain the geometric scale factor:

$$
\begin{aligned}
& \frac{S_{r}}{S_{m}}=\frac{G_{r}}{G_{m}}, \\
& \frac{T_{r}}{T_{m}}=\frac{E_{r}}{E_{m}}=\frac{C_{r}}{C_{m}}=\frac{W_{r} * G_{r}}{W_{m} * G_{m}}
\end{aligned}
$$

It can be seen that $\frac{G_{r}}{G_{m}}$ can be determined by mining excavation width and model length.

The ratio of density can also be determined by average density of the overburden and material density of the physical model. The strength and Young's modulus scale factor can be determined by the geometric scale factor multiplied by the density ratio. Assuming that the average overburden 
density is $162 \mathrm{lbs} / \mathrm{ft}^{3}$ and the material density of the physical model is $110 \mathrm{lbs} / \mathrm{ft}^{3}$, the strength and modulus scale factor should be 123 for modeled excavation width of $500 \mathrm{ft}$ and the physical model height of $6 \mathrm{ft}$.

\subsubsection{Physical Model Construction}

The physical model is constructed by steel frames to support the materials and to simulate the boundary conditions of the model. Based on the size and scale of the model, 2-D planar model and 3-D spatial models have been used. A planar model is widely used and its main part is composed of tubing and angle steel sections with holes in their two sides to stabilize the model frame. The size of the frame depends on length-to-height ratio. Generally, the length is $6-20 \mathrm{ft}$ $(2-6 \mathrm{~m})$, the height is $5-8 \mathrm{ft}(1.5-2.5 \mathrm{~m})$, and the width is $8-30$ in $(0.2-0.8 \mathrm{~m})$. The frame support, normally made by metal plank or plate is erected by the two sides of the model support. Due to the constraint of the model height, the material's own weight may not be enough to simulate the overburden pressure. In this case, external pressure is applied on the top of the model by applying a distributed hydraulic pressure. Figure 2-2 shows physical modeling experiment being conducted in Xi'an University of Science and Technology in China.

The material in the physical model includes two parts: aggregate and binder. Aggregate includes sand, aluminate powder and mica powder; the binder material includes cement, lime, gypsum, and paraffin. The strength of the material in the physical model depends on type of binder, the proportion of the binder and aggregate. 


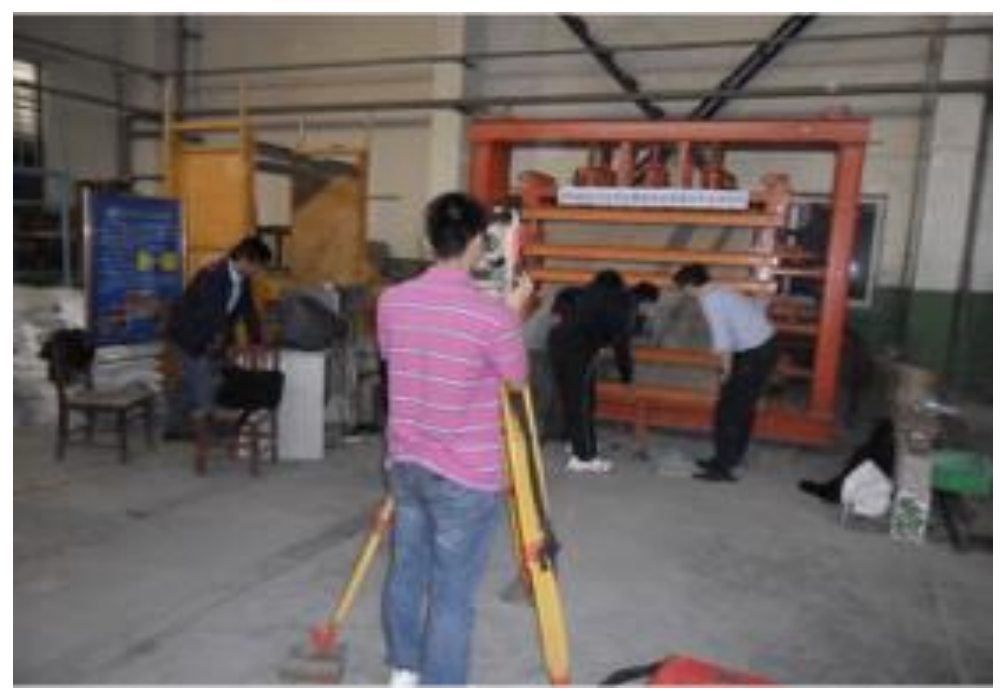

Figure 2-2 A physical modeling experiment being conducted in Xi'an University of Science and Technology in China.

For loading the model, a hydraulic jack is typically used to add uniform pressure on the top of the model. As the load is concentrated around the head of the jack, less pressure is applied over the outer edge of the model.(Figure 2-3)

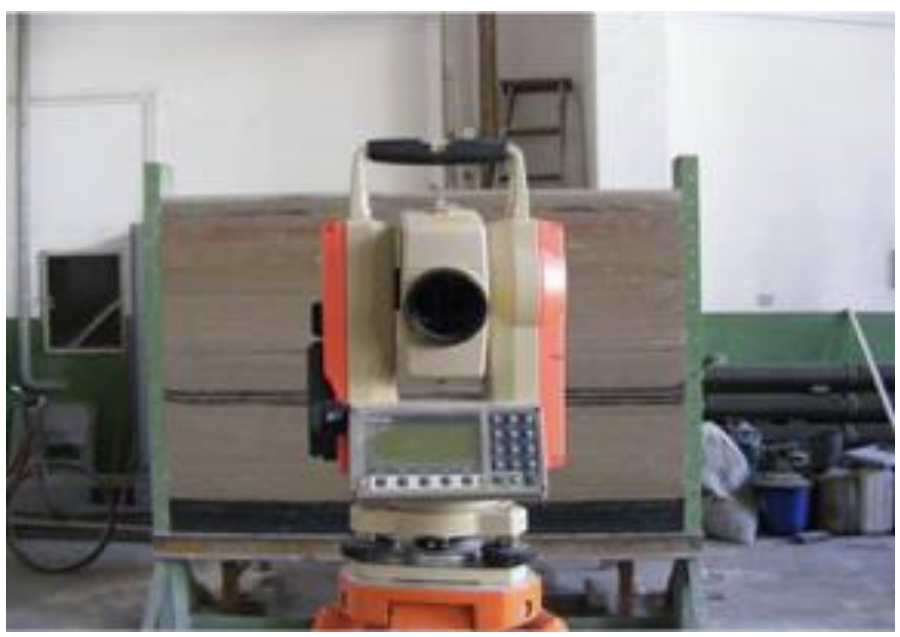

Figure 2-3 Electronic Total Station for Survey Data Acquisition 


\subsection{Physical Modeling of Fracture Development during Longwall Mining}

Very few physical models have been used to study the effects of ground movement caused by longwall mining in the United States, but physical modeling has been successfully used in other countries to effectively study subsurface movement and roof caving process.

The University Of Nottingham, UK, used a large subsidence model testing facility to study fracture development in overburden strata above longwall panels for a number of years (Whittaker and Reddish, 1989). The model employed gravity loading to generate caving, fracturing and subsidence of the ground above the longwall panels. The rock strength in the model could be readily adjusted by selecting the appropriate sand to plaster ratio in the mixing stages of model construction. The test rig had approximate internal dimensions of about $10 \mathrm{ft}$ long, $5 \mathrm{ft}$ high and $0.5 \mathrm{ft}$ thick. Extraction dimensions were pre-determined and built into the physical model so that the mining stage could be easily performed by progressively removing blocks from near the base of the model. The physical model was constructed in layers, and the layers were cast 0.5 in thick using a sand/plaster mix with a thin interface of sawdust to facilitate bed separations to develop. Dyed layers were used at intervals to help photographic comparisons. A convenient grid, commonly 4 inches square, was drawn over the face of the model prior to the beginning of the test.

One physical model was set up for a shallow overburden depth of $275 \mathrm{ft}$, see Figure 2-4. During the test, well-defined fracture lines occurred at the edges of the excavation, and bed separations occurred at the interfaces between the layers. The central portion of the collapsed strata showed that the beds have collapsed in an almost intact condition near the mining horizon but significant separations existed at higher horizons.

Figure 2-5 shows the fully developed overburden movement and the fracture distribution between the mining horizon and the surface. The fractures occur over the mined-out region, and 
their main concentration is associated with the longwall extraction edge effect. The fractures gradually dissipate from the extraction edge but are still visible at the surface. The fractures tends to close in the region over the extraction and significantly away from the edge effect. The type of overburden will greatly influence the development and occurrence of such fractures. Strong sandstone beds would develop open fractures but weak mudstone layers are more likely to deform without voids during the subsidence phase.

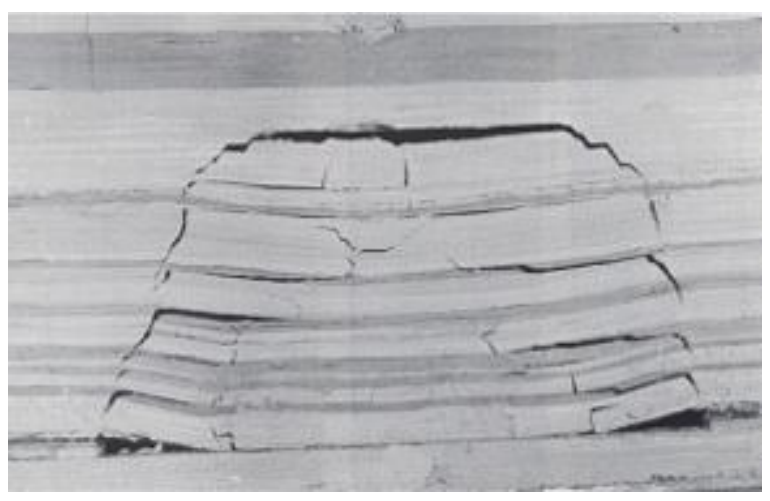

Figure 2-4 Physical model for caved strata above longwall extraction (Whittaker and Reddish, 1989)

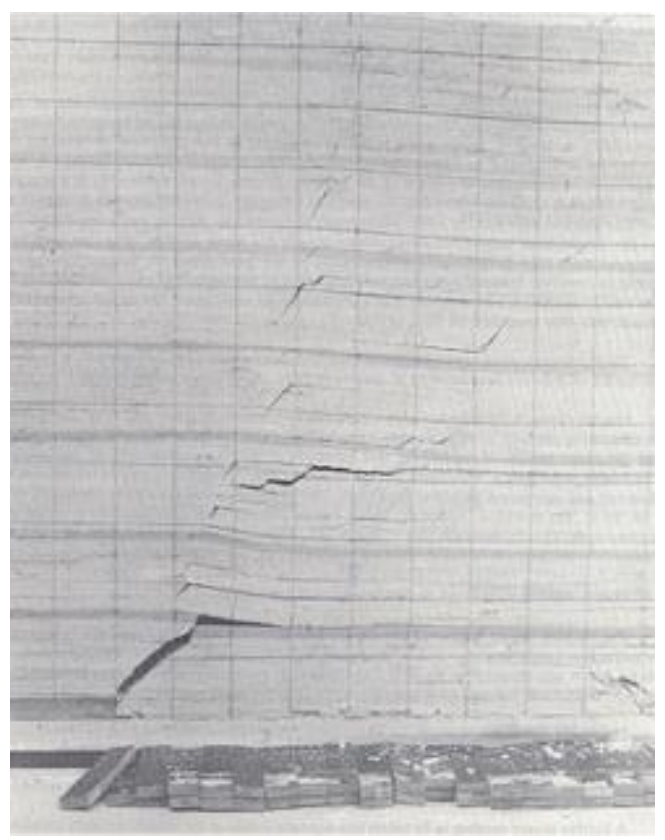

Figure 2-5 Fracture distribution between the mining horizon and the surface (Whittaker and Reddish, 1989) 
Xue (2015) used physical models to simulate the movement and fracture development of the overlying strata after longwall panels with yield pillars were mined. Displacement, strain and failure process were obtained from the model by the means of displacement meter, strain gauges, and digital photography. 2-6 shows the model setup and Figure 2-7 shows the overburden movement and fracture development from the model. The modeling results gave the initial caving interval of the immediate roof, periodic weighting interval of the main roof, maximum caving height and fractured height. Figure 2-8 shows the vertical displacement at different horizon of the modeled strata. Based on displacement measurement from the model, the stress field and dynamic development and distribution of fractures are also analyzed.

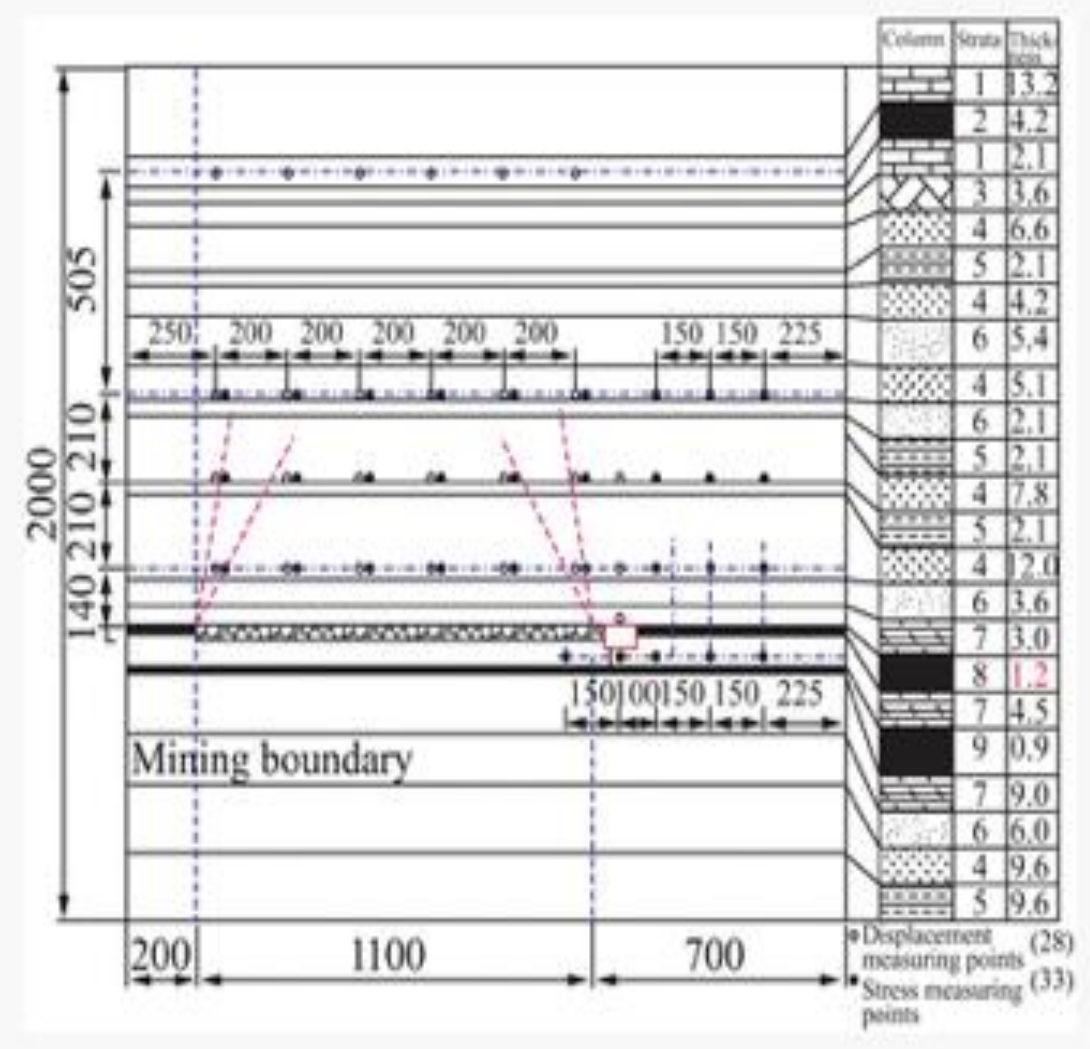

Figure 2-6 Model Layout (Xue, 2015) 


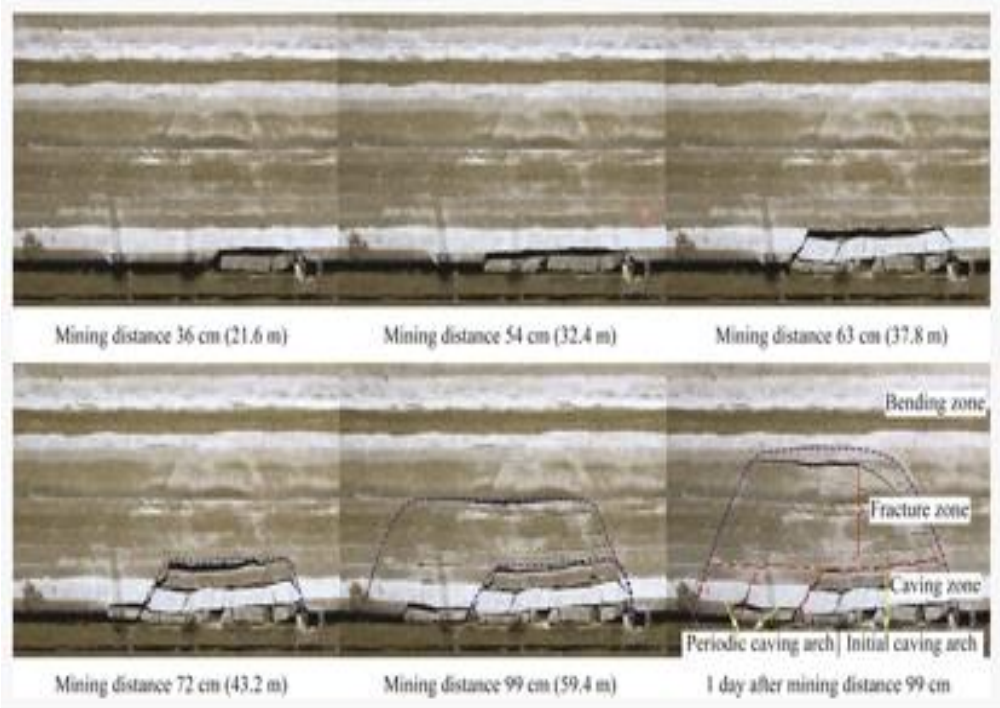

Figure 2-7 Overburden Movement and Fracture Evolution (Xue, 2015)

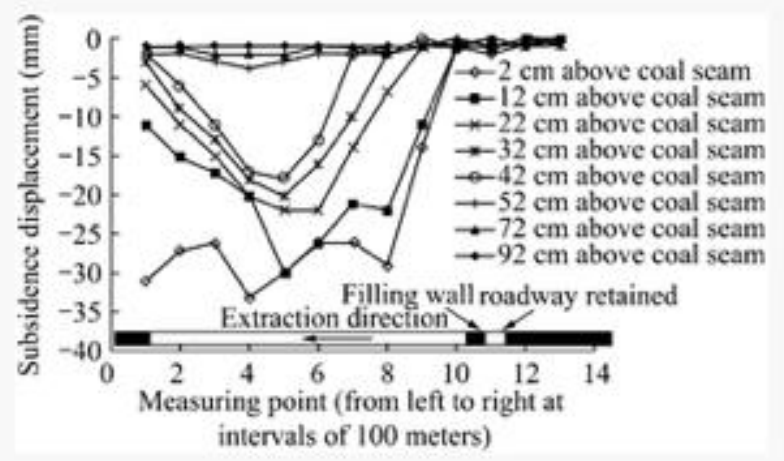

Figure 2-8 Vertical Displacement at Different Horizon of the Modeled Strata.

\subsection{Physical Modeling of Caving and Fractured Zones}

Zhang (2014) used physical modeling to study the height of the caving and fractured zones for a longwall panel in North West China. The physical model was designed to simulate a longwall panel with a $787 \mathrm{ft}$ panel width and $1384 \mathrm{ft}$ overburden depth in a $15 \mathrm{ft}$ thick coal seam. The physical model was $5.2 \mathrm{ft}$ long, $3 \mathrm{ft}$ high and 6 in wide. The first $262 \mathrm{ft}$ of overburden was modeled using the materials with scaled mechanical properties, and remainder of the overburden was simulated by applying uniform pressure on the top of the model. The physical modeling found that the caving height was $41 \mathrm{ft}$ and the height of the fractured zone was $123 \mathrm{ft}$. The experimental 
results were compared to the in-situ measurements from angled water injection holes drilled over the gob from the gate entry near the gob. The in-situ measurements showed a caving height of 43.6 $\mathrm{ft}$ and a fracture height of $131 \mathrm{ft}$, slightly greater than the results from physical modeling.

\subsection{Physical Modeling of Longwall Mining in Inclined Thick Seams}

Xi'an University of Science and Technology (research report, 2013) conducted physical modeling of longwall mining in inclined thick seams. Both seam inclination and shield support in the longwall face were considered. Figure 2-9 shows the model setup, and Figure 2-10 shows the scaled shields in the model. Strata movement and shield pressure were monitoring during the process of model excavation. Figure 2-11 shows the overburden strata movement after mining. The physical modeling helped to determine the caving height, fractured zone, and the required shield capacity.

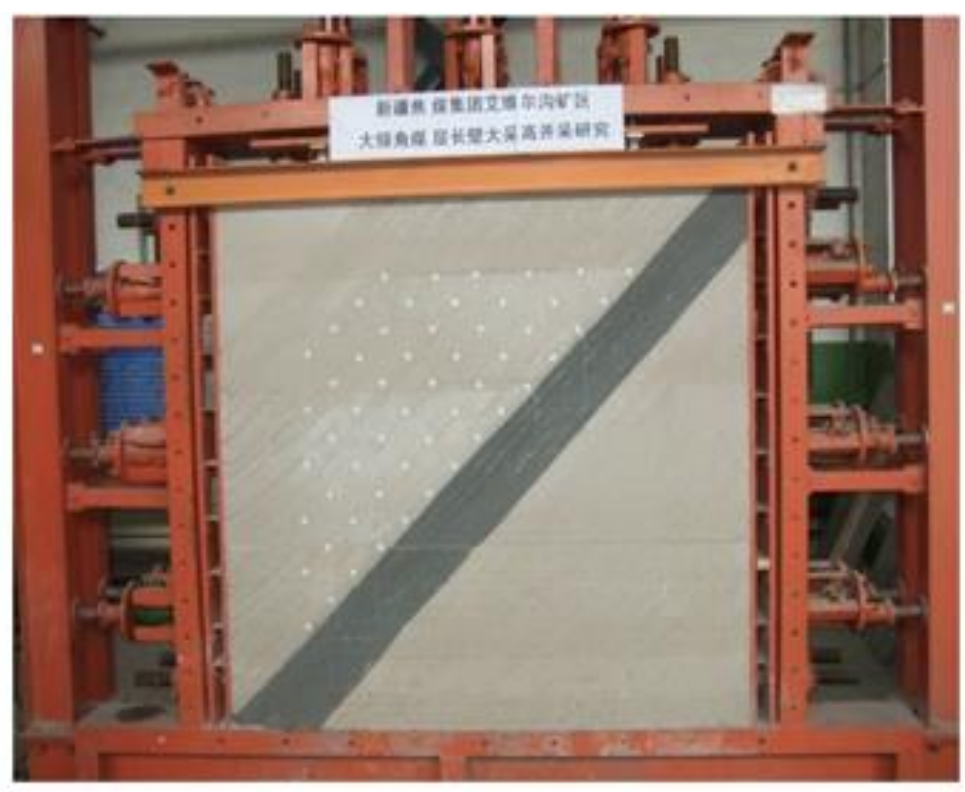

Figure 2-9 Model Setup 

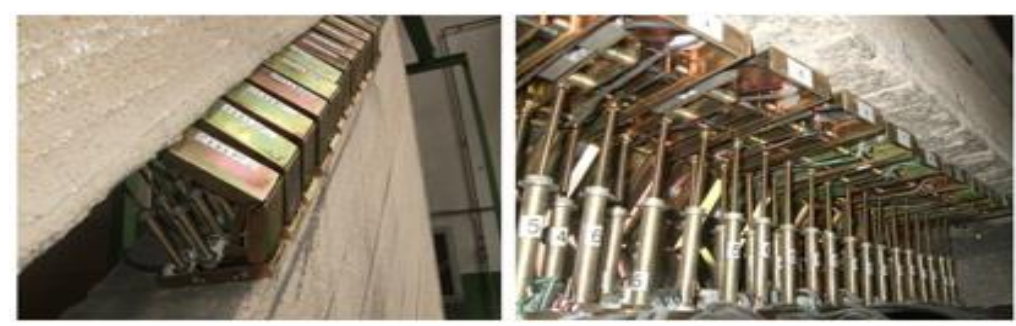

Figure 2-10 Scaled Shields in the Model
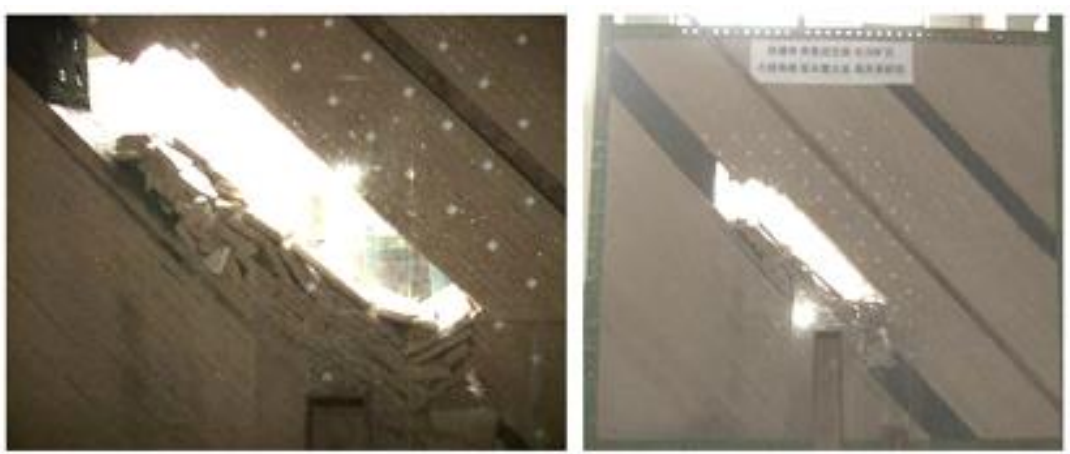

Figure 2-11 Strata Movement after Mining 


\section{Chapter 3. Program Design and Implementation}

Program design is a process to transform user requirements into some suitable form, which helps the programmer in program coding and implementation. In this chapter, this program's design and implementation is discussed.

\subsection{Development Environment and kit setup}

\section{Development environment selection}

At the beginning of this program development, an evaluation was performed on the compatibility of various development platforms with different operating systems, the richness of the API(Application Programming Interface), the report for OpenCV, development speed, and the comprehensiveness of supporting documents. Ultimately QT and MFC were compared. MFC (Microsoft foundation class) is a class library for developing graphical user interfaces, designed specifically for Windows. MFC uses the object-oriented approach to wrap Win32's API, so that these APIs are sometimes $\mathrm{C}++$, sometimes $\mathrm{C}$, and even $\mathrm{C}$ and $\mathrm{C}++$ mixtures, which means the API is not well-organized, bugs and shortcomings in the MFC framework requires a lot of intervention and rewrite. QT- the C++ graphics library was developed by Trolltech around 1994, which can run on Windows, Mac, OS X, Unix, and embedded systems like Sharp Zaurus, and so on, and it is fully object-oriented.

In QT, anything can be manually typed out because it's simple: to define a button, you can write that:

button = new PushButton( "buttonName", MyParentName );

When a function is executed after pressing a button, it can be written like this: 
connect( button, SIGNAL( clicked() ), qApp, SLOT( action() ) );

QT has a very simple yet powerful graphical layout mechanism, so it can save a lot of coding time to use it.

QT also provides a graphical user tool, QT Designer, which can be used to help build user interfaces. The properties of any control can be easily modified. The code generated by this tool is easy to read and understand. Therefore, QT is the development framework that been used in this program development.

\section{Programming language selection}

QT can be used in several other programming languages via language bindings, for example, Java, python, C++. It runs on the major desktop platforms.

This program is mainly developed in $\mathrm{C}++\mathrm{C}++$ is a general purpose programming language and widely used nowadays for program development. It has imperative, object-oriented and generic programming features, because it acquire the feature of low level $\mathrm{C}$ language, it provides performance and memory efficiency.

QT uses standard C++ with extensions including signals and slots that simplify handling of events, and this helps in development of both the GUI and server applications which receive their own set of event information and should process them accordingly.

\section{Program developer's kit for image processing selection}

In image processing, two program development kits for image processing are considered, namely OpenCV and openGL. OpenGL is mainly used in 3D processing, while OpenCV is an 
open library for digital image processing. It includes several hundreds of computer vision algorithms.

OpenCV is short for Open-source Computer Vision, referring to the open source computer visual system which is comprised of a series of $\mathrm{C}$ functions and a few $\mathrm{C}++$ groups to implement many common algorithm in image processing and computer vision. OpenCV possesses the crossplatform medium or high layer API comprising over $300 \mathrm{C}$ functions. It doesn't depend on other external libraries-though it can use some of them and is both free for non-commercial and commercial applications.

In comparison, OpenGL is short for Open Graphics Library, referring to the interface for an open Graphics program, which mainly aims at the algorithm library of computer graphics. OpenGL is a program interface irrelevant to the hardware and therefore has excellent portability among different platforms. Therefore, program supporting OpenGL possess good transplantation and can be applied broadly.

For the ultimate transplantation of the program, OpenCV possesses good cross-platform support and is totally free. By using a series of $\mathrm{C}$ functions and a few $\mathrm{C}++$ groups, it implements many algorithms in image processing and computer vision. It is faster than OpenGL and OpenCV is relatively independent, not relying on other external libraries to truly realize lightweight development. Therefore, OpenCV is used to process the images for this program development.

\subsection{Program design and modularization}

Program design is a process used to transform user requirements into some suitable form, which helps the programmer in program coding and implementation. In this chapter, this program's design pattern and implementation is discussed. 
Before starting to code, program design is the first step that needs to be taken. It tries to specify how to fulfill the requirements mentioned in program requirement specification, below is the approach used in this program design.

\section{Top down approach and modularization}

A system is composed of more than one sub-systems that it contains a number of components. Further, these subsystems and components may have their own sub-systems and components and therefore create a hierarchical structure in the system.

A top-down approach takes the entire program system as one entity and then decomposes it to achieve more than one subsystem or component based on defined characteristics. Each subsystem or component is then treated as separate system and decomposed further. This approach keeps occurring until the lowest level of system in the top-down hierarchy is achieved.

On the other hand, each sub-system should be treated as discrete and independent modules, which are expected to be capable of performing tasks independently. The design of each module follows the rules of 'divide and conquer' problem-solving strategy called: "Modularization". The reasons for modularization are:

- Smaller modules are easier to maintain. If a bug is been found in one module, the coder can focus on the buggy module rather than the whole system.

- Each module contains strongly related functionality, which achieves high cohesion, Cohesion is a useful tool for managing complexity because developers will find the component they need more easily among the cohesive set of operations provided by the module, which dramatically increases module reusability. 
- Modules can be divided based on functional aspects.

\section{Program requirements and high level design}

According to general process of photogrammetry method (See Figure 1.3), high level program design can be performed, high level design focuses on how the system along with all of its components can be implemented into modules, this subsurface subsidence monitoring program can be divided into 4 subsystems, as shown in Figure 3-1.

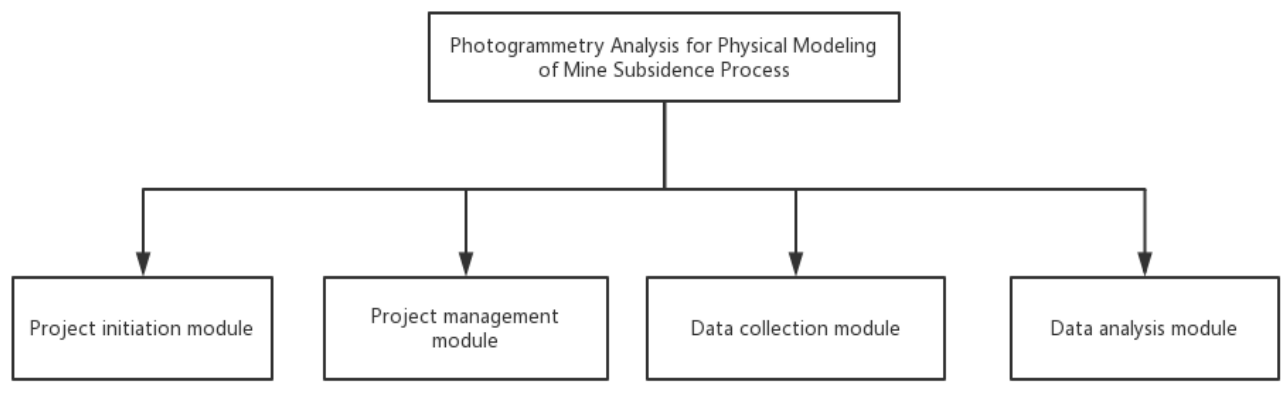

\section{Figure 3-1 Program's first and second level design}

\section{Detailed design}

After high level design, each module's detailed design needs to be established. Detailed design deals with the implementation part of what is seen as a system and its sub-systems in highlevel design. It is more detailed towards modules and their implementations. It defines the logical structure of each module and their interfaces to communicate with other modules.

It is widely believed that every cycle of the similar simulation experiment costs a long time, thus leading to more pictures been collected in the project initiation module. However, the data analysis is primarily relying on comparing the amount of deformation between two pictures which may cause the repeated analysis. To avoid this problem, the deformation information of the analyzed picture should be saved after finishing each analysis. Based on above consideration, an 
efficient project initiation module needs to satisfy the requirements of create, opening and saving projects, as described in bellowing (Figure 3-2):

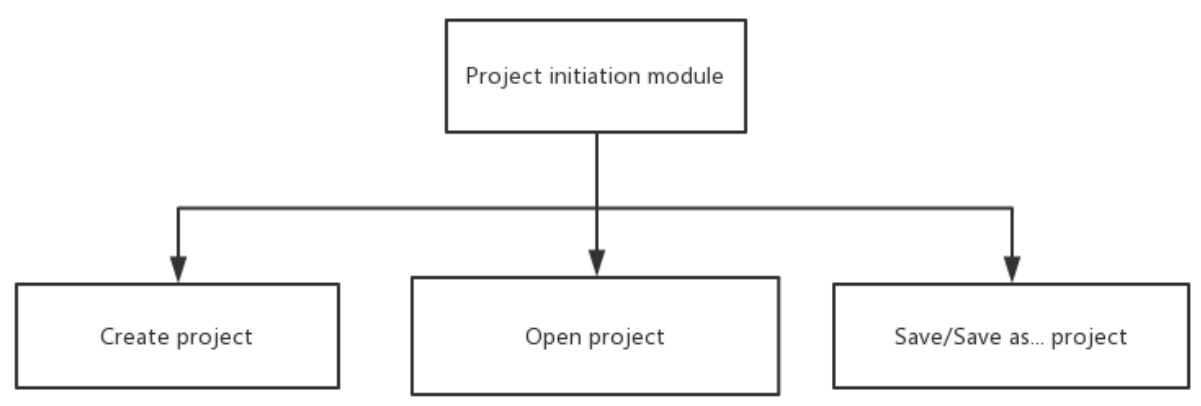

Figure 3-2 Project initiation module design

In the project management module (Figure 3-3), we need to consider adding/deleting simulated images. Because the experiment cycle may takes long time, there's the need to add name, date, author and description to each picture to prevent future confusion. In order to facilitate the contrast of two pictures at different stages, the program designs two editing areas, left and right, so that two pictures can be more intuitively shown in front of the users. This way is also adds some functional bedding for follow-up manual operation in which, the users can refer to the right picture while adding the points in the left editing area, thus avoid in mistakes. 


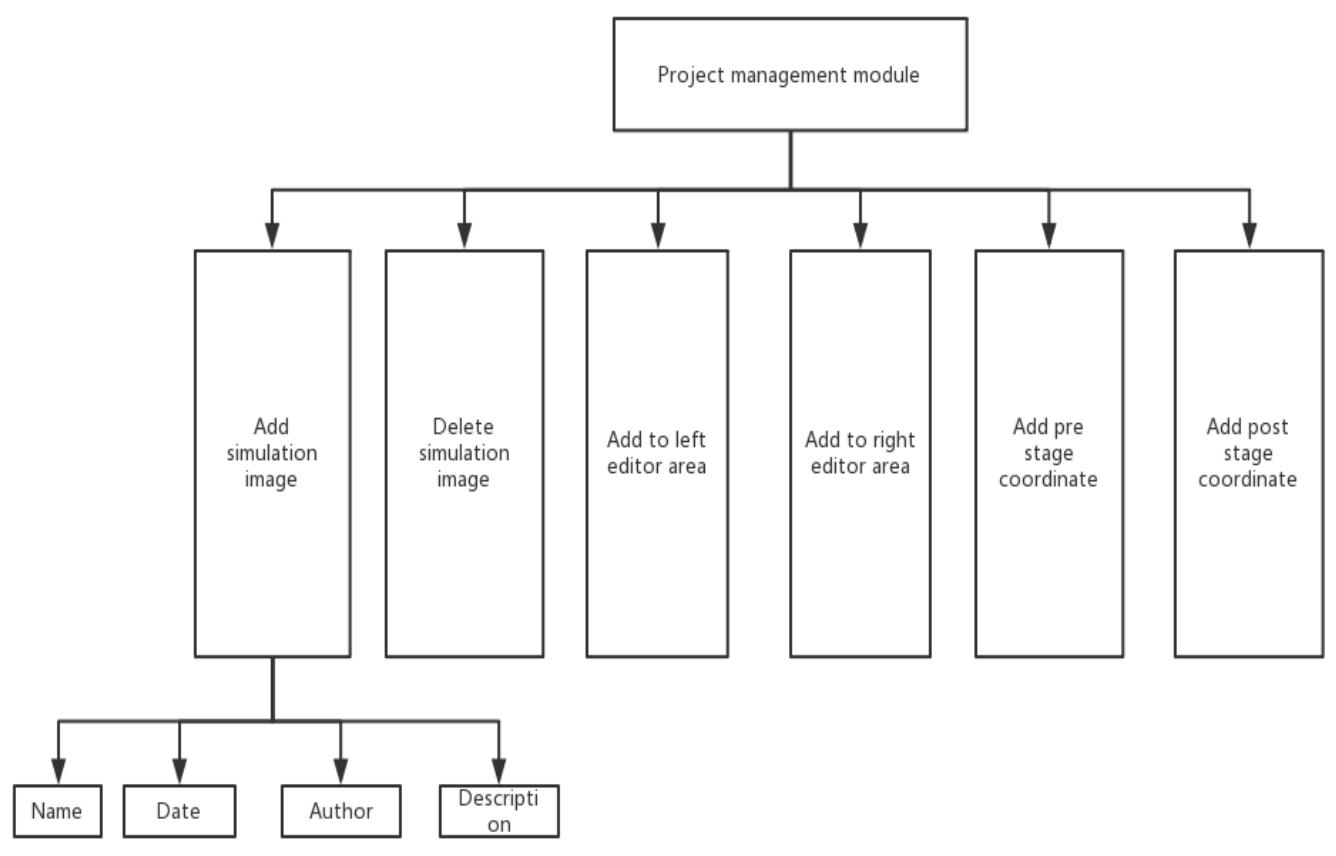

Figure 3-3 Project management module design

The data collection module is divided into four sub-modules (Figure 3-4), the first module is the parameter setup module, and this module receives the model length and width input from the user. The second module is ROI setup module. This module is capable of conducting the fourpoint affine correction. The ROI setup module is divided into two sub-modules, manual mode module and automatic mode module. Under the automatic mode, the user can affine correction by simply clicking mouse one time. In manual mode, the user needs to manually drag the four points to the four angles of a similar model, this is designed to avoid some pictures that are not marked with four points or four points are lost during the experiment circle. The third module is the target detection module, this module supports two functions of automatic detection points and manual mark points. The fourth module is the data segmentation module, this module supports to process binarization of the pictures and serialize the mark points, and add the points to the database. 


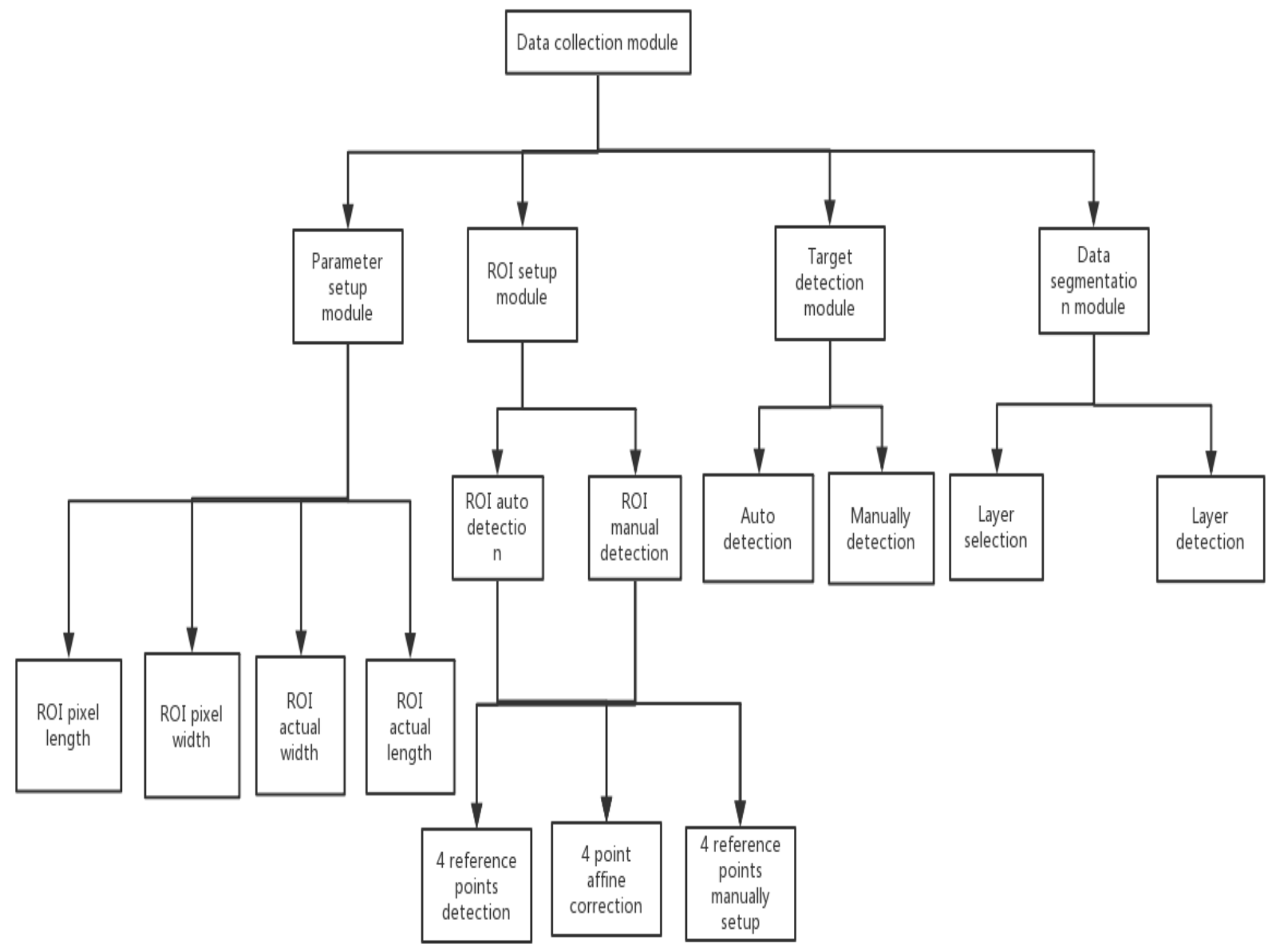

Figure 3-4 Data collection module design

In the data analysis module, the data process module is responsible for the calculation of deformation data (Figure 3-5). Data save module can save the data in spreadsheet for follow-up analysis. Curving plotting module respectively draws the horizontal displacement, vertical displacement, slope and strain in the program's interface. 


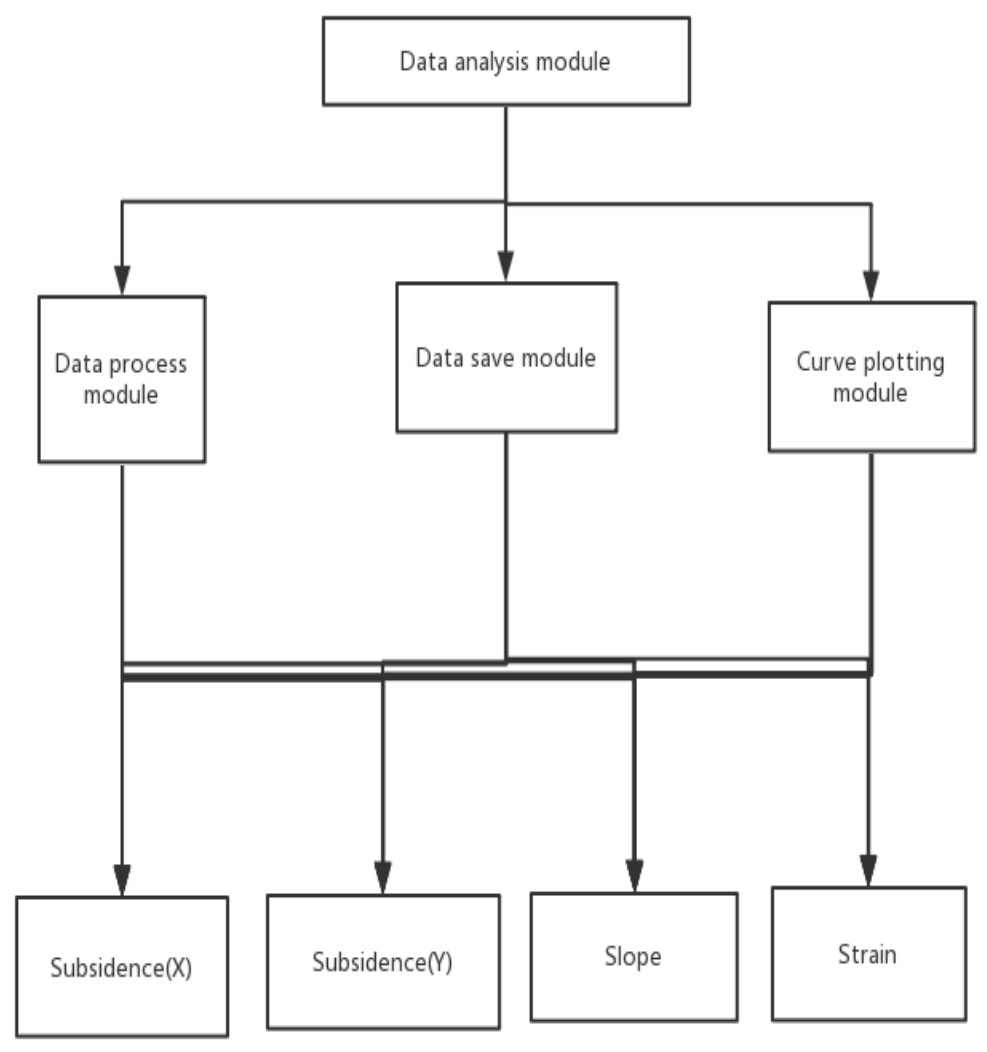

Figure 3-5 Data analysis module detail and design

Based on the above sub-system structure, the program substructure is created, class hierarchy and relation among them is defined, and the whole application framework is shown in Figure 3-6. 


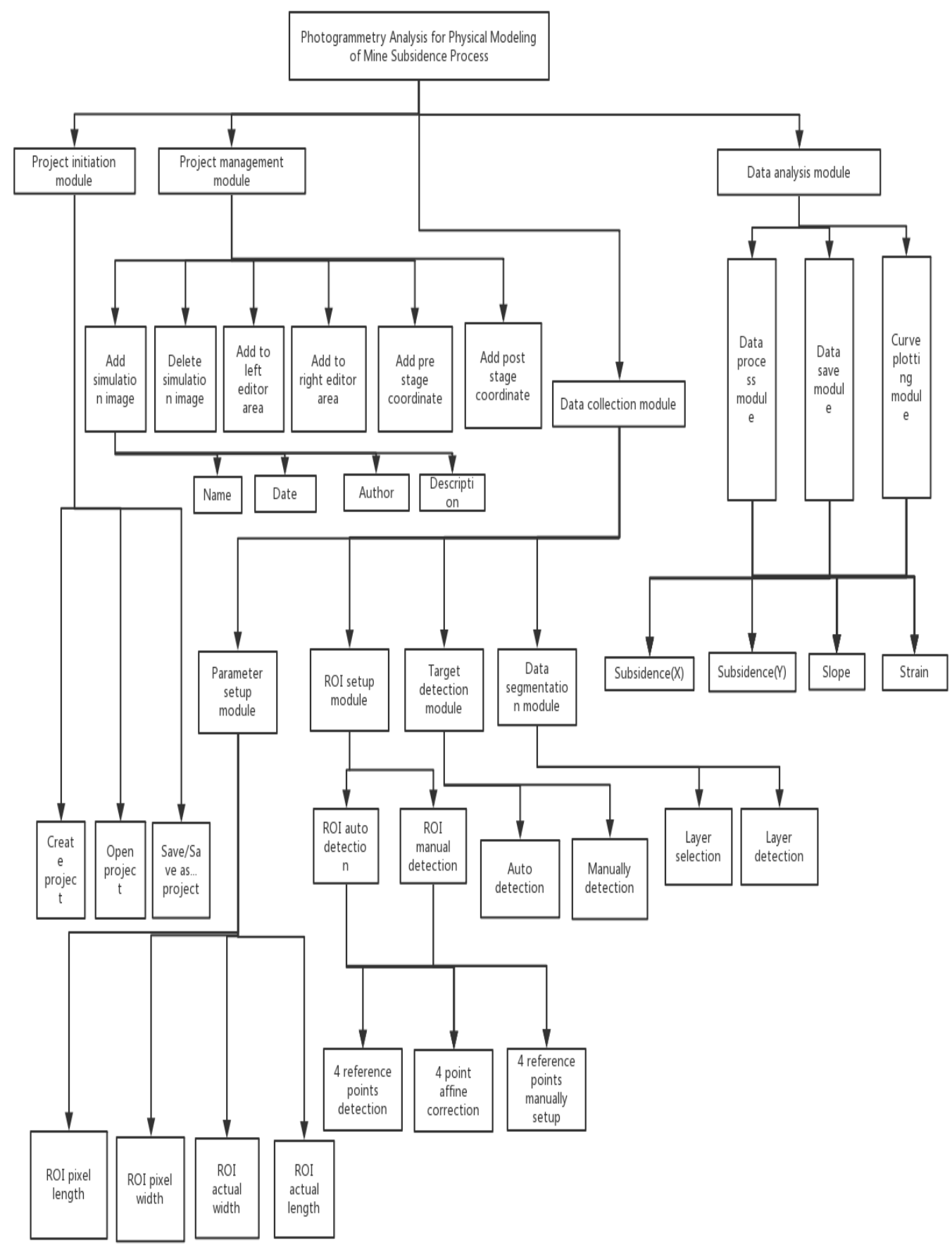

Figure 3-6 Program system design 


\subsection{Computer vision techniques implemented in program}

\section{Binarization of colored image in OpenCV}

In image processing, binarization of a digital image plays a vital role. Image binarization greatly reduces the amount of data in the image so as to highlight the outline of the target. Binarization divides the image into several sections with the part of interest becomes foreground and remain becomes background. Usually a certain intensity is used as the standard for division and this division intensity is called the threshold. The part whose intensity exceeds the threshold is regarded as the foreground, otherwise it is regarded as the background. To be more specific, if pixel value is greater than a threshold value, it is assigned one value (may be white), else it is assigned another value (may be black). The function used is as follows:

threshold(InputArray src, OutputArray dst, double thresh, double maxval, int type).

First argument is the source image which we taken during the experiment. Second argument is the output image, third argument is the threshold value which is used to classify the pixel values. Forth argument is the maxVal which represents the value to be given if pixel value is more than (sometimes less than) the threshold value. OpenCV provides different styles of thresholding and it is decided by the fifth parameter of the function. There are totally 8 different type of thresholding method in this program, Otsu thresholding method is been used, detail about Otsu is been discussed below.

In computer vision and image processing, Otsu's method, named after Nobuyuki Otsu, is used to automatically perform clustering-based image thresholding or, the reduction of a gray level image to a binary image. In general thresholding method, user used a designated value for threshold value, but the problem is it is hard to determine whether the value been selected is good 
or not, especially when it comes to bimodal image (Bimodal image is an image whose histogram has two peaks), for this kind of situation, the Otsu binarization can automatically calculates the optimal threshold value in the middle of those peaks and return the output image. To achieve this, passing 8, which refers to Otsu method, to the fifth parameter of threshold() function. For threshold value, simply pass zero. Then the Otsu algorithm finds the optimal threshold value and returns the image.

Subsequently, the traditional threshold and the Oust methods are compared in Figure 3-7. If the threshold ranges in a higher level, partial details of object will be loss. On the opposite, it is not easily to differentiate the background and wanted information if fixing the threshold in a lower value.
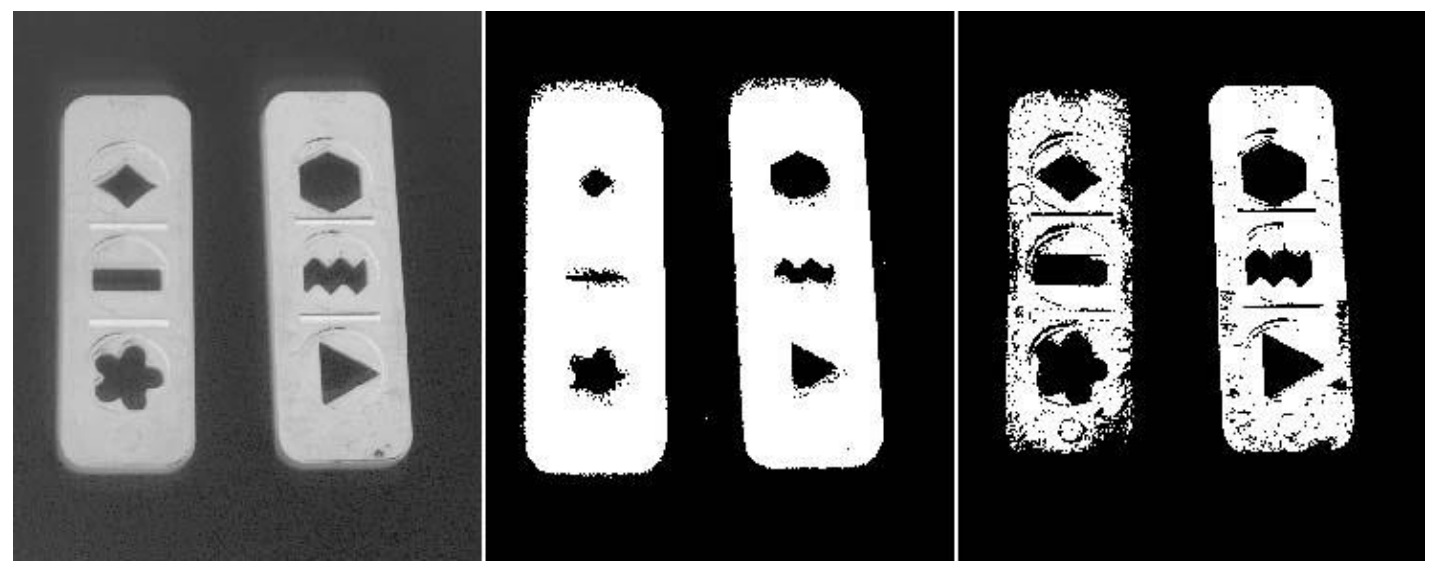

Figure 3-7 The original image on the left. Threshold level 85 selected manually at the center and threshold level 191 on the right.

A desirable result can be gained if the Otsu method been applied in these mentioned segmented objects.(Figure 3-8) 


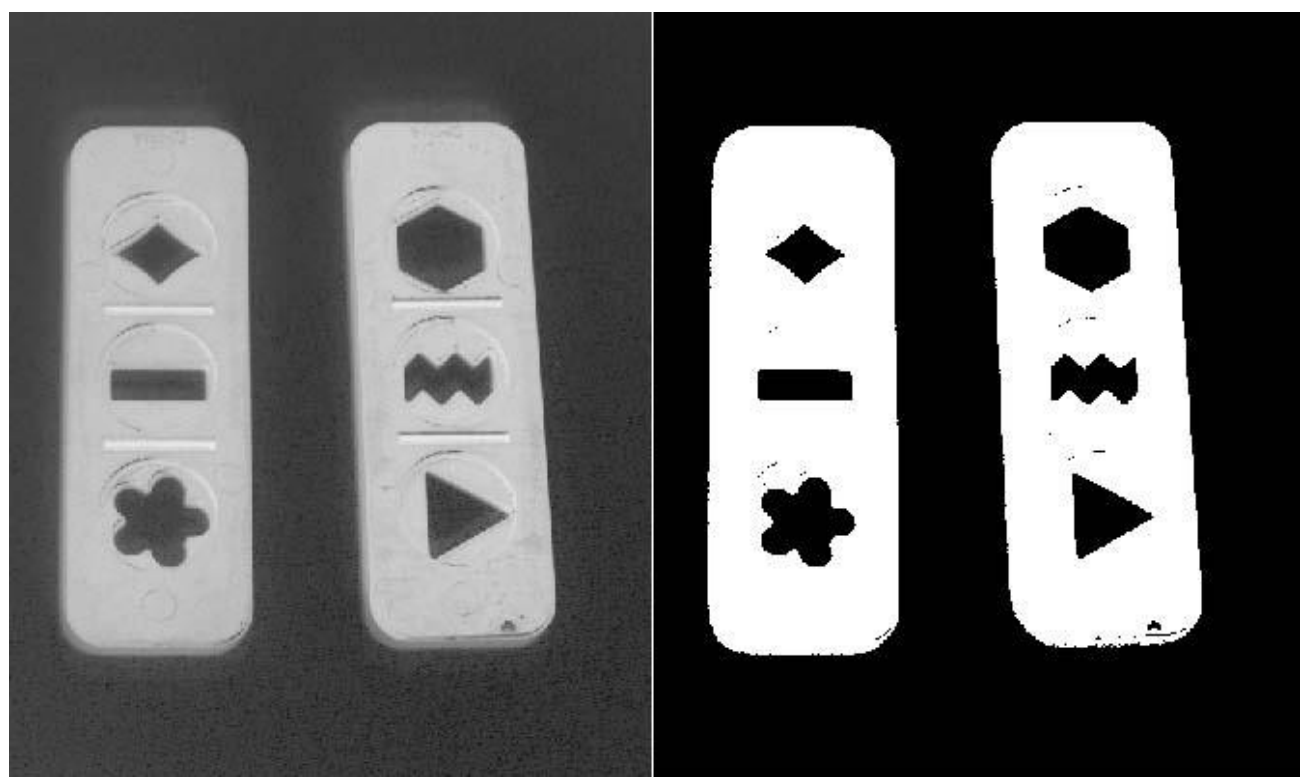

Figure 3-8 The threshold level given by Otsu's algorithm, the original image on the left and the binary image on the right.

\section{Contours detection}

After binarization, the points in the image has been extracted, the marked points' contour needs to be detected. The contours can be explained simply as a curve joining all the continuous points along the boundary. These points have same color and intensity. In this program, we use red color points as survey points. The contours are useful for shape analysis and object detection.

In OpenCV, the findContours() function retrieves contours from the binary image, after contours been extracted, the results are stored as a vector of points. In this program, since the marked points is circular, the contours are also circular, by obtain the center point of the circular, we can obtain the target point's coordinate.

Perspective transformation to eliminate errors caused by the position of the camera

In image processing of physical modeling, the position of the camera when the image is taken is also considered. Since the experimental cycle of the physical modeling takes time, it is impossible for the camera to stay at the exact same position all the time. The photos taken change 
with the position of the camera and its focal length. So in image processing, a inconsistencies occur in the photos. Reprocessing of the image can lead to great errors, so affine transformation is introduced to deal with the errors in image processing.

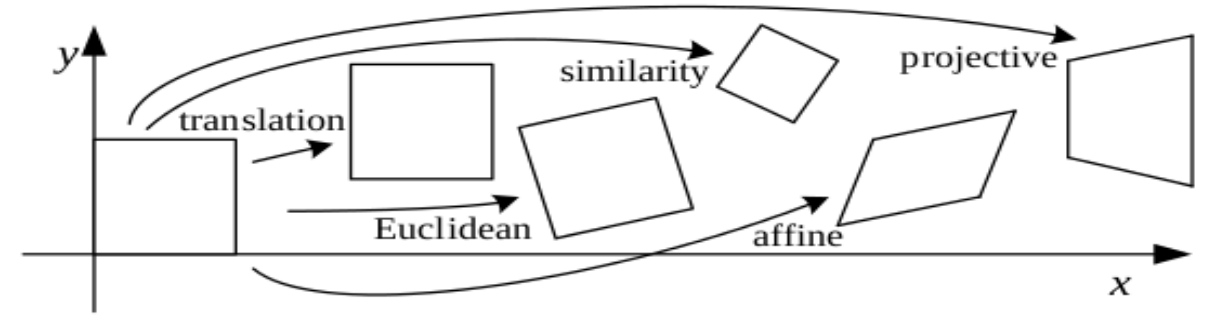

Figure 3-9 Different type of image transformation

Affine transform and perspective transform are of significance in image restoration and handling the local change of the image (Figure 3-9). Usually, affine transform is widely used in 2D plane, while perspective transform is widely used in $3 \mathrm{D}$ plane. The principles of the two transforms are similar, producing similar results and appropriate changes can be adopted according to different occasions.

The principles of perspective transform and affine transform are similar. Here affine transform is introduced. The so-called affine transform includes rotation, movement, magnification and reduction. Besides remap(), OpenCV provides warpAffine() function which is more widely used to deal with affine transform. Besides perspective transform, operations such as magnification, reduction, rotation, horizontal flip, distortion and perspective transform can produce new images by using the warpAffine() function. If warpAffine() is used to obtain the image after an affine transform, an affine matrix must be input and OpenCV offers getAffineTransform() and get RotationMatrix2D() functions. GetAffineTransform() obtains the target matrix by changing three points in front and at the back, getRotationMatrix $2 \mathrm{D}()$ obtains the 
target matrix by rotating the center, rotating the angle and magnification. The affine matrix is a $2 \times 3$ matrix, and every input point $(\mathrm{x}, \mathrm{y})$ corresponding to an output point(Figure $3-10)$.

$$
T=\left[\begin{array}{l}
a_{00} x+a_{01} y+b_{00} \\
a_{10} x+a_{11} y+b_{10}
\end{array}\right] \quad X=\left[\begin{array}{l}
x \\
y
\end{array}\right]
$$

\section{Figure 3-10 Image matrix transformation}

Based on the equation, there are six unknown numbers, so at least three points must be disclosed. In total there are six parameters in $\mathrm{x}, \mathrm{y}$ coordinate. At this time, the values before and after the transform are put into the simultaneous equations to solve them and a00 、 a10、a01 、

a11 b b0 - b10 are obtained. The figure 3-11 can be used as a reference. This affine matrix can be obtained by transforming three points.

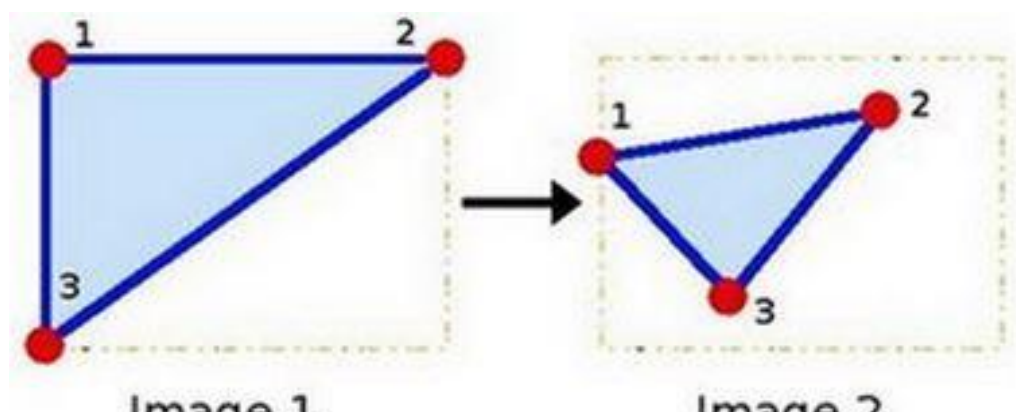

Image 1

Image 2

Figure 3-11 Affine transformation example

Perspective transform utilizes similar method to affine transform. It gets the perspective matrix and uses it to carry out perspective transform. The difference is that 4 points need to be used as inputs so as there are enough parameters to determine the matrix. The getPerspectiveTransform() function is used to obtain the perspective matrix, and the warpPerspective() function is used to obtain the perspective transform. The perspective transformation deals with the conversion of 3D world into 2D image which means it can transfer an image from one state to another. Since perspective transform preserves distances and orthogonal 
lines in the image, the OpenCV's perspective function is used in this program to perform the transform, also because the program already use the red color as the color of the survey points, for 4-point perspective transform, the program use blue color to denote the 4 points in order to differentiate from red survey points.
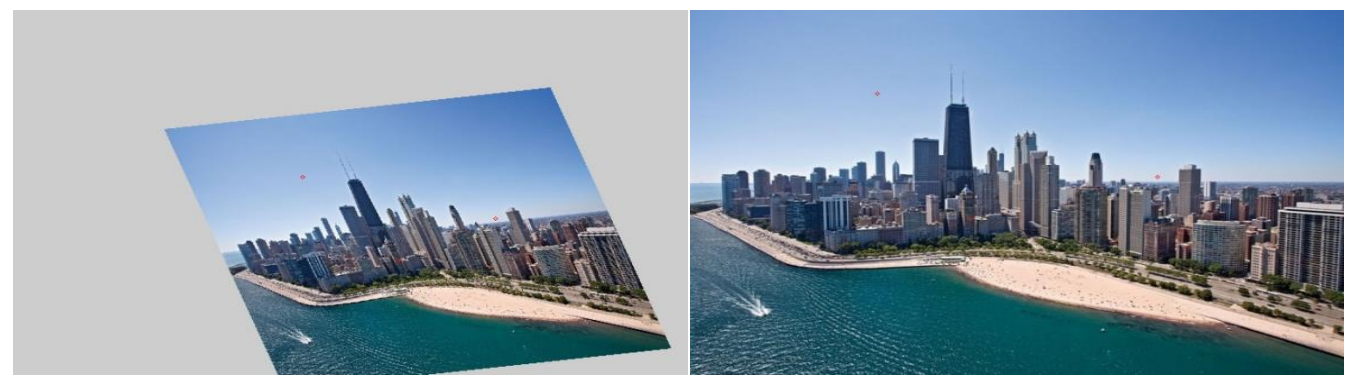

Figure 3-12 Image before and after affine transformation

In Figure 3-12, red points are used to show the chosen triangle points. It is obvious that though changes occur in the whole image, the pixel values of the corresponding points are identical.

\subsection{Program experiment and verification}

After completing the program development, the accuracy of the program is verified, a white board with the length of 30 inches and width of 20 inches is used as simulation model, and two rows of red round shaped mark points are made from left to right with a distance of 5 inches arrange on the board, as shown. (Figure 3-13) 


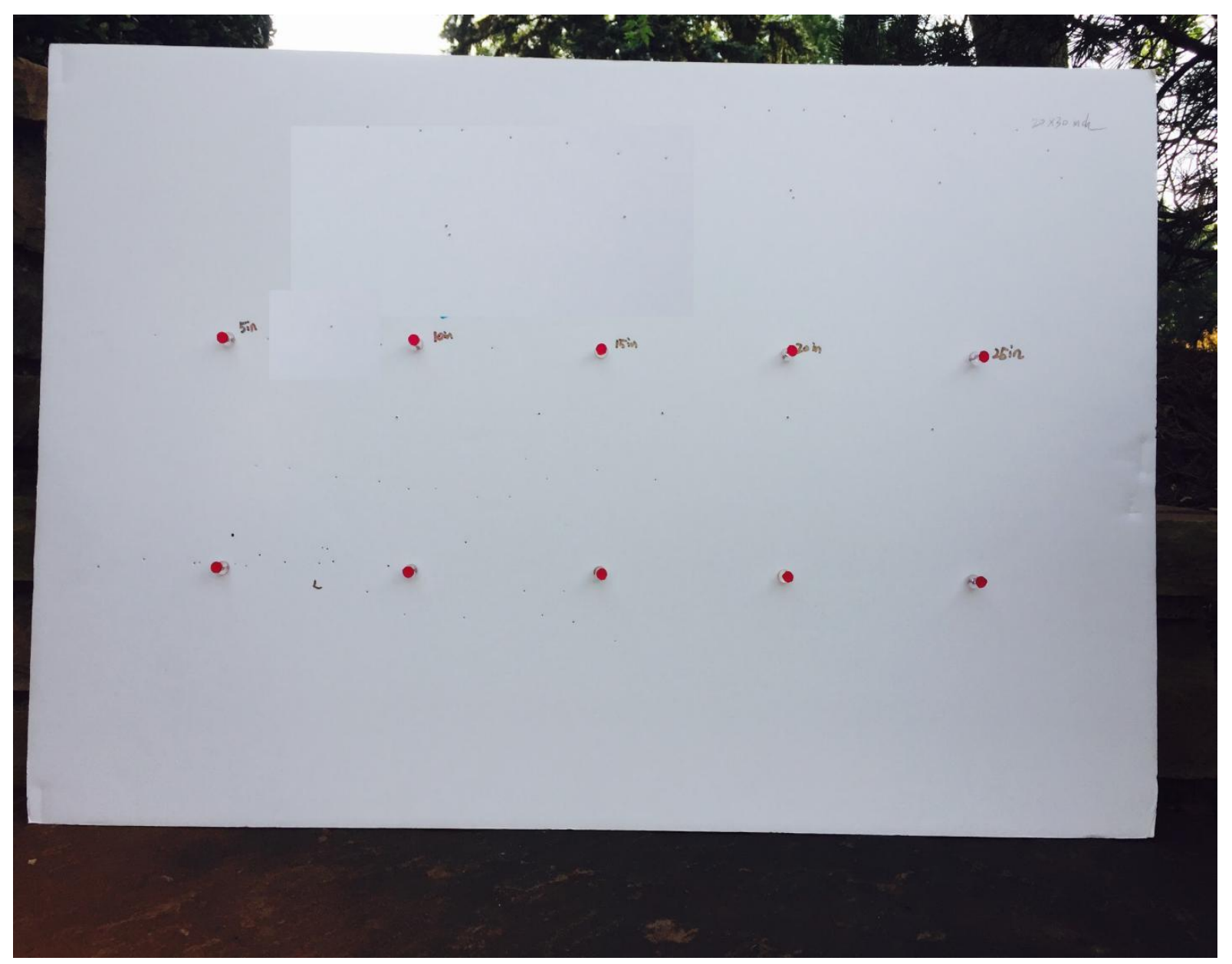

Figure 3-13 White board used in the experiment

In order to verify the accuracy of the points detection and the reliability of four-point affine, the digital cameras are used, respectively, to capture the pictures from the front and the right side of the board, and the capture pictures are showed in Figure 3-14. 


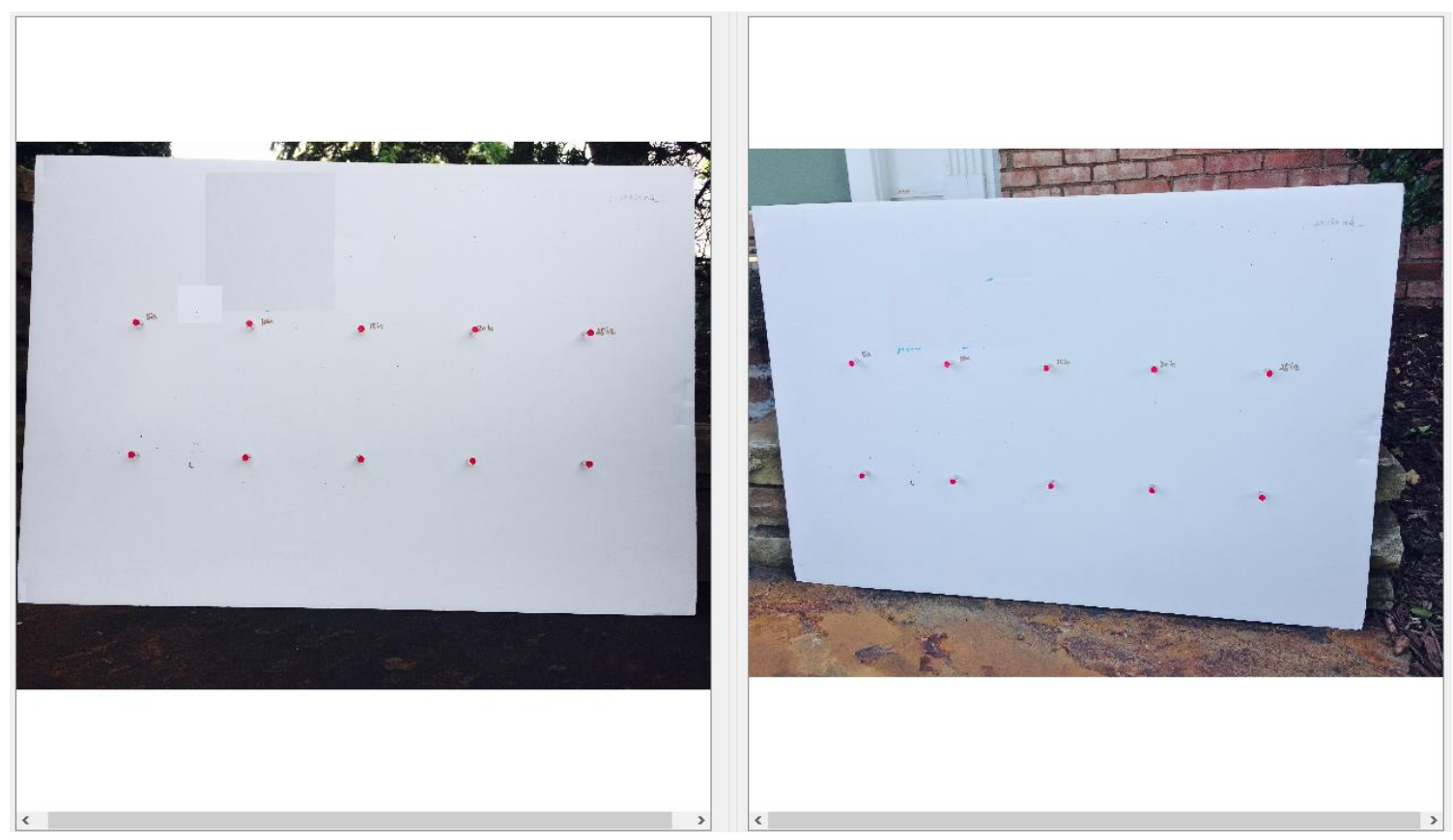

Figure 3-14 Front and side photos taken during the experiment

The manual operation mode of the program is used to complete four-point affine, the results are as follows. (See Figure 3-15)

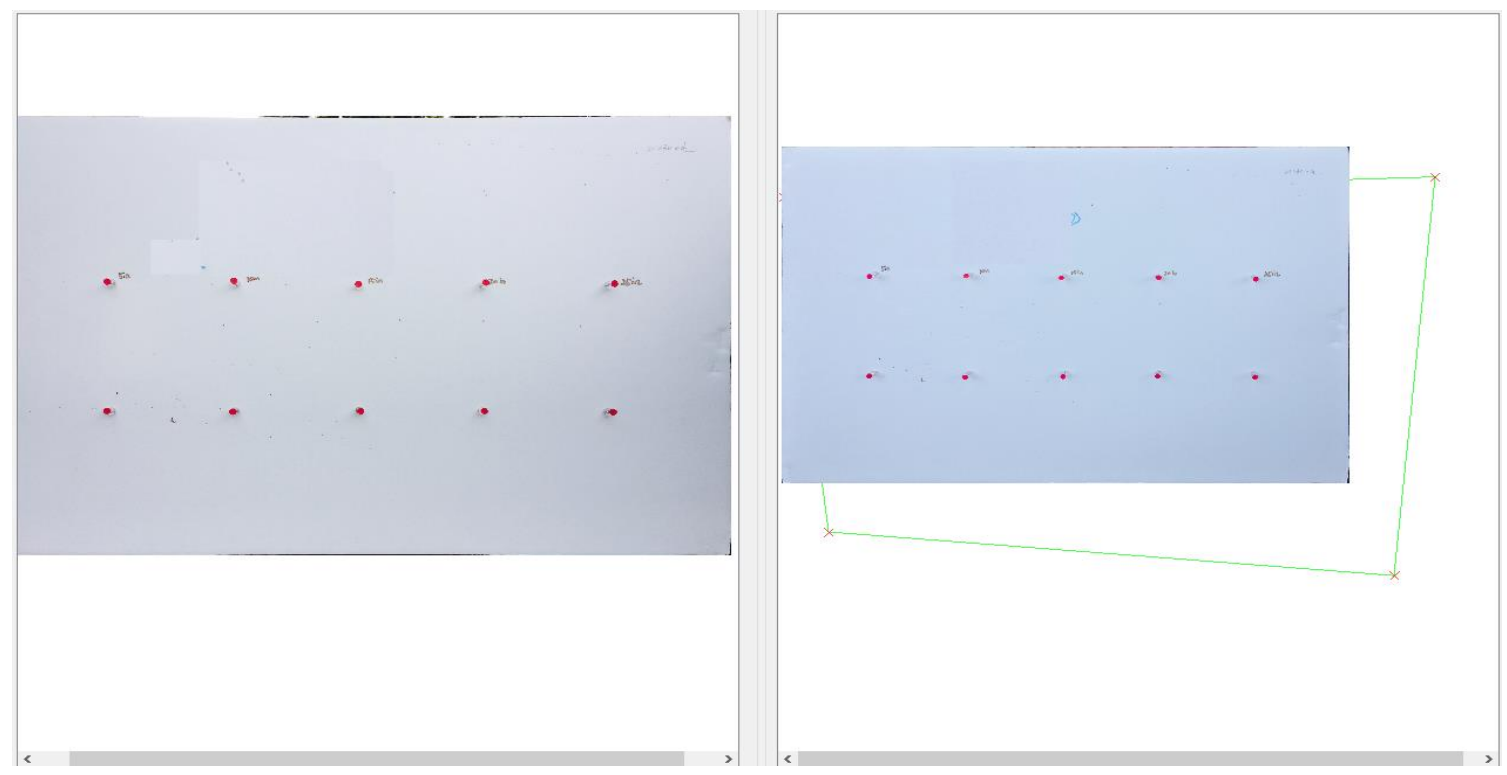

Figure 3-15 Photo after affine correction

It can be seen clearly that the pictures after four-point affine correction matches with the pictures taken in front. 
The results of the data analysis of the two pictures conducted by the program are shown as follows. (See Table 3-16)

\begin{tabular}{|c|c|c|c|c|c|c|}
\hline C $\quad 7$ & D & E & $\mathrm{F}$ & G & H & । \\
\hline$X($ Front) & X/4 point correction & i. In inch(Front) & In inch(4 points correction) & ) Actual inch & Relative accuracy & Relative accuracy (4 points correction) \\
\hline 0.4111 & 0.4123 & 4.9333 & 4.9480 & 5 & $98.67 \%$ & $98.96 \%$ \\
\hline 0.8350 & 0.8244 & 10.0203 & 9.8934 & 10 & $99.80 \%$ & $98.93 \%$ \\
\hline 1.2600 & 1.2500 & 15.1200 & 14.9994 & 15 & $99.21 \%$ & $100.00 \%$ \\
\hline 1.6806 & 1.6851 & 20.1672 & 20.2215 & 20 & $99.17 \%$ & $98.90 \%$ \\
\hline 2.1024 & 2.1106 & 25.2292 & 25.3274 & 25 & $99.09 \%$ & $98.71 \%$ \\
\hline 0.4116 & 0.4110 & 4.9397 & 4.9323 & 5 & $98.79 \%$ & $98.65 \%$ \\
\hline 0.8423 & 0.8298 & 10.1076 & 9.9576 & 10 & $98.94 \%$ & $99.58 \%$ \\
\hline 1.2609 & 1.2576 & 15.1309 & 15.0909 & 15 & $99.13 \%$ & $99.40 \%$ \\
\hline 1.6854 & 1.6815 & 20.2245 & 20.1780 & 20 & $98.89 \%$ & $99.12 \%$ \\
\hline \multirow[t]{2}{*}{2.1030} & 2.1175 & 25.2360 & 25.4100 & 25 & $99.06 \%$ & $98.39 \%$ \\
\hline & & & & Relative accuracy & $99.08 \%$ & $99.06 \%$ \\
\hline
\end{tabular}

\section{Table 3-16 Data accuracy analysis for the experiment}

It can be seen that the relative accuracy for the points detection is $99.08 \%$, and the point detection after four-point correction is $99.06 \%$. 


\section{Chapter 4. Program instruction and user interface}

The program design and implementation have been discussed deeply in previous chapter. Subsequently, the function, requirement, including installation of the program well be discussed in this chapter through an actual case.

\subsection{Program Overview}

In general, this program contains three parts, namely project initiation, data collection and data analysis, respectively.

The function of project initiation is to create, load, add, save, and exit the project file.

In the data collection factor, the region-of-interest can be automatic or manual set. Meanwhile, it exhibits the function of automatic detection the marked points and manual annotation. Manual annotation refers to add/delete the marked points, convert the color of picture into white and black, and synchronize data to database.

The data analysis is able to add analyzed pictures coordinates into the pre- or post-editor area for the subsequent calculation and generation of the subsurface subsidence database in the forms of $\mathrm{m}, \mathrm{ft}$ or pix. Final, the data in different layers can be drawn or exported into excel for the analysis.

\section{Program features}

- Data in a physical modeling experiment can be analyzed by stages, saved as project or loaded as existing project. New pictures can be added for analysis, thus avoiding repeated work. 
- To decrease the errors, a correction process should be carried out by the means of the library of OpenCV perspective affine transformation. In this case, a relative position of the obtained picture can be kept in all the stages of experiment process.

- The survey speed is greatly improved with the following steps: binarizing pictures, reading the point layers via contour detection and adding the marked points in database.

- Automatic background completion of the subsequent data processing simplifies the complex data processing.

Hardware requirements:

- Computer OS: Windows XP or above;

- Minimum system requirements;

- $\quad$ CPU: $1.8 \mathrm{GHZ}$;

- Memory 512M;

Program requirements:

- Visual Studio 2013 or above.

\section{Program Installation:}

The program related files are compressed into one zipped file.

- User will need a program called WinRAR to unzip and restore the files. User can download this free application and install it after downloading. 
- Double click on file PAPMMSP.rar, it will restore all the program files to a temporary sub-directory PAPMMSP at the place where the download files are stored.

- Open this sub-directory, because we already include all the dependent file into zip file, just find the exe file name PAPMMSP.exe, double click to start the program.

\subsection{Instruction of the program}

\section{Project initiation stage}

(1). Open PAPMMSP folder, Double-click the PAPMMSP icon to enter the main program interface. Figure 4-1 shows initial opening of the program.

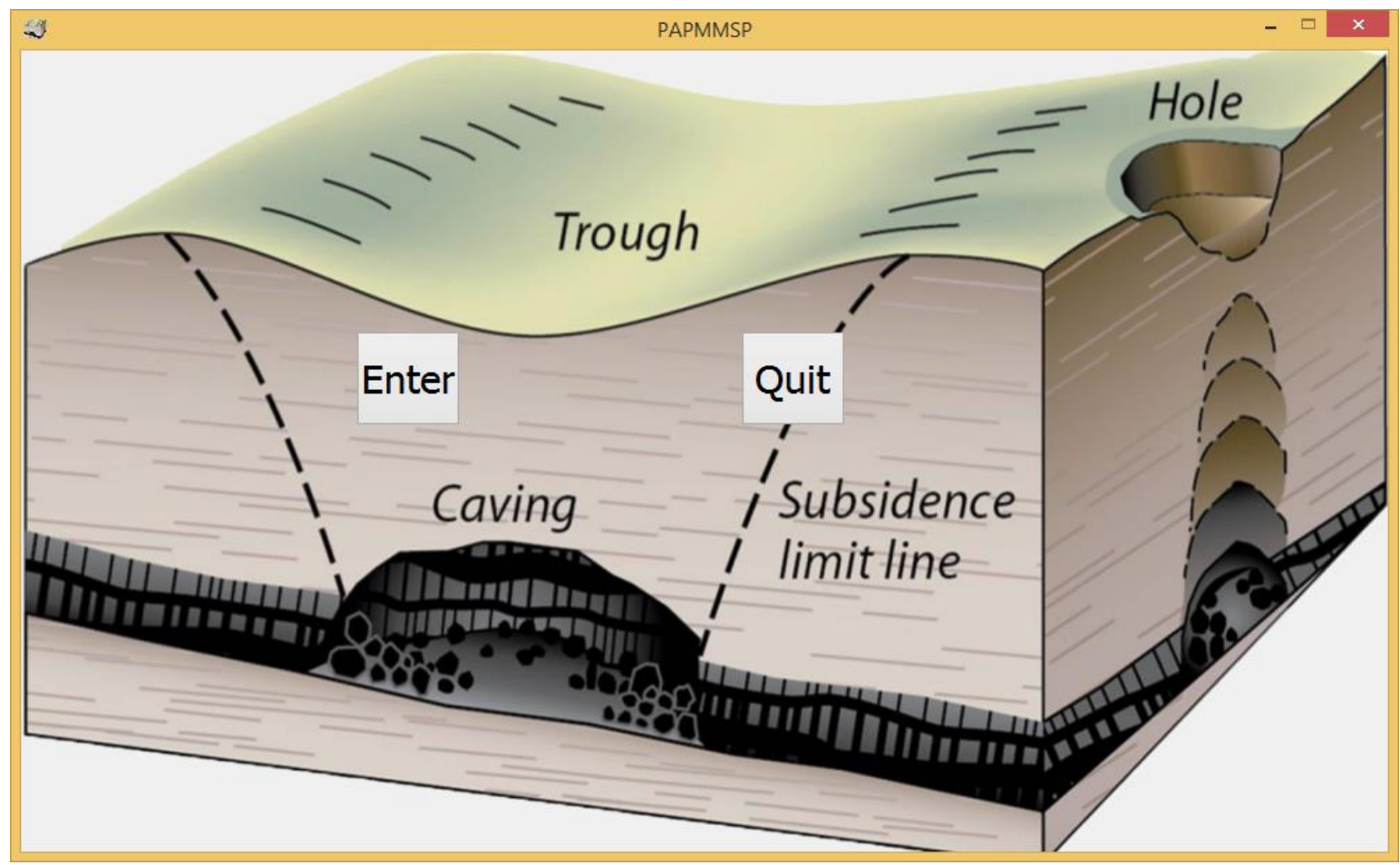

Figure 4-1 Initial opening screen of the program 
(2). Click "Enter" to enter the program main interface. (See-Figure 4-2).

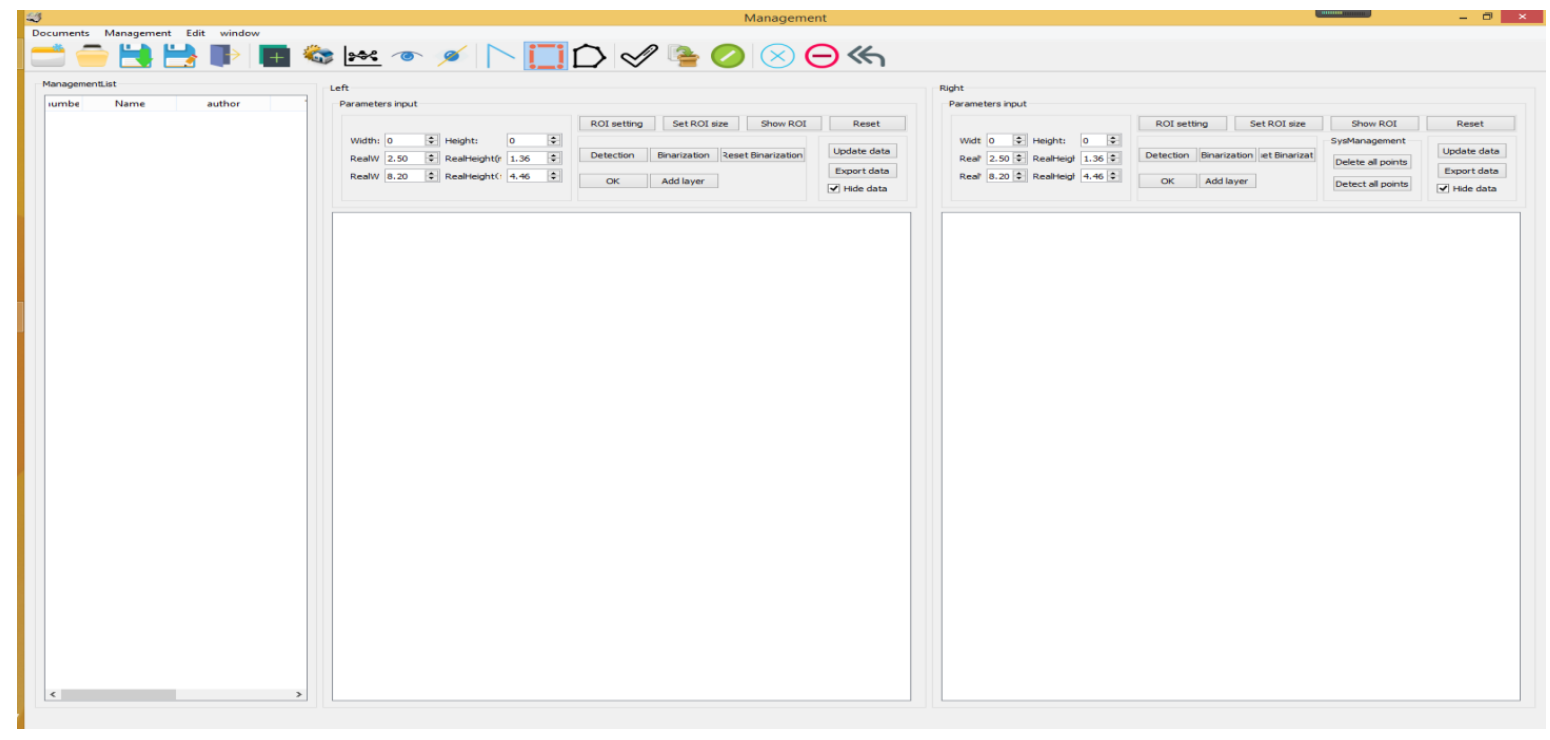

Figure 4-2 Program's main interface

(3). Create a new project folder in the working folder, click "New Project" in the "File" menu to create a new project (or press the shortcut key $\mathrm{Ctrl}+\mathrm{N}$ ) and enter the project name. For example: create a folder "coal mine", enter the project name. The system automatically initializes and creates the corresponding project base files and folders. Figure 4-3 shows the project initiation. 


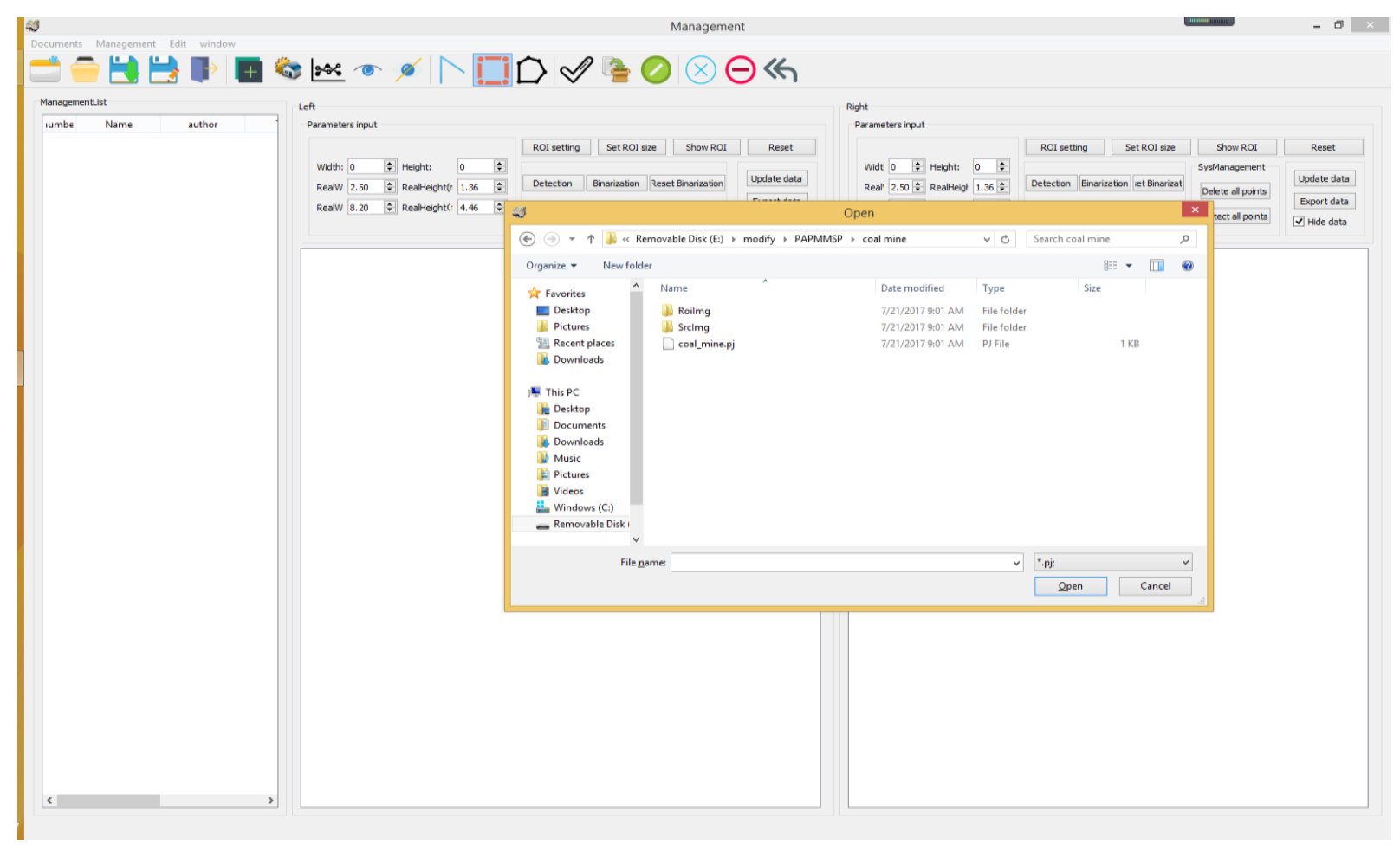

Figure 4-3 Project initiation

\section{Data collection stage}

(1). Load the image taken from the physical model. Click the "Create Project" in "Project Management" or click the " ++ icon to load the simulation experiment picture, and import the picture location in the pop-up dialog box that appears. Enter picture name, project time, author, and picture descriptions, and click "Add" to add to the picture list. On the left side of project list, right click one of the added pictures, in a chronologic order, to place it to the "pre-editor area" or "post-editor area". Figures 4-4 and 4-5 show pop-ups of the forms for loading image to the project. 


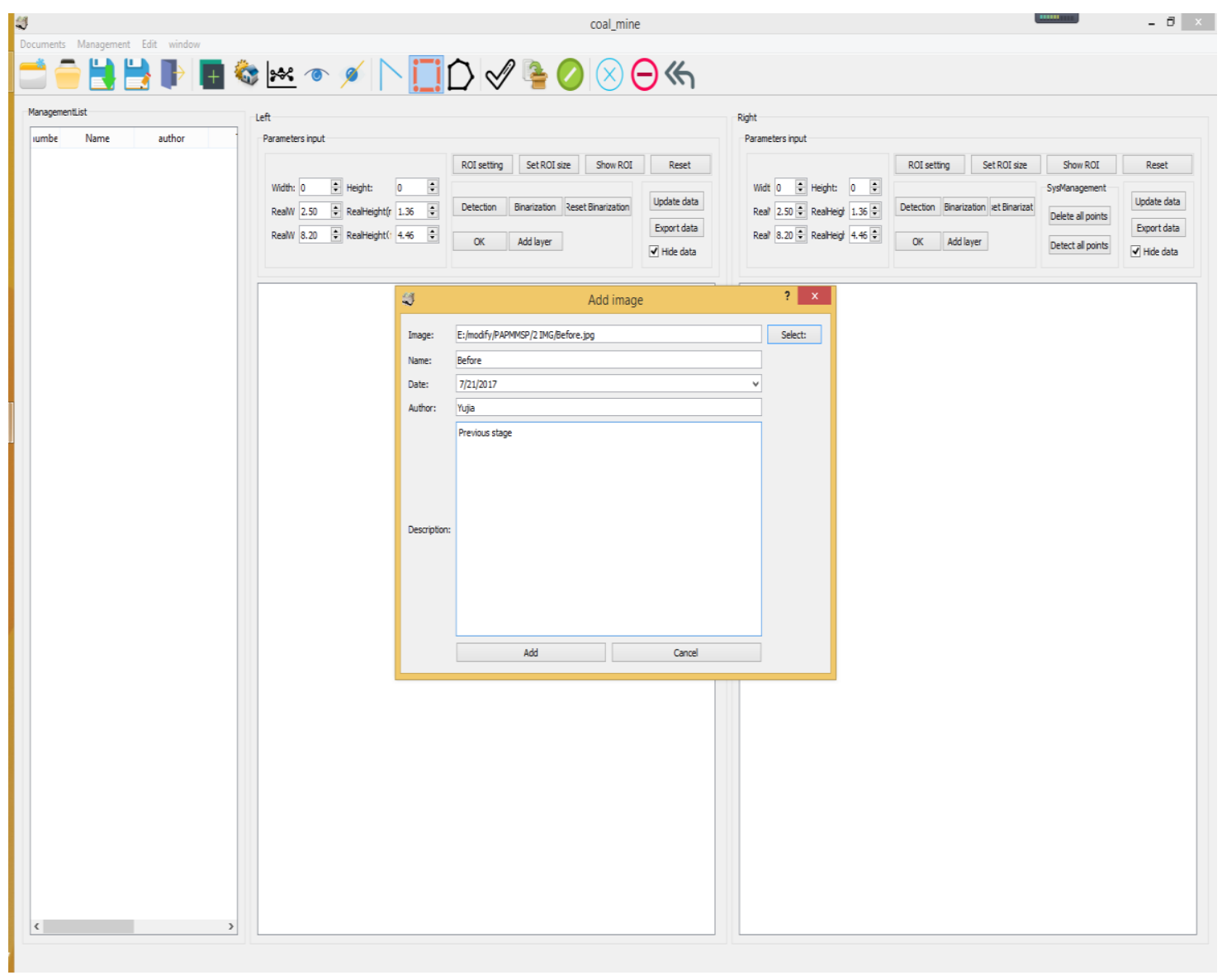

Figure 4-4 Load image to the project

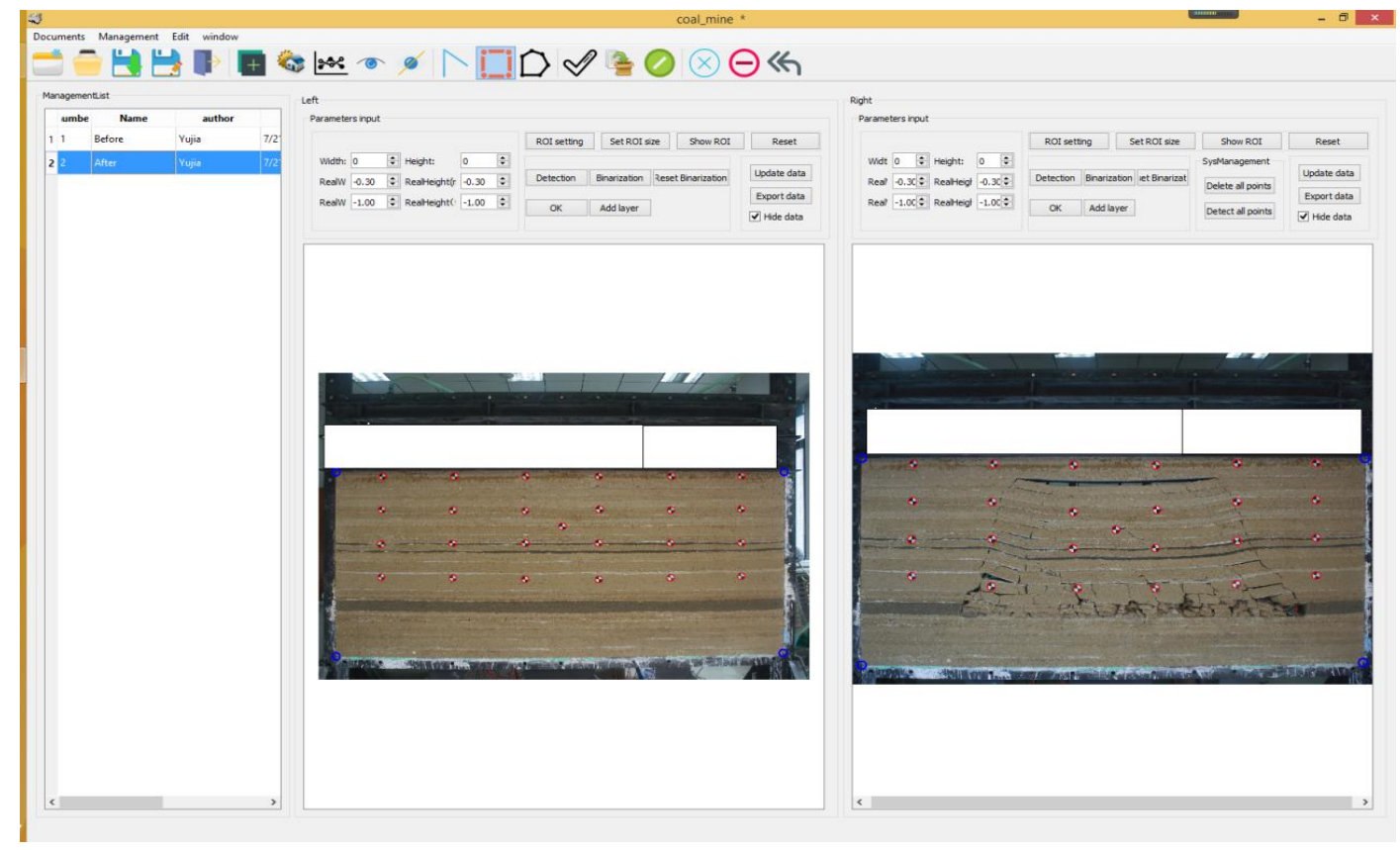

Figure 4-5 Image successfully loaded to the project 
(2). Since the program uses the four-point transformation to correct the position of picture, four reference points are needed to be set up in advance using RGB colors. Click on the "ROI Setting". The system automatically captures and intercepts ROI. If the picture is not marked in advance, the program also provides a manual annotation function: right click "Affine Correction" on a picture to manually conduct the four-point transmission, zoom-in the picture (click "Ctrl" and roll the mouse wheel at the same time) move the four points to the corresponding positions(Figure 4-6), click "ROI Setting" to complete the setting. Figure 4.6 shows the manual setting of four affine correction points. Repeat this operation to set the left and right pictures separately, if mistake occurs, the operation can be restarted by clicking the button of "Reset". Figure 4-7 shows the image after ROI setting.

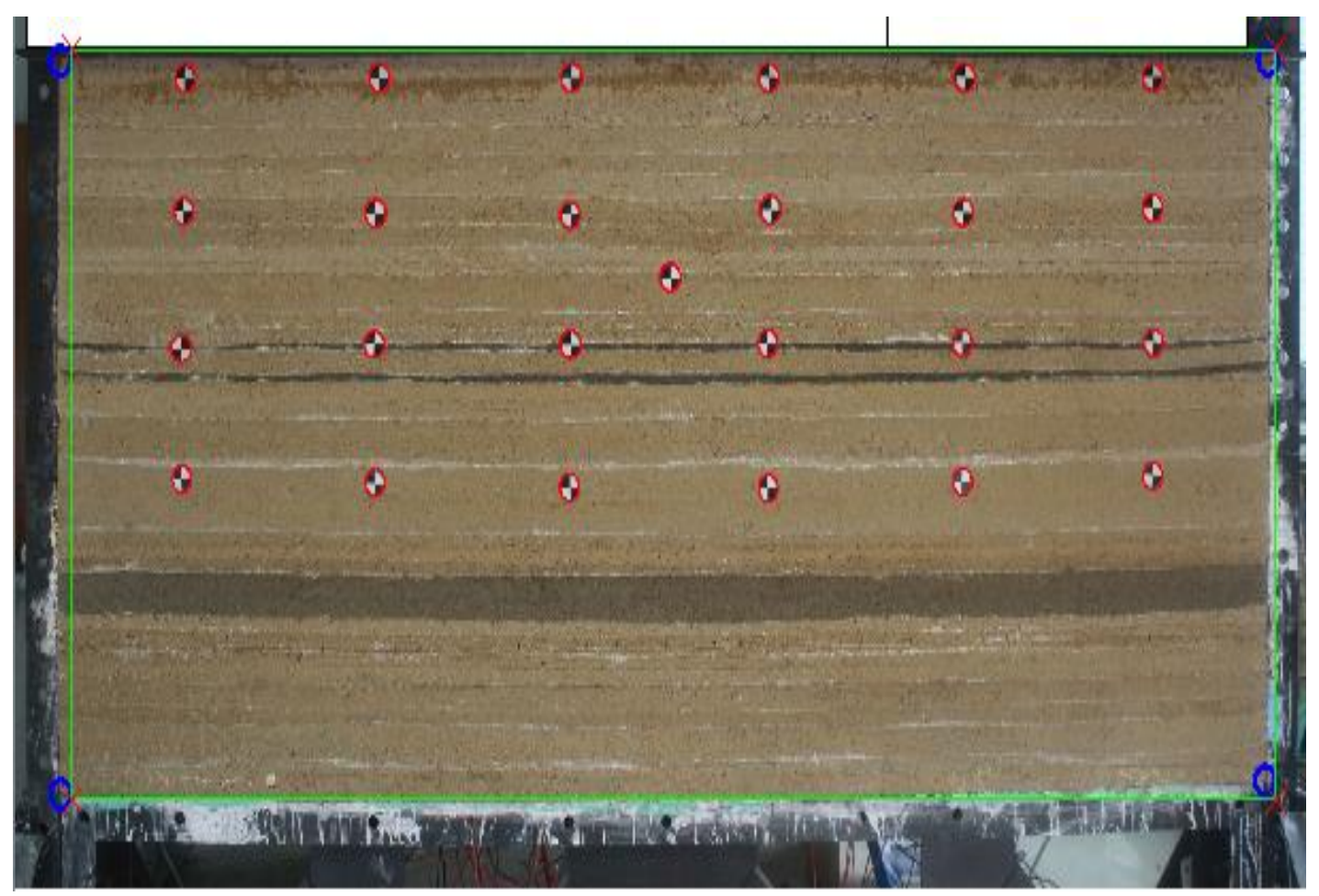

Figure 4-6 Manually set 4 affine correction points 


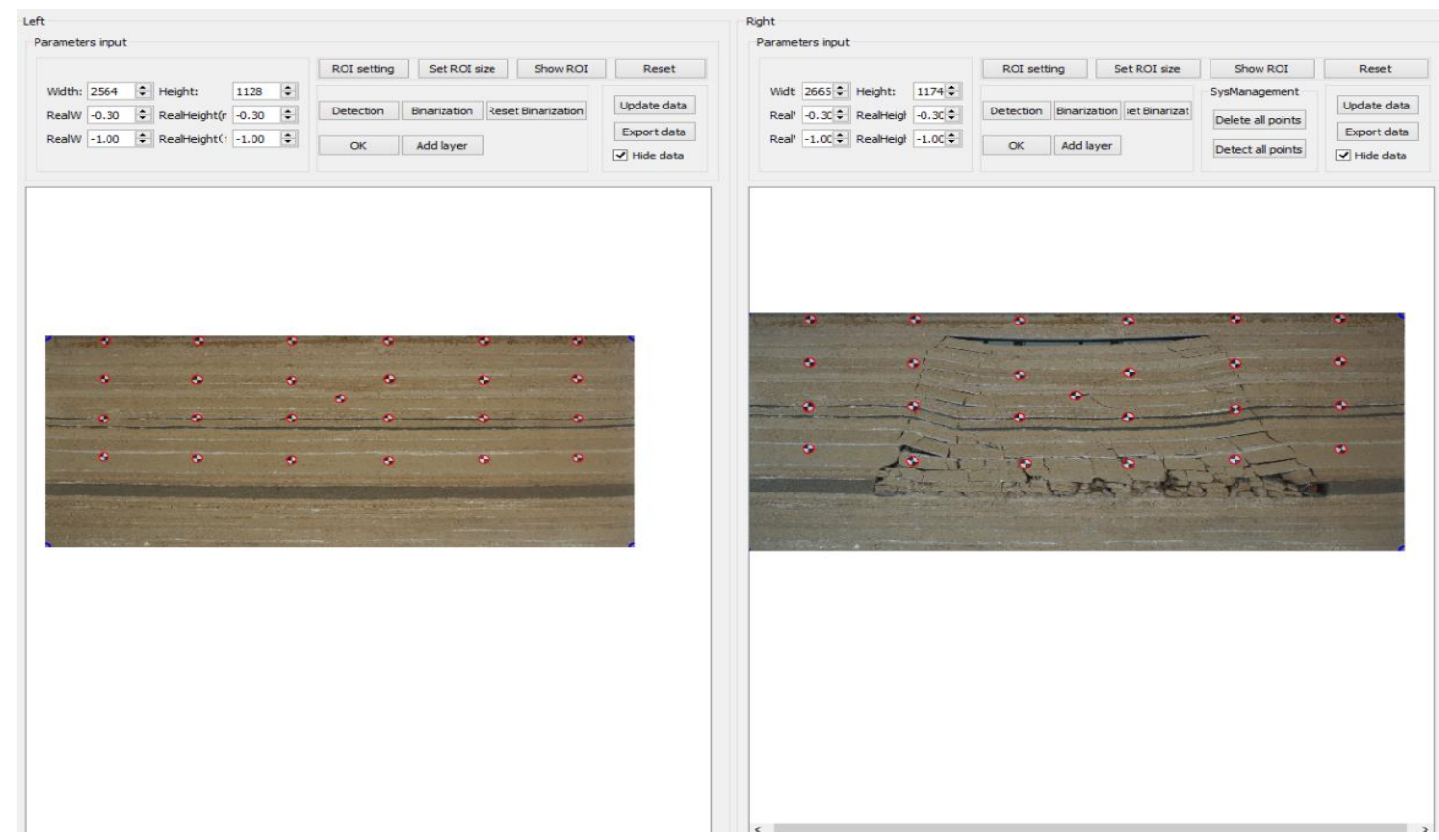

\section{Figure 4-7 Image after ROI setting}

(3). Enter the model length and width parameters (in $\mathrm{m}$ or $\mathrm{ft}$ units) to the left and right editor areas, click on "Detection" to further mark the points of the picture. Figure 4-8 shows the annotation in the detected image.
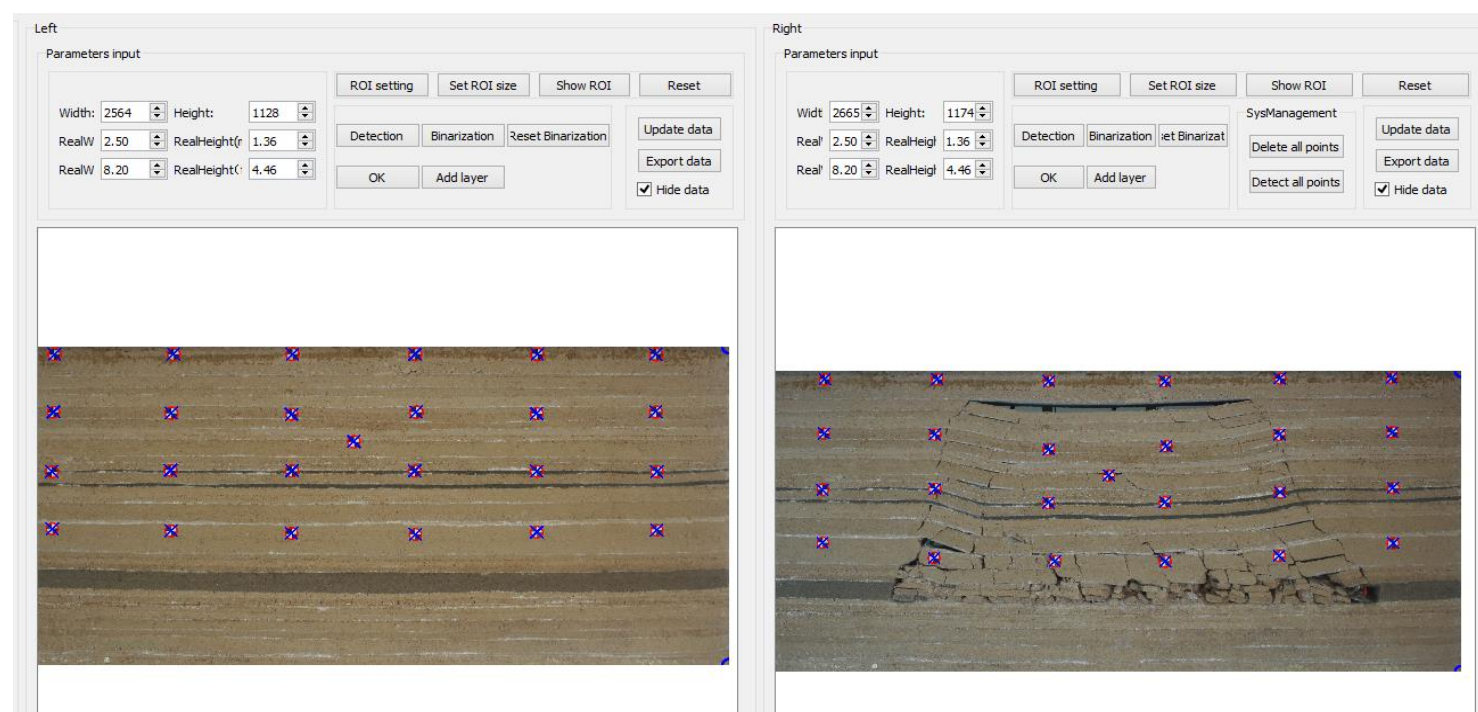

Figure 4-8 The marked points in the image detected 
(4). After marking point, the program has taken into account a situation that program analysis may encounter: insufficient number of marking points. To avoid such problems, user can manually mark the points. Click on the picture in the left editor area, right-click the "Point" and drag to the location to mark, as shown in Figure 4-9 below.

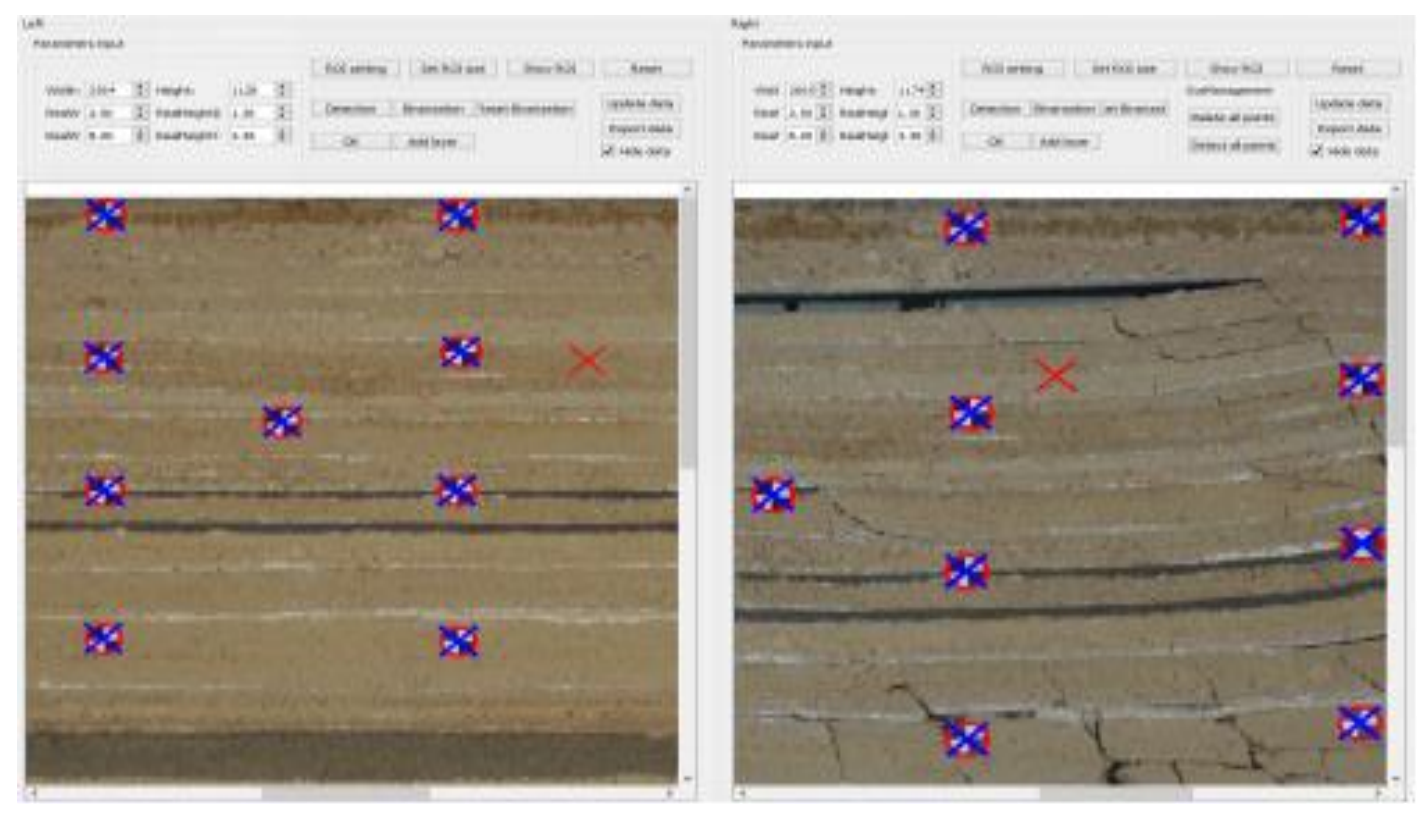

Figure 4-9 Manually set up the marking points

When the marked point in the left editor area is dragged to the target position, user can see a corresponding mark point in the right editor shows up and moves accordingly. After manually confirming the left image mark point position, click the "OK " button in left editor area, user can also notice that the mark point in the right editor area turns green, then move the right corresponding point manually to fine adjustment the right point the target position. Repeat this step to mark all the points that need to be manually marked. Figure 4-10 shows all the needed points. 

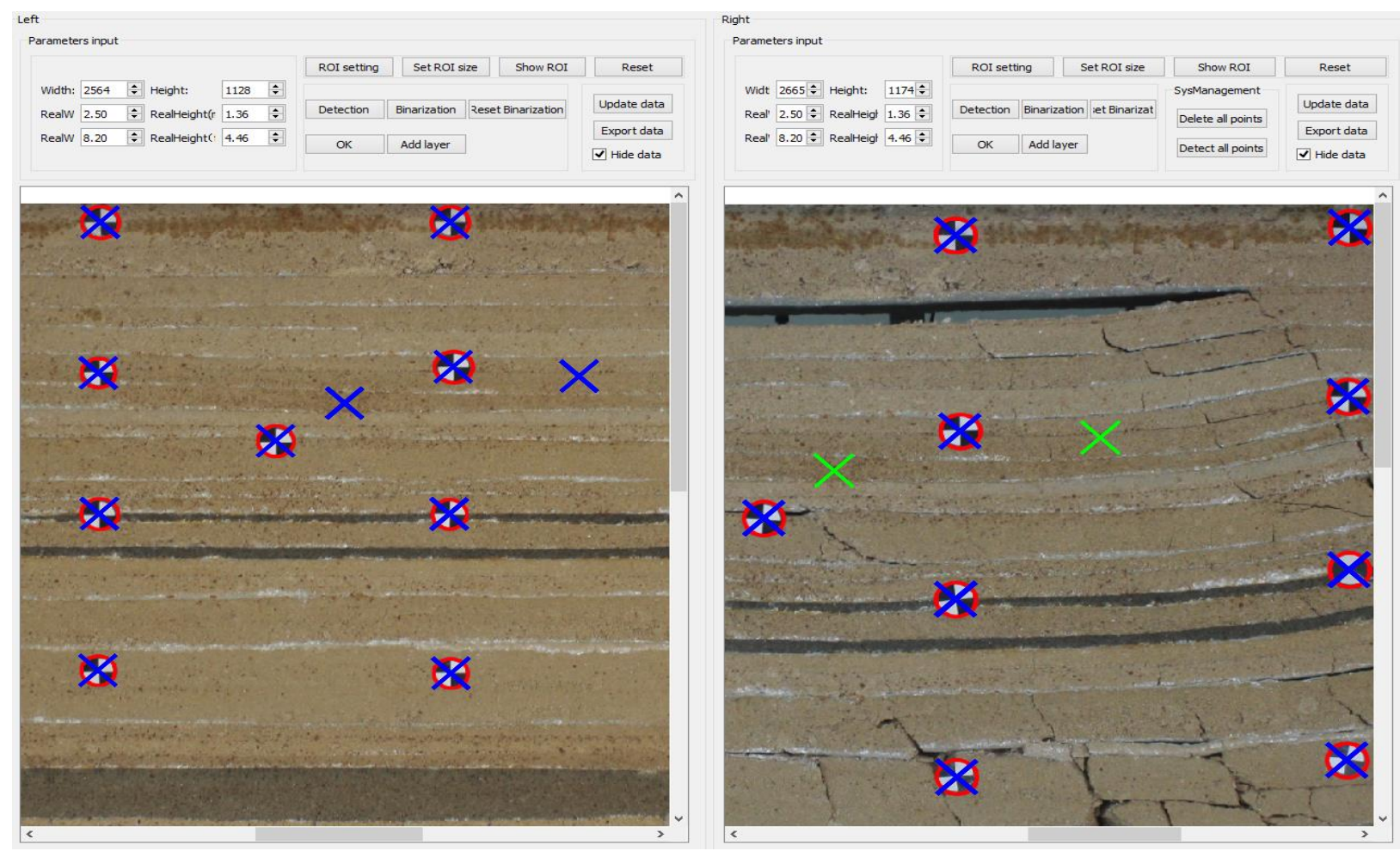

Figure 4-10 Automatically and manually set up all the needed points

(5). After the automatic and manual marking step, click the "Binarization" to binarize the picture, as shown in Figure 4.11.
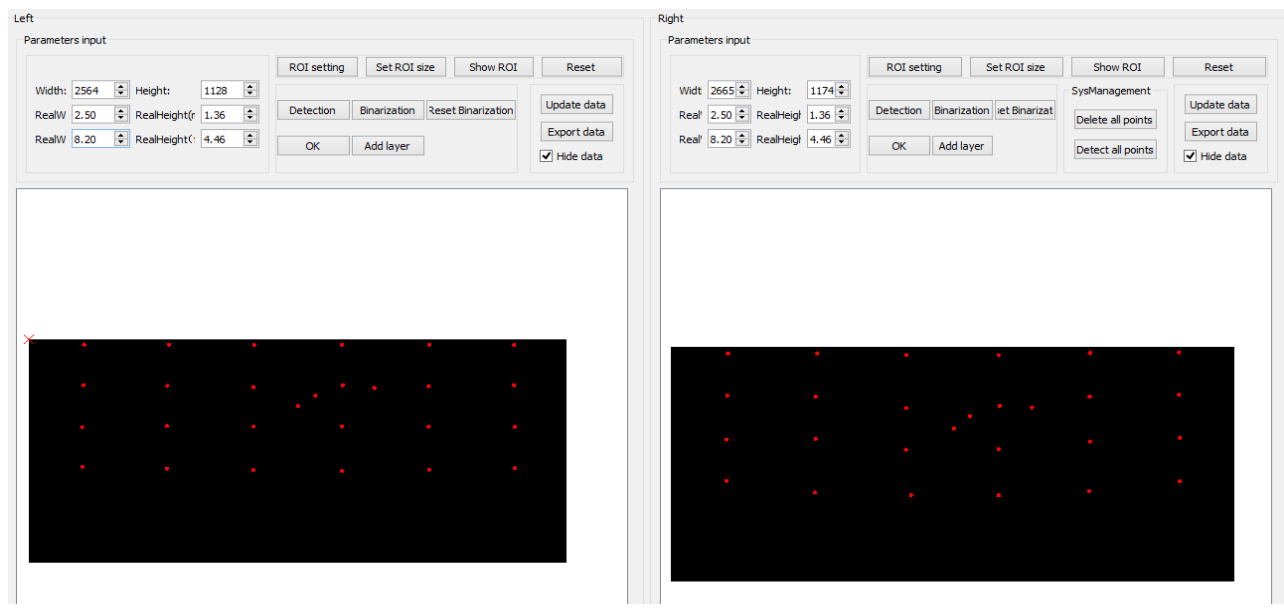

Figure 4-11 Image Binarization 
(6). Right click on the "Rect", then drag the mouse to select the first layer which showed in the green selected area of both left and right picture (figure 4-12).

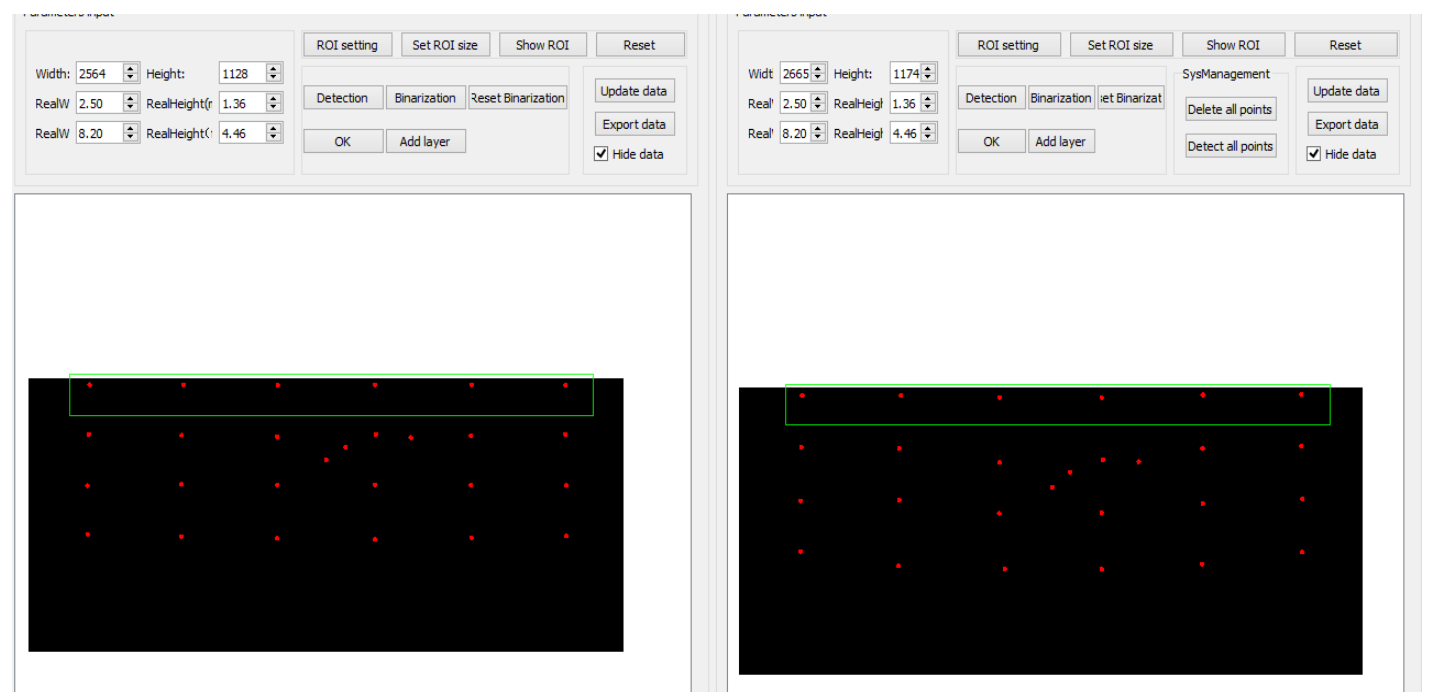

Figure 4-12 Select layer after Binarization

In the left and right edit area, right click on "confirm" to select the points. Note that the color of the box changes from green to blue, indicating that the layer has been selected. Click "Add layer" in the left and right editor areas respectively, the current pixel values will be added to the database, as shown in figure 4-13. 


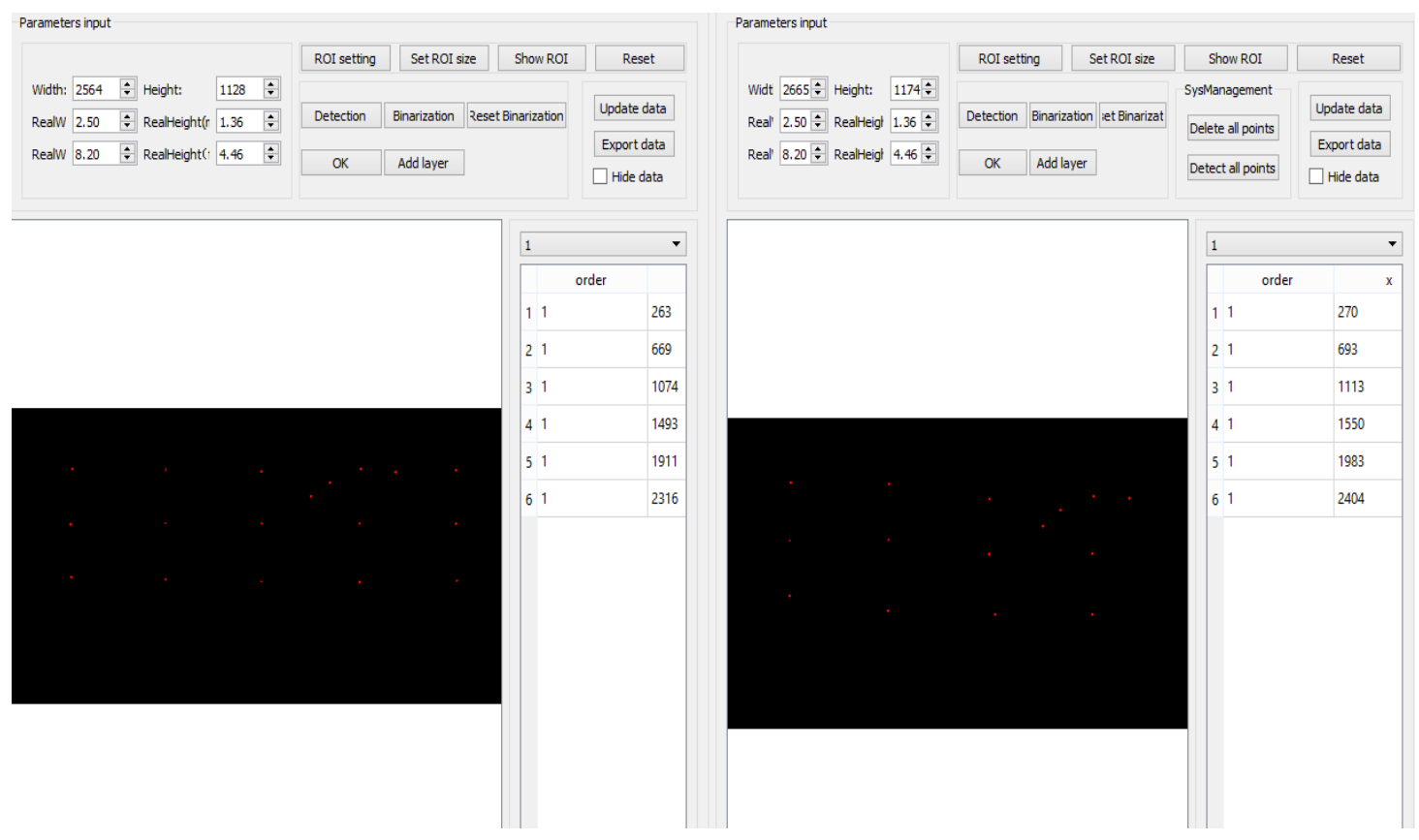

Figure 4-13 Add select layer to the database

There are circumstances that after subsidence, the points that are same layer before may subsides, in such situation one rectangular cannot select all the needed points, we can use multiple rectangular to include all the points and add them together to database, as shown in figure 4-14.

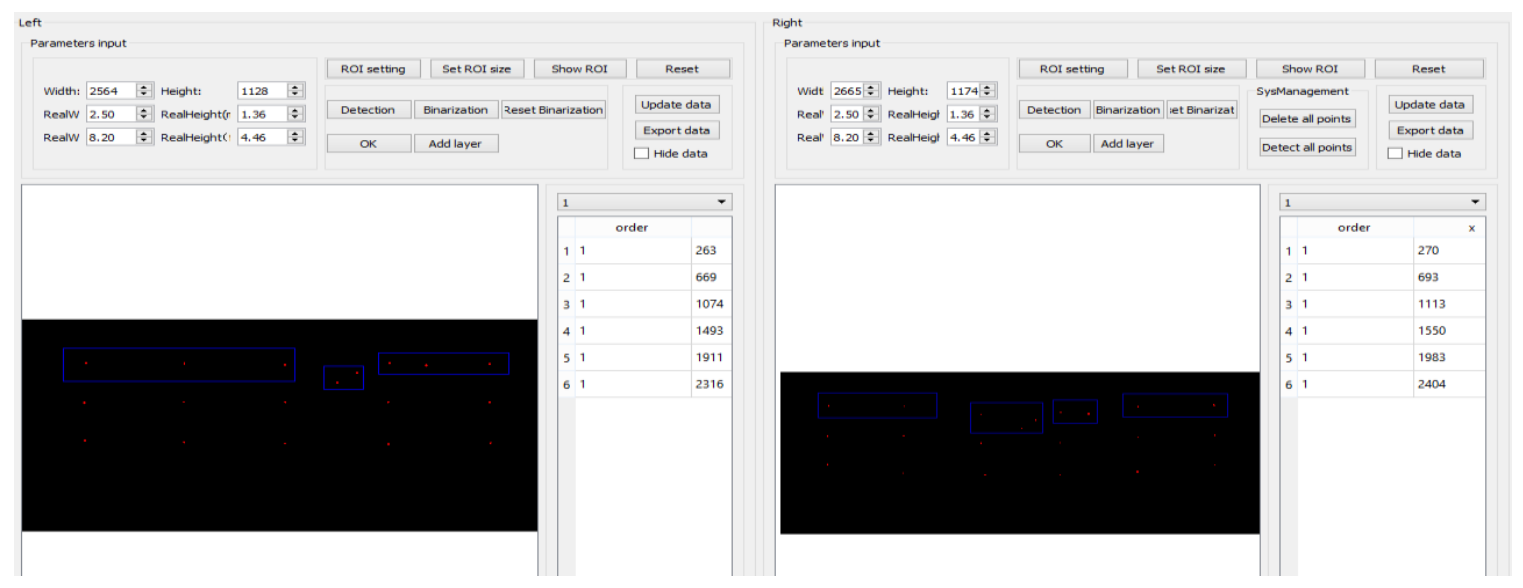

Figure 4-14 Using multiple rectangles to include all the points

Repeat this step to add all the points to the database. Note that, after the addition, the program will automatically remove the mark points of the added layer to avoid confusion. 


\section{Data analysis}

(7). After completing the data collection, click the "Data Analysis" line in the "Project Management" tab to switch to the data analysis module, as shown in the Figure 4-15. In the left list, right click to add the target project to the pre editor area and post editor area for analysis, and load the resulting pixel values and layer numbers into the two editor areas.

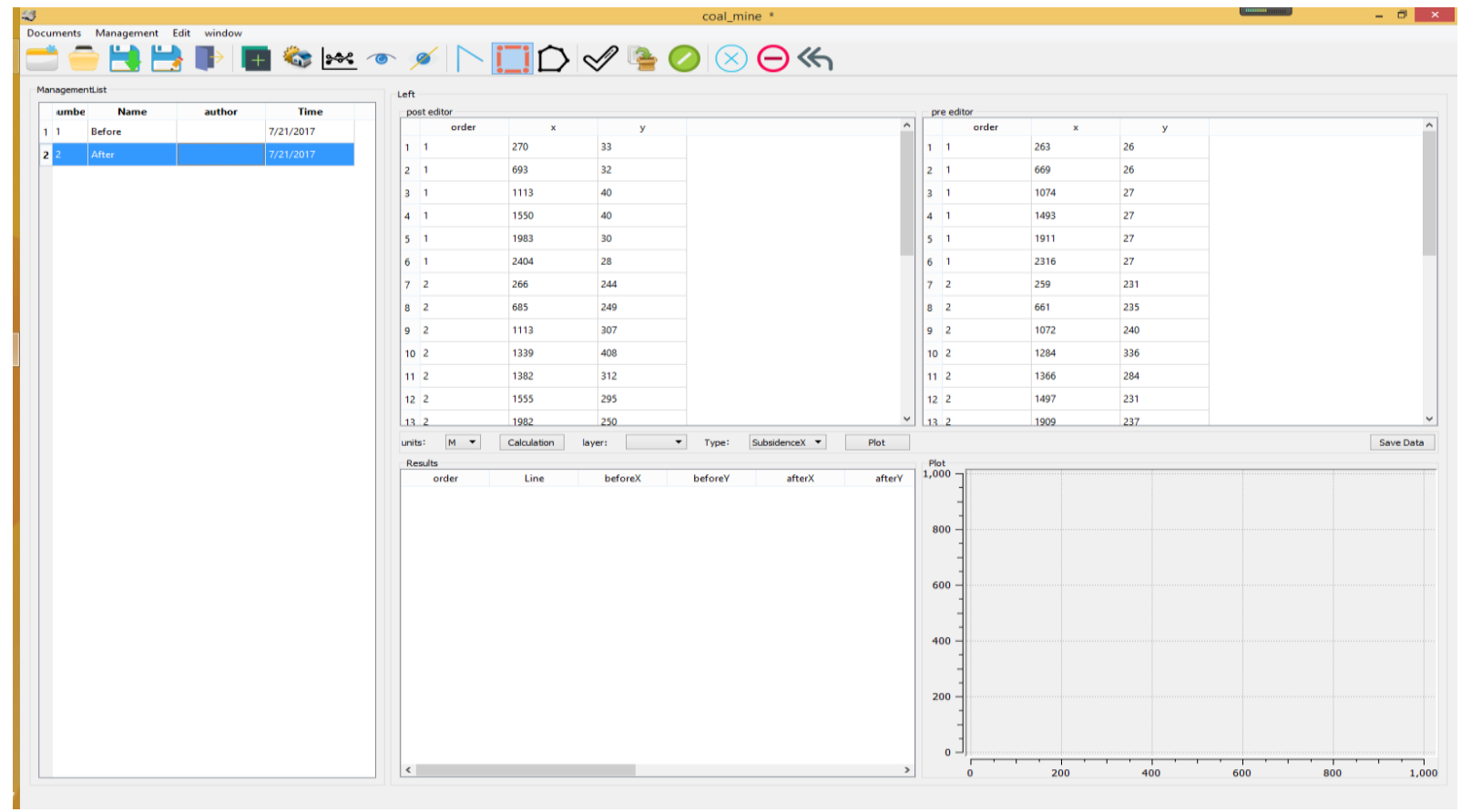

Figure 4-15 Data analysis

(8). Select the unit (m, ft or pixel) in the unit option after the loading step. Then click on the calculation, the program will automatically calculate in the background and generate the subsurface subsidence database, as shown in Figure 4.16. 


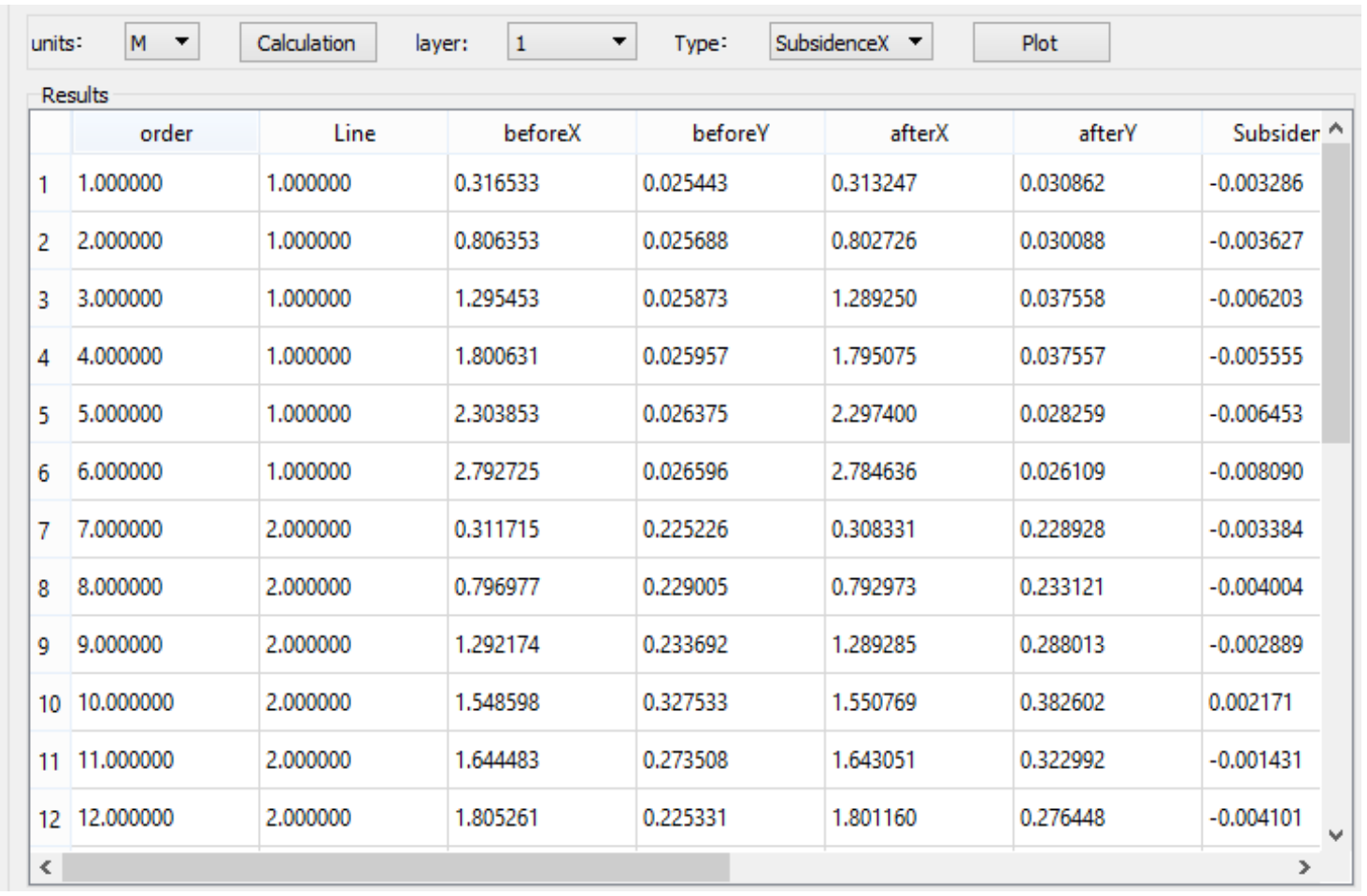

Figure 4-16 Data analysis results in meters

As shown in Figure 4-16, the program calculated the two pictures in different experimental stages and displays: 1. the amount of displacement in the $\mathrm{X}$ direction; 2. the amount of displacement in the Y direction; 3.The Slope; 4. The Strain.

(9). The result graph has been drawn. Select the line number user want to display in the "Row" tab, and select the type of data user want to display in "Type" tab. Click "Display" to display the parameter type of the selected layer, for example, the slope of the first row, as shown in Figure 4-17. 


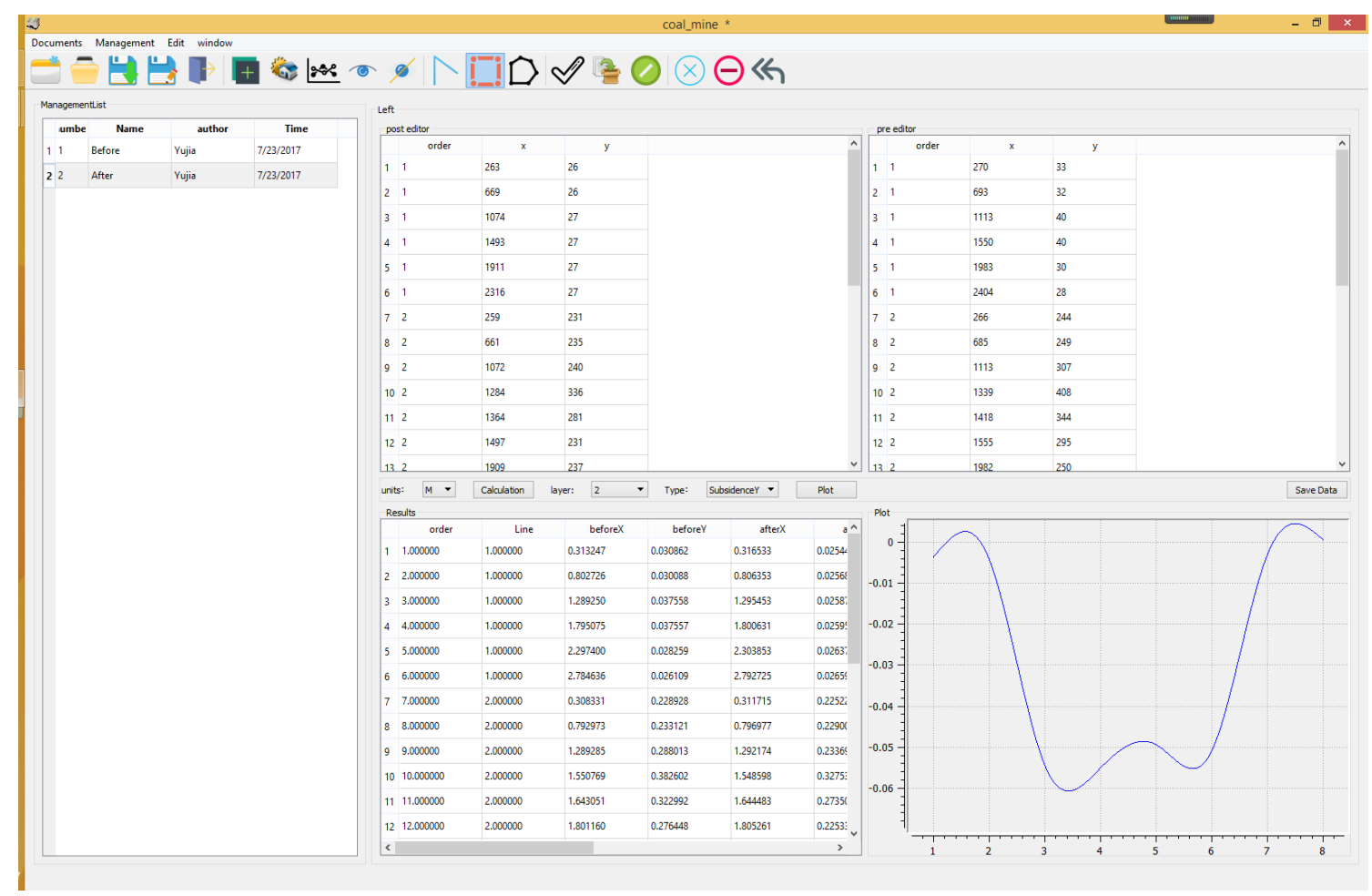

Figure 4-17 Plot the data analysis results

(10). Export to CSV file. Click "Save" and a pop-up dialog box shows up, enter the .CSV file name and select the folder in which to save (Table 4.18).

Click "Save", the data will be all stored in the CSV folder for further analysis. 


\begin{tabular}{|c|c|c|c|c|c|c|c|c|c|c|}
\hline der & Line & beforex & beforeY & afterX & afterY & Subsidenc & Subsidenc & Slope & Curvature & train \\
\hline 1 & 1 & 0.313247 & 0.030862 & 0.316533 & 0.025443 & 0.003286 & -0.00542 & 0 & 0 & 0 \\
\hline 2 & 1 & 0.802726 & 0.030088 & 0.806353 & 0.025688 & 0.003627 & -0.0044 & 0.00208 & 0.004246 & 13.42097 \\
\hline 3 & 1 & 1.28925 & 0.037558 & 1.295453 & 0.025873 & 0.006203 & -0.01169 & -0.01489 & -0.0347 & 19.53925 \\
\hline 4 & 1 & 1.795075 & 0.037557 & 1.800631 & 0.025957 & 0.005555 & -0.0116 & 0.000166 & 0.029812 & 74.21854 \\
\hline 5 & 1 & 2.2974 & 0.028259 & 2.303853 & 0.026375 & 0.006453 & -0.00188 & 0.019308 & 0.038038 & 13.29416 \\
\hline 6 & 1 & 2.784636 & 0.026109 & 2.792725 & 0.026596 & 0.00809 & 0.000487 & 0.00485 & -0.02958 & 29.20726 \\
\hline 7 & 2 & 0.308331 & 0.228928 & 0.311715 & 0.225226 & 0.003384 & -0.0037 & 0 & 0 & 0 \\
\hline 8 & 2 & 0.792973 & 0.233121 & 0.796977 & 0.229005 & 0.004004 & -0.00412 & -0.00086 & -0.00176 & 0.89551 \\
\hline 9 & 2 & 1.289285 & 0.288013 & 1.292174 & 0.233692 & 0.002889 & -0.05432 & -0.10138 & -0.20301 & 0.854368 \\
\hline 10 & 2 & 1.550769 & 0.382602 & 1.548598 & 0.327533 & -0.00217 & -0.05507 & -0.00292 & 0.384002 & 0.030789 \\
\hline 11 & 2 & 1.643051 & 0.322992 & 1.644483 & 0.273508 & 0.001431 & -0.04948 & 0.058248 & 0.637901 & 0.04019 \\
\hline 12 & 2 & 80116 & 0.276448 & 1.805261 & 0.225331 & 0.004101 & -0.05112 & -0.01016 & 546 & -0.02971 \\
\hline 13 & 2 & 2.295624 & 0.234289 & 2.301028 & 0.231048 & 0.005404 & -0.00324 & 0.09657 & 276 & 0.717399 \\
\hline 14 & 2 & 2.786267 & 0.224312 & 2.791483 & 0.224909 & 0.005216 & 0.000597 & 0.007825 & -0.18094 & -0.88029 \\
\hline 15 & 3 & 0.303158 & 0.434501 & 0.304515 & 0.431566 & 0.001357 & -0.00294 & 0 & 0 & 0 \\
\hline 16 & 3 & 0.792445 & 0.43152 & 0.793434 & 0.427082 & 0.000989 & -0.00444 & -0.00307 & -0.00629 & -0.30271 \\
\hline 17 & 3 & 1.28799 & 0.483176 & 1.293777 & 0.428028 & 0.005787 & -0.05515 & -0.10135 & -0.19642 & 1.045714 \\
\hline 18 & 3 & 1.795545 & 0.481273 & 1.799459 & 0.428484 & 0.003914 & -0.05279 & 0.004667 & 0.209655 & 12.68627 \\
\hline 19 & 3 & 2.296969 & 0.445344 & 2.300936 & 0.429932 & 0.003967 & -0.01541 & 0.074533 & 0.139321 & 2.70228 \\
\hline 20 & 3 & 2.790439 & 0.428051 & 2.796322 & 0.431224 & 0.005883 & 0.003173 & 0.037518 & -0.07472 & 3.070053 \\
\hline 21 & 4 & 0.303338 & 0.628837 & 0.306853 & 0.628413 & 0.003516 & -0.00043 & 0 & 0 & 0 \\
\hline 22 & 4 & 0.788842 & 0.68481 & 0.7963 & 0.635238 & 0.007459 & -0.04957 & -0.10041 & -0.20516 & 0.515099 \\
\hline 23 & 4 & 1.316491 & 0.69657 & 1.29187 & 0.644036 & -0.02462 & -0.05253 & -0.00598 & 0.19056 & 0.847775 \\
\hline 24 & 4 & 1.675401 & 0.586919 & 1.681935 & 0.530495 & 0.006534 & -0.05642 & -0.00997 & -0.01024 & 0.216842 \\
\hline 25 & 4 & 1.796729 & 0.697957 & 1.801566 & 0.648144 & 0.004837 & -0.04981 & 0.055262 & 0.545286 & 0.055536 \\
\hline 26 & 4 & 2.294035 & 0.677545 & 2.301715 & 0.640203 & 0.00768 & -0.03734 & 0.024935 & -0.06064 & -0.60918 \\
\hline 27 & 4 & 2.789968 & 0.631346 & 2.795739 & 0.633952 & 0.005772 & 0.002606 & 0.080862 & 0.113208 & -1.22853 \\
\hline
\end{tabular}

Table 4-18 Export all the data into an Excel file 


\section{Chapter 5. Analysis of Subsurface Ground Movement from Generated Data}

The subsurface movement data generated by the program can be used to further analyze ground deformations such as vertical and horizontal displacements, horizontal strain and void ratio. Two pictures from a physical modeling project are used as an example to demonstrate how the data from the program can be used for analysis of ground movements in the subsurface. Figure 5-1 and 5-2 show the pictures before and after excavation. Twenty five measurement points are shown in the model. The survey points are captured by the program as shown in Table 5-3.

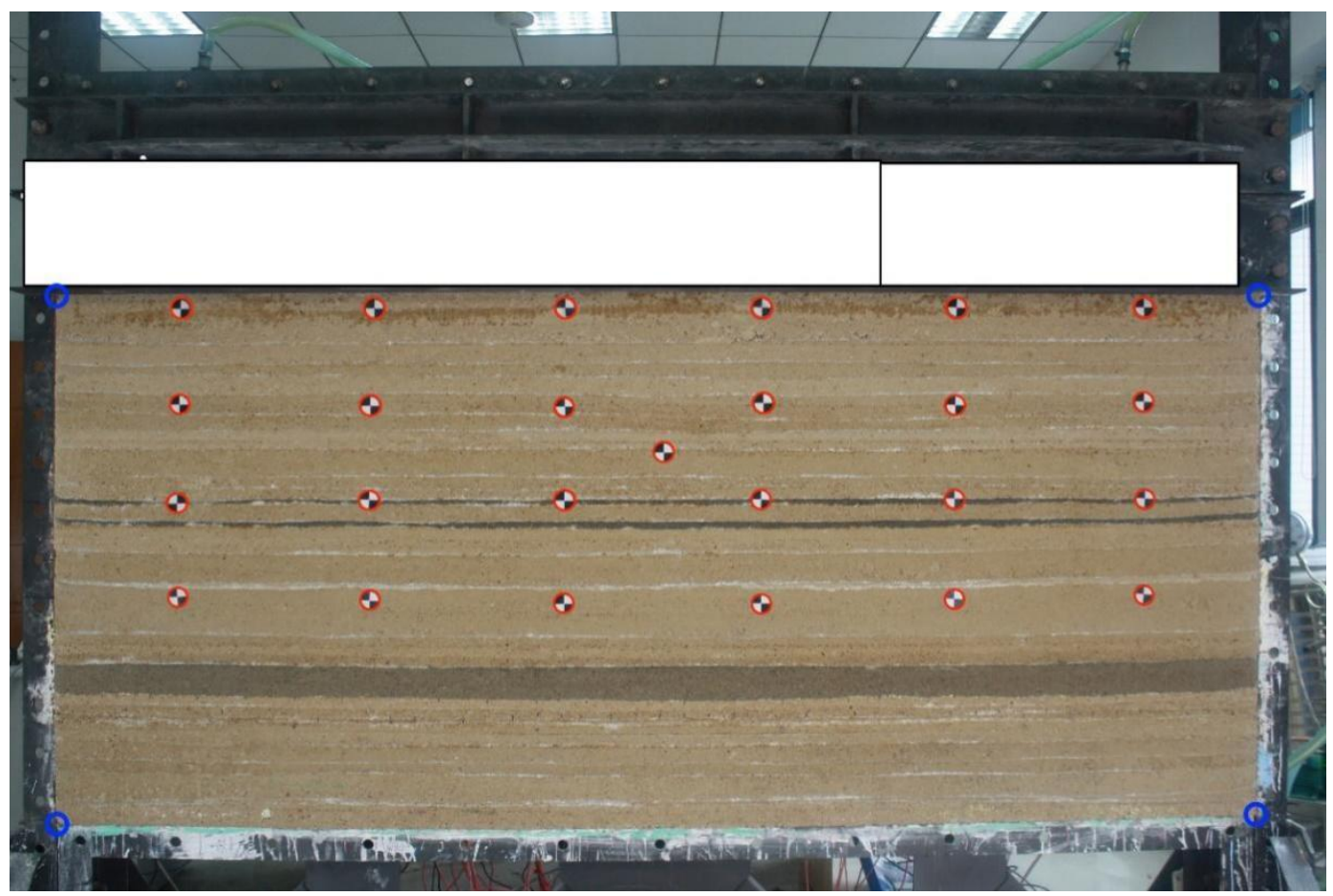

Figure 5-1 Physical Model before Excavation 


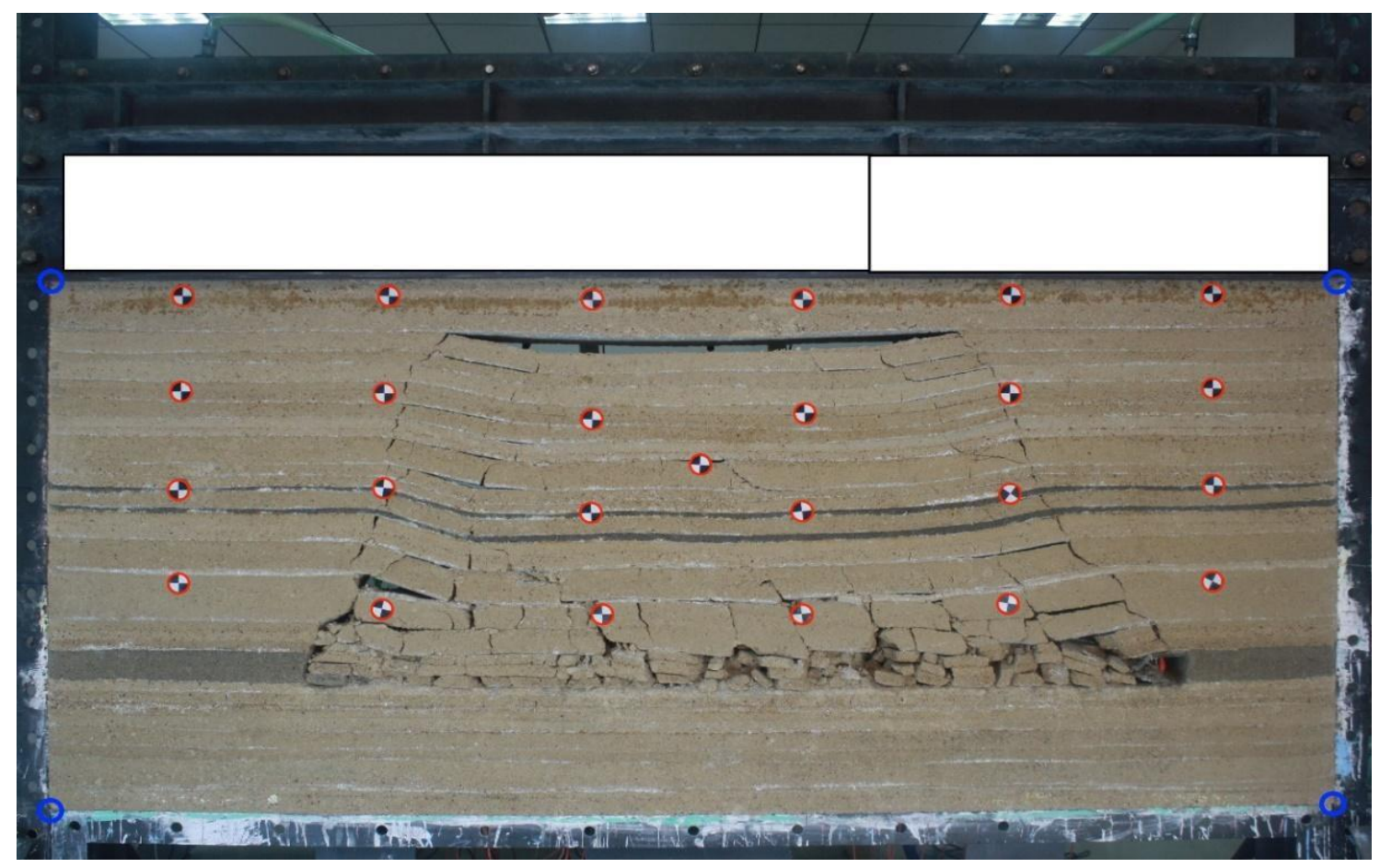

Figure 5-2 Physical Model after Excavation

\begin{tabular}{|c|c|c|c|c|c|c|c|}
\hline $\begin{array}{l}\text { Survey } \\
\text { Points }\end{array}$ & Row & beforeX & beforeY & afterX & afterY & $\begin{array}{l}\text { Horizontal } \\
\text { displacement, } \mathrm{ft}\end{array}$ & $\begin{array}{l}\text { Vertical } \\
\text { Displacement, } \mathrm{ft}\end{array}$ \\
\hline 1 & 1 & 1.038042 & 0.083453 & 1.027266 & 0.101226 & -0.010776 & 0.017773 \\
\hline 2 & 1 & 2.644363 & 0.084256 & 2.632468 & 0.098688 & -0.011895 & 0.014432 \\
\hline 3 & 1 & 4.248325 & 0.084865 & 4.227983 & 0.12319 & -0.020342 & 0.038325 \\
\hline 4 & 1 & 5.905009 & 0.085139 & 5.886792 & 0.123188 & -0.018217 & 0.038049 \\
\hline 5 & 1 & 7.555283 & 0.086509 & 7.534122 & 0.092689 & -0.021161 & 0.00618 \\
\hline 6 & 1 & 9.158496 & 0.087234 & 9.131967 & 0.085637 & -0.026529 & -0.001597 \\
\hline 7 & 2 & 1.02224 & 0.738742 & 1.011143 & 0.750882 & -0.011097 & 0.01214 \\
\hline 8 & 2 & 2.613616 & 0.751137 & 2.600484 & 0.764638 & -0.013132 & 0.013501 \\
\hline 9 & 2 & 4.23757 & 0.766509 & 4.228095 & 0.944683 & -0.009475 & 0.178174 \\
\hline 10 & 2 & 5.07849 & 1.074308 & 5.085611 & 1.254935 & 0.007121 & 0.180627 \\
\hline 11 & 2 & 5.920195 & 0.739085 & 5.906745 & 0.906749 & -0.01345 & 0.167664 \\
\hline 12 & 2 & 7.54602 & 0.757837 & 7.528298 & 0.768467 & -0.017722 & 0.01063 \\
\hline 13 & 2 & 9.154422 & 0.737702 & 9.137319 & 0.735744 & -0.017103 & -0.001958 \\
\hline 14 & 3 & 0.998629 & 1.415535 & 0.994178 & 1.425162 & -0.004451 & 0.009627 \\
\hline 15 & 3 & 2.601996 & 1.400828 & 2.598752 & 1.415385 & -0.003244 & 0.014557 \\
\hline 16 & 3 & 4.242826 & 1.403931 & 4.223849 & 1.584819 & -0.018977 & 0.180888 \\
\hline 17 & 3 & 5.901166 & 1.405427 & 5.888332 & 1.578575 & -0.012834 & 0.173148 \\
\hline 18 & 3 & 7.545715 & 1.410178 & 7.532708 & 1.46073 & -0.013007 & 0.050552 \\
\hline 19 & 3 & 9.170291 & 1.414415 & 9.151 & 1.404007 & -0.019291 & -0.010408 \\
\hline 20 & 4 & 1.006299 & 2.061193 & 0.994769 & 2.062587 & -0.01153 & 0.001394 \\
\hline 21 & 4 & 2.611397 & 2.08358 & 2.586936 & 2.246176 & -0.024461 & 0.162596 \\
\hline 22 & 4 & 4.236574 & 2.112438 & 4.317315 & 2.284751 & 0.080741 & 0.172313 \\
\hline 23 & 4 & 5.908078 & 2.125912 & 5.892215 & 2.289299 & -0.015863 & 0.163387 \\
\hline 24 & 4 & 7.54827 & 2.099866 & 7.523086 & 2.222347 & -0.025184 & 0.122481 \\
\hline 25 & 4 & 9.16838 & 2.079362 & 9.149452 & 2.070814 & -0.018928 & -0.008548 \\
\hline
\end{tabular}

Table 5-3 Coordinates Captured at the Measurement Points 


\subsection{Calculation of subsurface ground movement}

The vertical displacement at the measurement points is calculated as shown in Figure 5-4. Row number represents the measurement points at different horizon in the model with row IV close to the excavation horizon and row I near the surface. It can be seen that differential movement occurs over the edge of the gob, but the central portion of the model settles about the same amount except that the top portion of the model subsides only slightly.

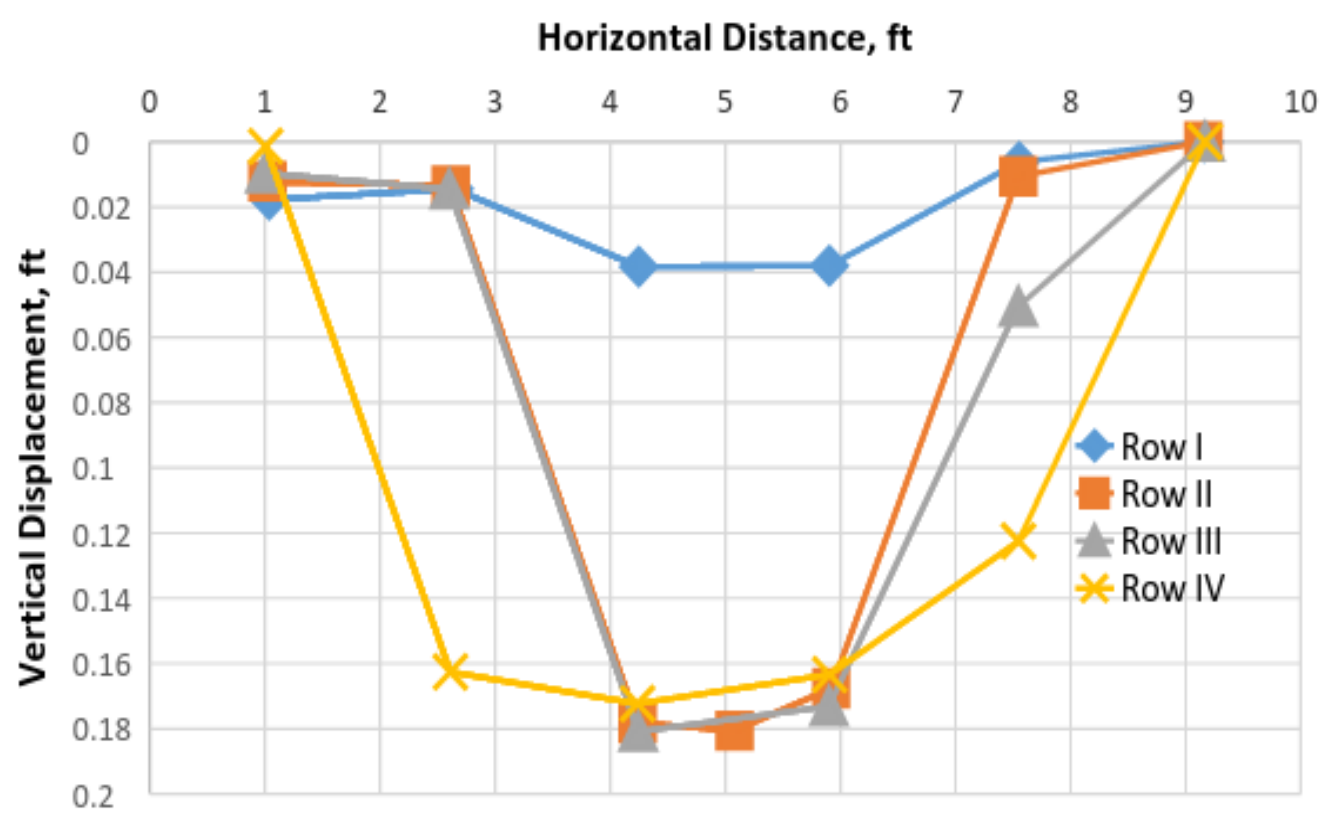

Figure 5-4 Vertical Displacement at the Survey Points

The horizontal displacement at the measurement points is calculated and plotted as shown in Figure 5-5. A negative value means that the displacement is towards the negative side of the Xaxis. It can be seen that generally the strata over the gob moves back as the longwall face advances towards the positive $\mathrm{X}$-axis direction. This agrees with the general trend of overburden movement 
with the caving of immediate roof. It should be notice that one large positive displacement occurs at a measurement point near the excavation horizon. Since this point is in the caving zone, ground movement could be irregular.

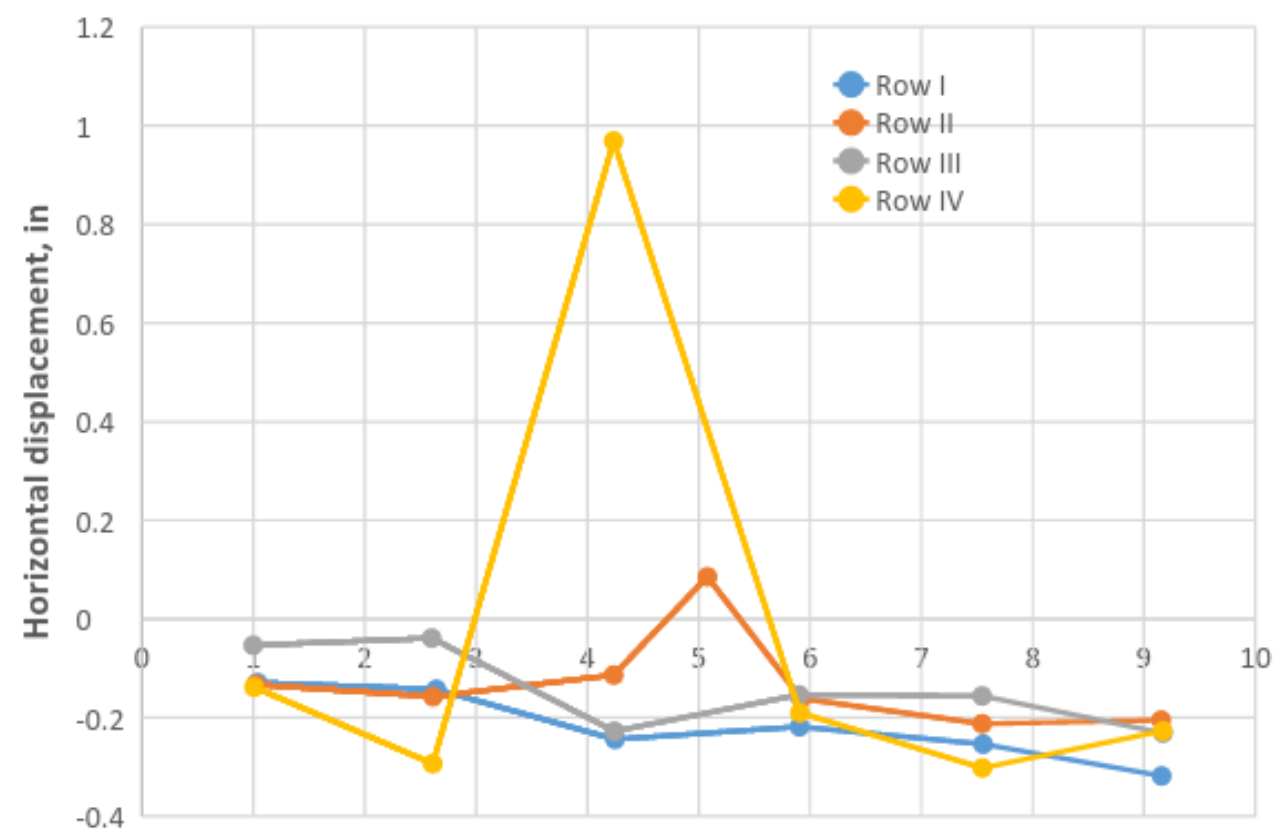

Figure 5-5 Horizontal Displacement at the Survey Points

\subsection{Calculation of subsurface horizontal strain}

The horizontal strain is calculated between any two measurement points along each measurement horizon as shown in equation 5.1. A positive value means tensile strain while a negative value means compressive strain. The formula for the horizontal strain calculation is shown as follows (5.1):

$$
\varepsilon_{(i, i+1), j}^{k}=\frac{\left(x_{i+1, j}^{k}-x_{i, j}^{k}\right)-\left(x_{i+1, j}^{0}-x_{i, j}^{0}\right)}{\left(x_{i+1, j}^{0}-x_{i, j}^{0}\right)}
$$


Where $x_{i, j}^{0}$ is the $\mathrm{X}$ coordinate at i's measurement point along $\mathrm{j}$ row in the model before excavation; $x_{i, j}^{k}$ is the $\mathrm{X}$ coordinate at i's measurement point along $\mathrm{j}$ row in the model after $\mathrm{k}$ stage of excavation.

It can be seen that generally positive strain occurs in the area where open fractures are present (Figure 5-6). The horizontal strain is greater near the excavation horizon than near the top of the model.

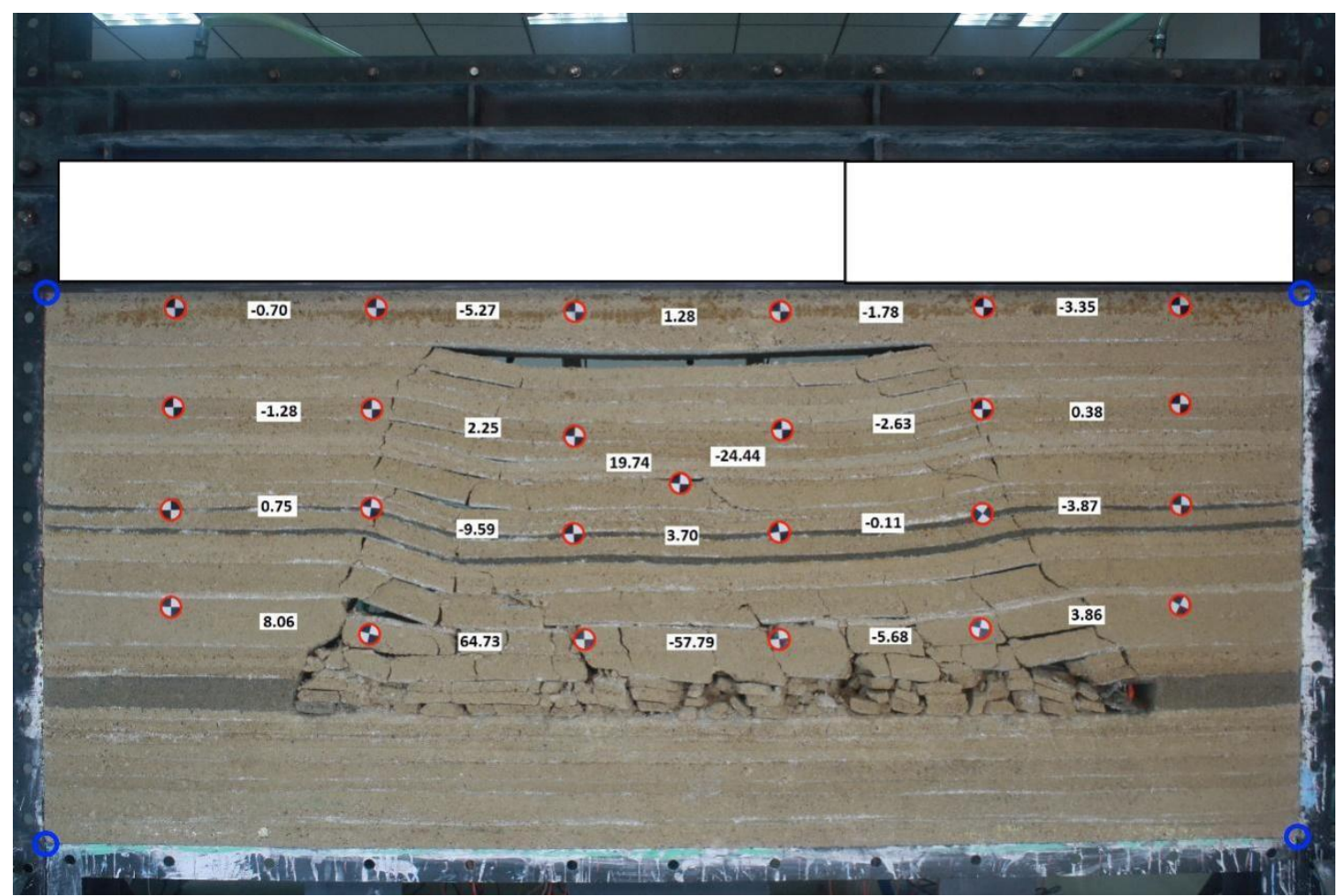

Figure 5-6 the calculated Horizontal Strain Calculated Based on Ground Movement

\subsection{Calculation of void ratio in the overburden}

The void ratio can be calculated by comparing the area within specified survey points between the original state of the model and certain the given stage of the model. Knowing the coordinates at four vertices of a polygon, the area can be calculated the by Gauss area formula. 
First, the vertices need to be numbered in clockwise order as shown in Figure 5-7. The area is then given by the formula:

$$
\text { Area }=\frac{\left|\left(x_{1} y_{2}-x_{2} y_{1}\right)+\left(x_{2} y_{3}-x_{3} y_{2}\right)+\left(x_{3} y_{4}-x_{4} y_{3}\right)+\left(x_{4} y_{1}-x_{1} y_{4}\right)\right|}{2}
$$

Where the $\mathrm{X}$ and $\mathrm{Y}$ are coordinates at vertex 1 .

Using the equation 5.2 formula, the void ratio between any four survey points in the model is calculated and is plotted as shown in Figure 5-8. Positive value means volume expansion while negative value means compression. It can be seen that the zones with high void ratio tend to occur over the edge of the gob, but the strata above the barrier pillar by the gob could be under compression.

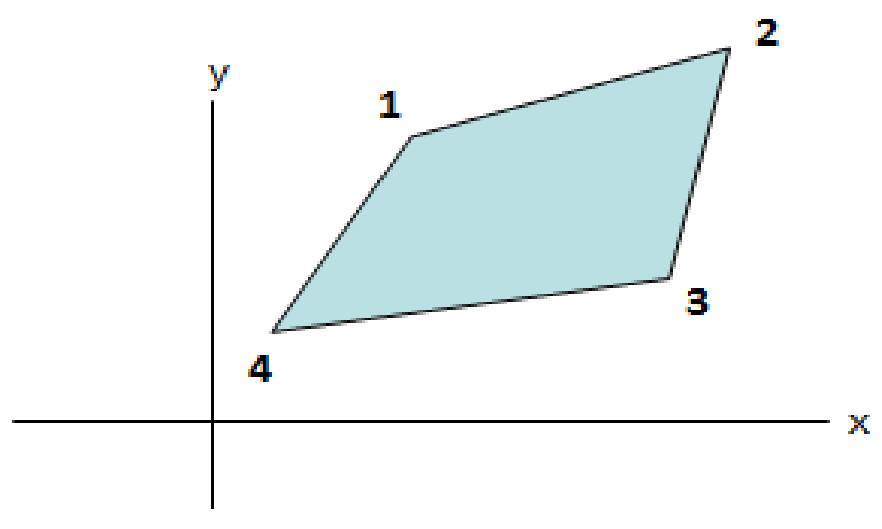

Figure 5-7 Area Calculation of Polygon by Coordinates of its Vertices 


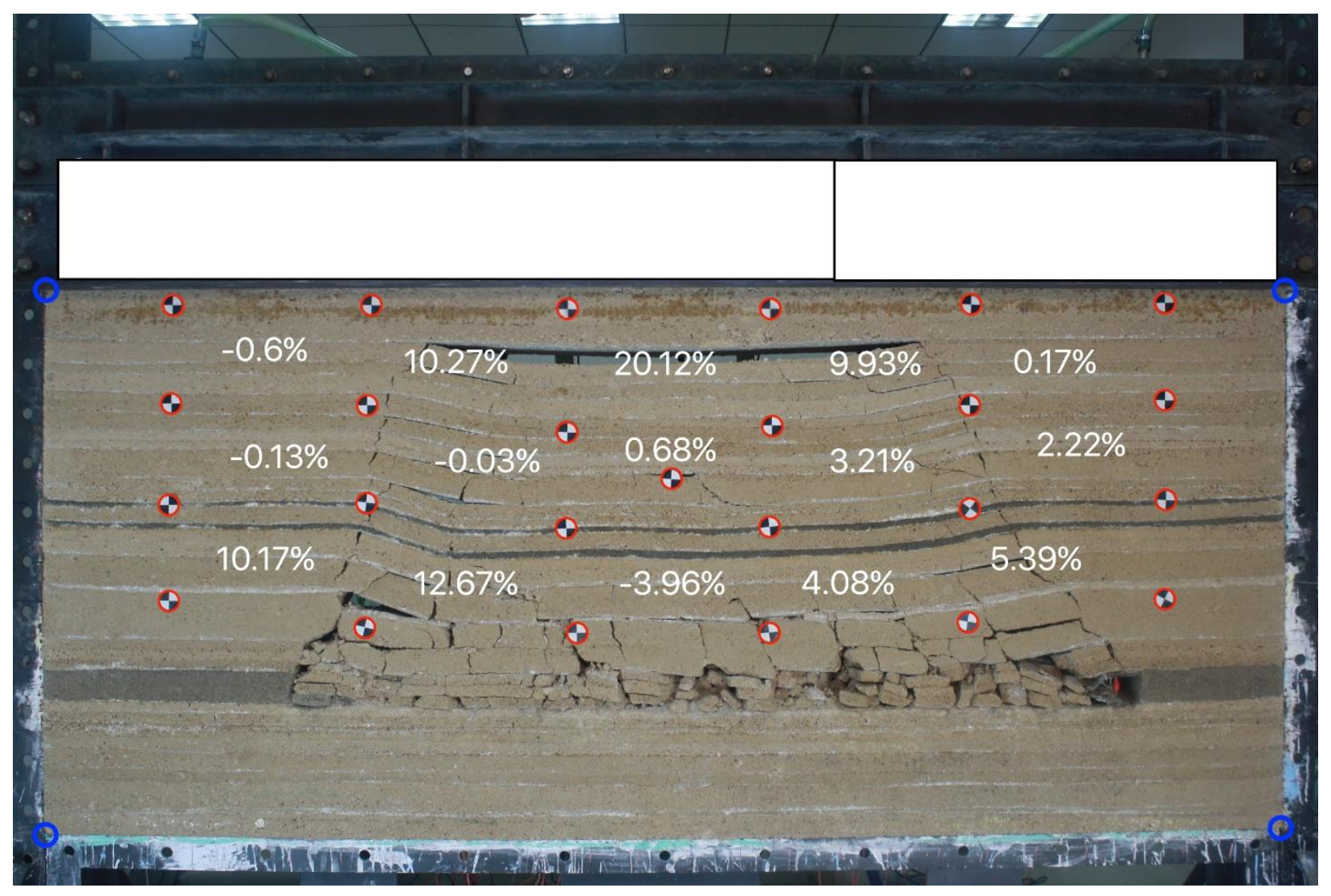

Figure 5-8 Void Ratio Calculated Based on Ground Movement (values in percentage) 


\section{Chapter 6. Conclusions}

Safe and economic longwall extraction requires good knowledge of overburden strata characteristics and understanding of overburden strata movement in response to the mining. Subsidence induced overburden movement will affect multiple seam mining, surface and subsurface water bodies, and methane emission and migration in overburden strata. Understanding of subsurface overburden movement is essential for optimal layout of multiple seam mining, protecting surface water resources, and designing of gob hole patterns for longwall degasification.

Physical modeling experiment as a supplementary modeling technique can provide a visual and quantitative understanding of overburden movement under specific conditions. Physical modeling can be used to study fracture development and caving characteristics above longwall mining excavations. Physical models have the advantages in observing fracture development and caving propagation as the longwall face proceeds from its starting position, and advances during all stages of full subsidence development.

To improve the means of obtaining and processing the measurement data during the physical model experiment, a computer program has been developed for processing of successive images from physical models. The program, based on computer vision, can be used to read the survey points accurately from the images taken during the process of physical model experiment.

The program is designed with top-down approach, and implemented using the Qt development platform and OpenCV package.

The program is developed with user-friendly interface, and is easy to use. Comparing to traditional total station method, the data processing by this program is relatively faster and more efficient with higher accuracy. 
The program can be used to quantitatively analyze subsurface ground movement such as vertical and horizontal displacement, horizontal strain and void ratio. 


\section{References}

Agioutantis, Z. and M. K. Karmis, 2008, SDPS surface deformation prediction system for Windows version 6.0, quick reference guide and working examples, Department of Mining and Minerals Engineering, Virginia Polytechnic Institute and State University, VA, pp.248.

Biao, Q., 2013, Application of surface and subsurface subsidence theories to solve ground control problems, Ph.D. Dissertation, Department of Mining Engineering, West Virginia University, pp.78-84

Guo, H., Q. Qu and D. Adhikary, 2017, Overburden response to longwall mining, Advanced in Coal Mine Ground Control, Edited by S. S. Peng, pp.111-155.

Jasmin Blanchette, Mark Summerfield, Feb 14, 2008, C++ GUI Programming with Qt 4 (2nd Edition) (Prentice Hall Open Source Program Development Series) .pp.20-39

Kendorski, F. S., 2006, Effect of full-extraction underground mining on ground and surface waters - A 25-year retrospective, Proc. 25th International Conference on Ground Control in Mining, Ed. S.S. Peng et al., West Virginia University, WV, pp. 425-430.

Luo, Y. and S.S. Peng, 2010, Subsurface subsidence prediction model and its potential applications in the study of lngwall subsidence effects on hydrologic system, SME Transactions, Vol. 328, pp.458-465.

Luo, Y. and S. Peng, and Z. Zhu, 2008, Upgraded comprehensive and integrated subsidence prediction model CISPM - W, Proc. 27th International Conference on Ground Control in Mining, Ed. S. S. Peng, West Virginia University, Morgantown, WV, pp.123-130.

Luo, Y. and S.S. Peng, 2000, Prediction of subsurface subsidence for longwall mining operations, Proc. 19th International Conference on Ground Control in Mining, Ed. S. S. Peng, West Virginia University, Morgantown, WV, pp.163-170. 
M A Sid-Ahmed, T B Mohamed, 1990, Dual Camera Calibration for 3D Machine Vision Metrology[J]. IEEE Trons. Instrm.Meas.

M. Pollefeys and L.Van Gool, 1997 A stratified approach to Stratified self-calibration. Proc. 1997 Conference on Computer Vision and Pattern Recognition, IEEE Computer Soc. Press, pp.407-412.

Research report, 2013, Physical Modeling of Longwall Mining along Strike in Inclined High Seams, Xi' an University of Science and Technology, China.

Syd S. Peng, 1992, Surface Subsidence Engineering, Society for Mining, Metallurgy, and Exploration, Inc, pp 62-80

Thomas Kersten,Hans-Gerd Maas,1995, Photogrammetric 3-D Point Determination for Dam Monitoring[J]. Optical 3-D Measurement Techniques III.

Whittaker, B.N., D.J. Reddish, 1989, Subsidence - Occurrence, Prediction and Control, Elsevier Science Publishers.

Walrus Vision Toolbox. June 23, 2014, “Algorithms of Digital Image Processing, Tools and techniques" http://www.walrusvision.com/wordpress/category/letters/algo/.

Xue, J., H. Wang, W. Zhou, B. Ren, C. Duan, and D. Deng, 2015, Experimental research on overlying strata movement and fracture evolution in pillarless stress-relief mining, International Journal of Coal Science Technology, published online on 21 May 2015 with open access at Springerlink.com, pp. 38-45.

Zhang, J, J. Wang, 2014, Physical modeling and verification of overburden strata movement in longwall mining, Journal of Mining \& Safety Engineering. March 2014, pp. 249 - 254. 